\title{
A streptozotocin-induced model of Alzheimer's disease in mice with wild-type human tau
}

Carolyn C. Rudy

West Virginia University

Follow this and additional works at: https://researchrepository.wvu.edu/etd

\section{Recommended Citation}

Rudy, Carolyn C., "A streptozotocin-induced model of Alzheimer's disease in mice with wild-type human tau" (2014). Graduate Theses, Dissertations, and Problem Reports. 620.

https://researchrepository.wvu.edu/etd/620

This Thesis is protected by copyright and/or related rights. It has been brought to you by the The Research Repository @ WVU with permission from the rights-holder(s). You are free to use this Thesis in any way that is permitted by the copyright and related rights legislation that applies to your use. For other uses you must obtain permission from the rights-holder(s) directly, unless additional rights are indicated by a Creative Commons license in the record and/ or on the work itself. This Thesis has been accepted for inclusion in WVU Graduate Theses, Dissertations, and Problem Reports collection by an authorized administrator of The Research Repository @ WVU. For more information, please contact researchrepository@mail.wvu.edu. 


\title{
A Streptozotocin-Induced Model of Alzheimer's Disease in
} Mice with Wild-Type Human Tau

\section{Carolyn C. Rudy}

\author{
Thesis submitted \\ to the Eberly College of Arts and Sciences \\ at West Virginia University \\ in partial fulfillment of the requirements for the degree of \\ Master of Science in \\ Psychology
}

\author{
Committee \\ Miranda N. Reed, Ph.D., Chair \\ Karen G. Anderson, Ph.D. \\ Steven G. Kinsey, Ph.D. \\ Department of Psychology
}
Morgantown, West Virginia
2014

Keywords: Alzheimer's disease, streptozotocin, cerebral hypometabolism Copyright 2014 Carolyn C. Rudy 


\section{ABSTRACT \\ A Streptozotocin-Induced Model of Alzheimer's Disease in Mice with Wild-Type Human Tau}

\section{Carolyn C. Rudy}

Alzheimer's disease (AD) accounts for 60 to $80 \%$ of all dementias, affects over 5 million Americans, and incurs annual healthcare costs of over $\$ 200$ billion (Alzheimer's Association, 2012). Hyperphosphorylation of tau, the main component of neurofibrillary tangles observed in $\mathrm{AD}$, leads to deficits in cell structure and function. Because recent data suggest impairments in cerebral glucose utilization and energy metabolism play a prominent role in the pathogenesis of $\mathrm{AD}$, we sought to create a mouse model that emulates the metabolic changes using intracerebroventricular infusions of streptozotocin (ICV-STZ) in transgenic mice expressing human tau. The Barnes maze, a test of spatial learning and memory, and a panel of antibodies directed at biochemical changes in tau associated with AD were used to assess memory deficits and tau pathology, respectively. The behavioral and biochemical findings of the current study provide inconsistent support for the use of an ICV-STZ model in mice expressing human tau, and future studies should employ a battery of behavioral assays to determine if subtle memory deficits occur. 


\section{Table of Contents}

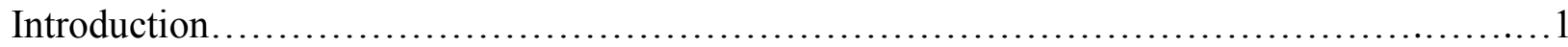

Tau Plays a Significant Role in AD Etiology....................................2

To Be Resolved.......................................................5

Modeling AD Using Intracerebroventricular Streptozotocin Infusions..................

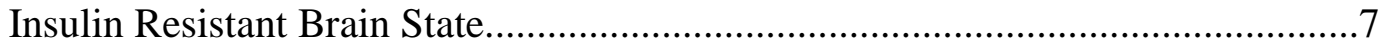

Decrement in Brain Glucose/Energy Metabolism...............................................

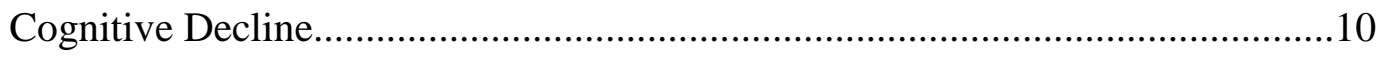

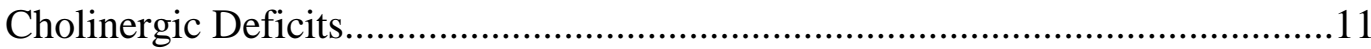

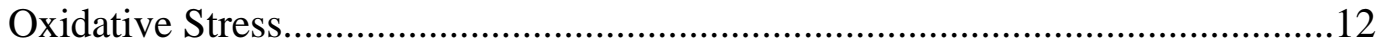

Testing of Spatial Memory Using the Barnes Maze.................................13

Statement of the Problem........................................................... 16

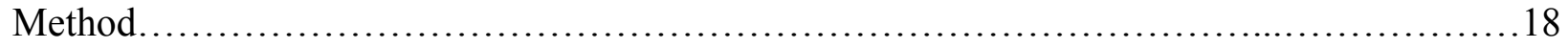

Subjects and Treatments.................................................... 18

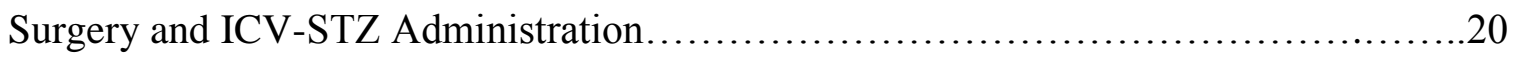

Barnes Maze................................................................ 21

Apparatus..........................................................21

Habituation......................................................... 22

Acquisition............................................................22

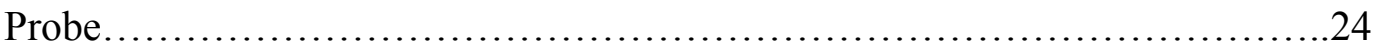

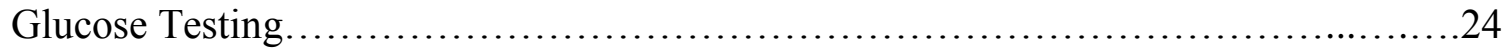

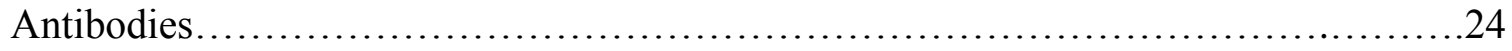

Dissection and Extraction of Mouse Hippocampus..........................25 
Western Blotting ...............................................26

Statistical Analyses..........................................................27

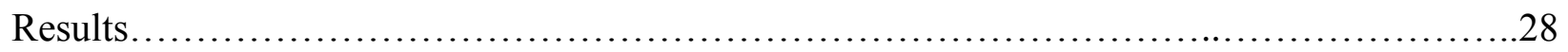

Physiological Parameters...................................................28

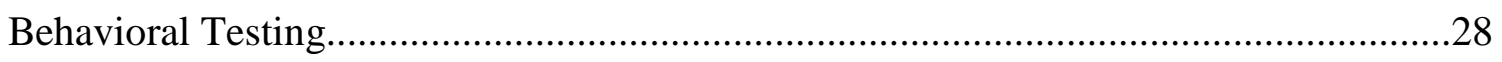

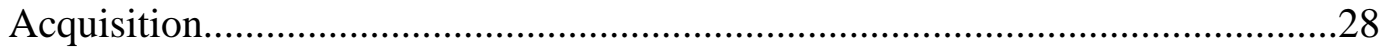

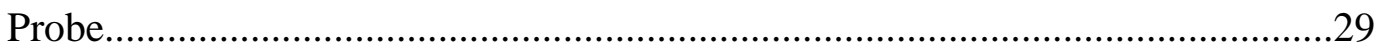

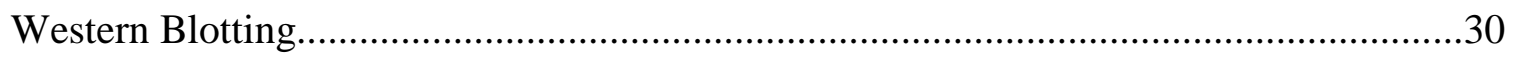

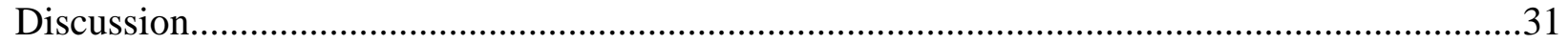

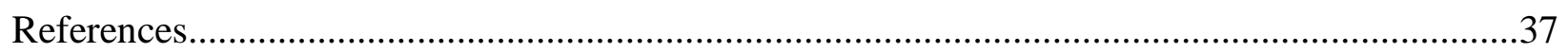

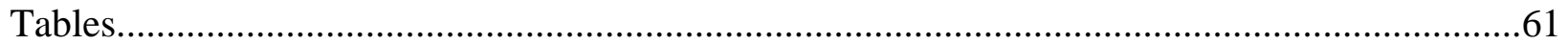

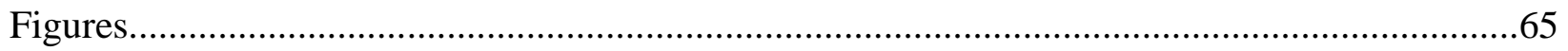




\section{A Streptozotocin-Induced Model of Alzheimer's Disease in Mice with Wild-Type Human Tau}

Tauopathies are a group of neurodegenerative disorders involving the tau protein (Clavaguera et al., 2009). Alzheimer's disease (AD), the most common tauopathy, accounts for 60 to $80 \%$ of all dementias and affects over 5 million Americans (Alzheimer's Association, 2012). As the American public ages, the societal and economic costs are becoming increasingly burdensome: unpaid caregivers of AD patients worked over 17.4 billion hours in 2011, and ADrelated health care costs are expected to exceed $\$ 200$ billion (Alzheimer's Association, 2012). In addition to memory loss, other early symptoms of AD include difficulties with problem solving, regulating one's emotions, and completing familiar tasks (Alzheimer's Association, 2012). The disease progresses over the course of about 4 to 8 years during which cognitive functioning declines steadily until death (Alzheimer's Association, 2012). Pharmaceutical treatment of AD, which cannot halt or slow the progression of cognitive decline (Piau, Nourhashémi, Hein, Caillaud, \& Vellas, 2011), is currently limited to two classes of drugs: uncompetitive N-methylD-aspartate (NMDA) receptor antagonists and reversible acetylcholinesterase inhibitors.

Tau, a microtubule-associated protein, is the main component of neurofibrillary tangles (NFTs) observed in AD and other neurodegenerative tauopathies (see Kolarova, García-Sierra, Bartos, Ricny, \& Ripova, 2012 for review). NFTs are primarily composed of hyperphosphorylated tau bound in paired helical filaments (Hong \& Lee, 1997; Tokutake et al., 2012). In AD, NFTs form when tau aggregates in the somatodendritic part of the neuron (Hébert, Sergeant, \& Buée, 2012), eventually resulting in neuronal death. Plaques are a distinct hallmark of $\mathrm{AD}$ and are not found in any other tauopathies. Plaques are composed primarily of beta-amyloid (A $\beta)$, a 39 to 42 amino acid fragment derived from proteolytic processing of the 
amyloid precursor protein (APP) (Haass et al., 1993; Ittner et al., 2010; Tokutake et al., 2012). Neuronal death, the third hallmark of $\mathrm{AD}$, is most pronounced in areas of the brain related to executive functioning and memory, such as the frontal cortex (Lemmens et al., 2011; Sabuncu et al., 2011) and hippocampus (Sabuncu et al., 2011).

\section{Tau Plays a Significant Role in AD Etiology}

Increased production or decreased clearance of $A \beta$ is believed to be the precipitating event in AD pathogenesis, a theory referred to as the amyloid cascade hypothesis (Hardy \& Higgins, 1992). However, several lines of evidence suggest that, although A $\beta$ pathology may occur before tau pathology, it does not fully explain the cognitive decline observed in AD. For example, NFT density is more closely correlated with disease severity than A $\beta$ plaques (Berg et al., 1998; Kolarova et al., 2012). A $\beta$ plaques are frequently observed in older individuals with no cognitive dysfunctions; however, it is unusual to find tangles without the presence of AD or another related tauopathy (Piau et al., 2011). Furthermore, tau pathology alone is capable of causing the neurodegeneration witnessed in sporadic and familial tauopathies (Sorrentino \& Bonavita, 2007). Further weakening support against the amyloid cascade hypothesis comes from clinical trials using drugs that lower $A \beta$ levels. Despite successfully lowering $A \beta$ levels, the drugs do not decrease neuronal death or significantly improve cognitive functioning (Gervais et al., 2007; Gilman et al., 2005; Klafki, Staufenbiel, Kornhuber, \& Wiltfang, 2006; Siemers, Dean, Demattos, \& May, 2006). For these reasons, the current proposal focuses on the role of tau in AD pathology.

Tau is a microtubule-associated protein responsible for microtubule nucleation and stabilization in neurons (Eckermann et al., 2007). In the human brain, there are a total of six isoforms of tau ranging from 352 to 441 amino acids long, with molecular weights between 45 
and 65 kDa (Buée, Bussière, Buée-Scherrer, Delacourte, \& Hof, 2000). The different isoforms are created by alternative splicing of exons 2, 3, and 10 of the tau gene (Luk et al., 2012). Exon 10 is particularly important in tauopathies. Inclusion of exon 10 results in the expression of four microtubule-binding repeat domains (4R), whereas the exclusion of exon 10 leads to only three microtubule-binding repeat domains (3R) (Kolarova et al., 2012). Tauopathies often shift from an approximately $1: 1$ ratio of $3 R$ to $4 R$ in young, non-demented human brains to an excess of $4 R$ tau in disease states, which is significant given the increased likelihood of $4 \mathrm{R}$ tau to dissociate from microtubules and aggregate (Adams, DeTure, McBride, Dickson, \& Petrucelli, 2010).

As a phosphoprotein, there are over 80 serine and threonine sites on tau that can be phosphorylated (Billingsley \& Kincaid, 1997; Kolarova et al., 2012). The abnormal phosphorylation of tau is a fundamental neuropathological event in AD (Kolarova et al., 2012). It is believed to be one of the earliest changes in the brain, with tau becoming more phosphorylated as the disease progresses (Crespo-Biel, Theunis, \& Van Leuven, 2012). The mechanisms by which tau becomes hyperphosphorylated are not fully understood, though a few have been identified. Mechanisms that lead to exacerbated tau phosphorylation often involve increased kinase activity, or decreased phosphatase activity, leading to a decrease in the removal of phosphate groups from tau (see Iqbal \& Grundke-Iqbal, 2008 for review). Some of the kinases implicated include glycogen synthase kinase 3 beta (GSK3ß) (Plattner, Angelo, \& Giese, 2006), cyclin-dependent kinase 5 (Cdk5) (Ahlijanian et al., 2000; Plattner et al., 2006), and calciumand calmodulin-dependent protein kinase-II (CaMKII; Bennecib, Gong, Grundke-Iqbal, \& Iqbal, 2001; Singh, Zaidi, Grundke-Iqbal, \& Iqbal, 1996). Both GSK3 $\beta$ and Cdk5 are proline-directed serine/threonine kinases responsible for phosphorylating tau at the sites most implicated in AD (Plattner et al., 2006). Tau is also phosphorylated at two particular sites by CaMKII, which does 
not belong to the same category of kinases as GSK3 $\beta$ and Cdk5 (Bennecib et al., 2001; Singh et al., 1996). CaMKII does not phosphorylate tau at nearly as many sites as GSK3 $\beta$ and Cdk5 but contributes to further hyperphosphorylation (Cho \& Johnson, 2003). Similarly, down-regulation of phosphoseryl/phosphothreonyl protein phosphatase-2A (PP2A), which dephosphorylates tau at several sites, also contributes to phosphorylation of tau (Gong et al., 2000; Liu, GrundkeIqbal, Iqbal, \& Gong, 2005; Wang, Grundke-Iqbal, \& Iqbal, 2007). PP2A activity, which is reduced in $\mathrm{AD}$, further exacerbates the phosphorylation of tau caused by other proline-directed serine/threonine kinases (Liu \& Wang, 2009; Qian et al., 2010). Why the activity of kinases and phosphatases changes in AD is unclear, but research suggests metabolic abnormalities may play a role. Early stages of $\mathrm{AD}$ are accompanied by metabolic abnormalities, such as a decrease in insulin levels in the brain (Frölich, Blum-Degen, Riederer, \& Hoyer, 1999) and a drop in cerebral glucose utilization (Hoyer \& Nitsch, 1989), resulting in alterations of these kinases in ways that promote tau phosphorylation (de la Monte, 2012). PP2A is also implicated in negatively regulating the insulin signaling pathway (Mandavia \& Sowers, 2012; Ugi et al., 2004).

Tau hyperphosphorylation can lead to various deficits in cell structure and function. The hyperphosphorylation of tau prevents proper binding of microtubules, leading to decreased cell stability (Mongradón-Rodríguez et al., 2008) and axonal transport (Mandelkow, Stamer, Vogel, Thies, \& Mandelkow, 2003). In addition, tau hyperphosphorylation, and the subsequent unbinding of tau from microtubules, causes tau to mislocalize into the somatodendritic compartment (Götz, Chen, Barmettler, \& Nitsch, 2000) and dendritic spines (Hoover et al., 2010). In vitro studies suggest that mislocalization of tau to dendritic spines, which is dependent 
upon tau hyperphosphorylation, causes alterations in glutamatergic receptor trafficking, leading to long-term potentiation (LTP) deficits (Hoover et al., 2010) and presumably memory deficits.

Although tau mutations have been linked to the pathogenesis of some tauopathies, including frontotemporal dementia (Goedert, Crowther, \& Spillantini, 1998), Pick’s disease (Pickering-Brown et al., 2000), and progressive supranuclear palsy (Ezquerra et al., 1999), there are no reported tau mutations in $\mathrm{AD}$. To model tau pathology in $\mathrm{AD}$, mutations linked to other tauopathies are often expressed in mice, and in some cases, the expression is restricted to brain regions involved in $\mathrm{AD}$ through the use of specific promoter systems (i.e., a region of DNA that initiates transcription of a particular gene). For example, the $\operatorname{rg}(\mathrm{TauP} 301 \mathrm{~L}) 4510$ mouse (herein called TauP301L) expresses the proline-to-leucine mutation at the $301^{\text {st }}$ amino acid (P301L) in human tau associated with frontotemporal dementia and Parkinsonism linked to chromosome 17 (FTDP-17) (Ramsden et al., 2005). To create a more AD-like model, P301L human tau expression is driven by a forebrain-specific CaMKII promoter system, resulting in high levels of human tau expression in brain regions related to $\mathrm{AD}$, including the hippocampus and neocortex (Ramsden et al., 2005). TauP301L mice exhibit age-dependent tau hyperphosphorylation, NFTs, neuron loss, and memory impairment (Ramsden et al., 2005). Although this model is incredibly useful and the phenotype closely parallels the tau-related changes observed in AD, identifying and characterizing the etiology of AD using such a model is not possible given that this tau mutation does not occur in AD.

\section{To Be Resolved}

Here, it was proposed to create a mouse model that closely mimics the precipitating events believed to underlie AD-related changes and to examine the resulting changes in tau pathology and memory. Recent data have suggested that impairments in cerebral glucose 
utilization and energy metabolism play an important role in the pathogenesis of AD. The early stages of cognitive impairment in $\mathrm{AD}$ are accompanied, or even preceded, by decrements in glucose utilization and energy metabolism (de la Monte, 2012; Hoyer, 2004). Furthermore, insulin injections can improve cognitive functioning in individuals with AD (Craft et al., 1999; Watson \& Craft, 2004). To model the metabolic changes that take place in AD, intracerebroventricular (ICV) infusions of streptozotocin (STZ) were used. ICV-STZ produces insulin-resistance in the brain, as well as a myriad of molecular and pathological features that mimic AD, including tau hyperphosphorylation (Grünblatt, Salkovic-Petrisic, Osmanovic, Riederer, \& Hoyer, 2007). To date, however, effects of ICV-STZ on tau pathology have only been examined in rodents that have rodent, not human, tau. To determine effects of ICV-STZ on human tau, the rTg(TauWT)21221 mouse model (herein called TauWT), that expresses wildtype human four-repeat (4R) tau, was used. The TauWT mouse model does not exhibit memory deficits nor tau pathology (Hoover et al., 2010) but allowed us to foster a determination of effects of ICV-STZ on $4 \mathrm{R}$ human tau - a version of tau that is more prone to AD-related changes (Barghorn \& Mandelkow, 2002) but does not lead to tau pathology on its own (Hoover et al., 2010). In a healthy brain, there is typically a $1: 1$ ratio of $3 R$ to $4 R$ tau, but in tauopathies, including AD, there is a shift to an excess of $4 \mathrm{R}$ (Liu \& Gong, 2008). Thus, the TauWT model allows an assessment of effects of ICV-STZ on a version of tau that is increased in AD and more prone to AD-related changes (Barghorn \& Mandelkow, 2002). Effects of ICV-STZ in TauWT mice were compared with control littermates expressing mouse tau, as well as with TauP301L mice, the most commonly used tau model of AD. Whereas the pathology in ICV-STZ treated TauWT mice was not anticipated to be as severe as that in ICV-STZ treated TauP301L mice, it was expected to be more advanced than treated controls because of the presence of human $4 \mathrm{R}$ tau 
in TauWT mice. It was also predicted that memory deficits will correspond with levels of tau phosphorylation.

\section{Modeling AD Using Intracerebroventricular Streptozotocin Infusions}

Many models of AD use intracerebroventricular infusions of streptozotocin (ICV-STZ) to induce the following changes witnessed in human AD: an insulin resistant brain state, a decrement in brain glucose and energy metabolism, cognitive decline, cholinergic deficits, and oxidative stress. Insulin is a vital hormone for carrying out day-to-day processes. Problems with insulin in the brain, as witnessed in AD (Aviles-Olmos, Limousin, Lees, \& Foltynie, 2013; Schubert et al., 2004) and induced by ICV-STZ (Grünblatt et al., 2007; Hoyer \& Lannert, 2008; Salkovic-Petrisic \& Hoyer, 2007), lead to a decrement in brain glucose and energy metabolism in which glucose cannot properly fuel cognitive functions. This decline in cognitive functioning is a prominent feature of AD and can be replicated by an ICV-STZ model. Glucose also plays a role in the regulation of acetylcholine (Loubatières-Mariani, Chapal, Alric, \& Loubatières, 1973), a neurotransmitter implicated in learning and memory (Hasselmo, 2006). In AD and ICV-STZ models, acetylcholine levels are decreased compared to healthy controls (Blokland \& Jolles, 1994; Bowen, Smith, White, \& Davison, 1976; Davies \& Maloney, 1976; Hellweg et al., 1992; Perry, Perry, Blessed, \& Tomlinson, 1977). Lastly, oxidative stress, an imbalance between reactive oxygen species and chemicals that can break them down, is another damaging effect of AD emulated by an ICV-STZ model (Mao, 2013; Sharma \& Gupta, 2001; Shoham, Bejar, Kovalev, \& Weinstock, 2003). The preceding changes are described in detail below.

\section{Insulin Resistant Brain State}

Insulin and insulin-like growth factors promote the uptake, oxidation, and storage of glucose (Bingham et al., 2002), a main energy source of the body. Insulin receptors are 
extensively expressed in the brain (Schubert et al., 2004) and have a high density in the hippocampus (Unger et al., 1989; Wickelgren, 1998) and cerebral cortex (Wickelgren, 1998), areas that are important for learning and memory and exhibit extensive AD pathology (Lalonde, Dumont, Staufenbiel, Sturchler-Pierrat, \& Strazielle, 2002). Insulin plays a role in modulating many cognitive functions including learning, memory, and synaptic plasticity (Zhao, Chen, Quon, \& Alkon, 2004).

In some disease states, the body can no longer appropriately respond to insulin. The result, insulin resistance, prevents the body from accessing its stores of glucose. In other words, the body loses its sensitivity to insulin, and insulin no longer effectively lowers blood glucose levels (Shanik et al., 2008). Insulin resistance may impede the uptake of glucose as well as the ability of insulin to stimulate its receptors in the brain (Messier \& Teutenberg, 2005). An insulin resistant brain state has since been implicated in the pathogenesis of both AD and Parkinson's disease, another neurodegenerative disorder (Aviles-Olmos et al., 2013; Schubert et al., 2004).

In $\mathrm{AD}$, there is a decrease in insulin levels in the brain (Frölich et al., 1999; Chen et al., 2012). Furthermore, insulin, insulin-like growth factor 1, and insulin-like growth factor 2 receptor expression decline with the progression of AD (de la Monte \& Wands, 2008). That is, expression of these receptors decreases as the stage of pathology increases. Insulin also plays a role in regulating the insulin signaling cascade, alterations of which can induce tau phosphorylation (Ho et al., 2004). Normal or increased levels of cerebral insulin and insulin-like growth factor 1 down-regulate GSK-3 $\beta$ (Hong \& Lee, 1997), a kinase that is responsible for phosphorylating tau (Plattner et al., 2006). When this insulin signaling pathway is disturbed, higher levels of GSK-3 $\beta$ lead to greater tau phosphorylation (Connell et al., 2001). 
ICV-STZ is an appropriate way to induce brain insulin system dysfunction as seen in AD (Grünblatt et al., 2007; Hoyer \& Lannert, 2008; Salkovic-Petrisic \& Hoyer, 2007). Following ICV-STZ administration, there is a dramatic decrease in insulin receptor expression in the hippocampus along with a significant increase in tau phosphorylation (Grünblatt et al., 2007). It is likely that this increase in tau phosphorylation is related to the over-activation of GSK-3 $\beta$ due to decreased phosphorylation at Ser9 (the serine at the ninth amino acid position) caused by the impaired insulin signaling pathway (Deng et al., 2009). GSK-3 $\beta$ is a proline-directed serine/threonine kinase that readily phosphorylates tau at many of the phosphorylation sites implicated in AD (Plattner et al., 2006).

\section{Decrement in Brain Glucose/Energy Metabolism}

Glucose provides both the body and, in particular, the central nervous system with the biological energy needed to carry out its various functions (Sokoloff, 1980). All bodily processes, including those in the central nervous system (Gibbs, Gibbs, Lennox, \& Nims, 1942; Pardridge, 1983), are supported by the metabolism of glucose. Glucose/energy metabolism in the brain is antagonistically controlled by insulin (Hoyer, 1996), so it is not surprising that decreases in insulin correspond with deficiencies in this system as well.

The parietotemporal and frontal areas of the brain, which have high demands for glucose, as well as heightened sensitivities to insulin, develop early abnormalities in brain glucose/energy metabolism in AD (Correia et al., 2011; Henneberg \& Hoyer, 1995; Hoyer, 2002; Hoyer, 2004). In early stages of AD, cerebral glucose utilization drops by $45 \%$ (Hoyer \& Nitsch, 1989) and the production of adenosine triphosphate (ATP), a molecule used to transport chemical energy for metabolic processes, from glucose is cut in half (Mattson et al., 2001). 
ICV-STZ administration results in long-term glucose/energy metabolism deficiencies (Hoyer, Henneberg, Knapp, Lannert, \& Martin, 1996). ICV-STZ, which has debilitating effects on brain glucose metabolism without perturbing basal blood glucose levels (Salkovic-Petrisic, Tribl, Schmidt, Hoyer, \& Riederer, 2006), precipitates abnormalities in glucose/energy metabolism in numerous regions in the frontal, parietal, sensory, and entorhinal cortices (Duelli, Schröck, Kuschinsky, \& Hoyer, 1994). Following ICV-STZ in rats, reduced glucose utilization has been found in over a dozen brain areas, most notably in the frontal cortex and in all hippocampal subfields (Duelli et al., 1994). Similar to what is witnessed in AD, there is a decrease in activity of glycolytic enzymes (chemicals which facilitate glycolysis) in the hippocampus (Plaschke \& Hoyer, 1993). In fact, glucose and glycogen metabolism falls by 10 to $30 \%$ in rats receiving ICV-STZ (Plaschke \& Hoyer, 1993).

\section{Cognitive Decline}

Progressive cognitive decline is a prominent feature of AD (Albert et al., 2011). Memory deficits, including those in working (Miller, 1971; Morris, 1984; Kopelman, 1985) and semantic (Chertkow \& Bub, 1990; Martin \& Fedio, 1983; Weingartner, Grafman, Boutelle, Kaye, \& Martin, 1983) memory types, comprise the most characteristic consequence of AD (Sjögren, Sjögren, \& Lindgren, 1952). Individuals with AD perform poorly on tests of semantic memory, such as picture naming or word finding, and these memory deficits become more profound as AD progresses (Hodges, Patterson, Oxbury \& Funnell, 1992). Patients with AD are also known to get lost in familiar surroundings, partially impacted by visuospatial disorientation (Henderson, Mack, \& Williams, 1989).

ICV-STZ results in progressive declines in cognitive functioning resembling those observed in AD (Grünblatt et al., 2007; Salkovic-Petrisic \& Hoyer, 2007). Rats that receive 
ICV-STZ show deficits in learning and memory (Hoyer \& Lannert, 1999; Lannert \& Hoyer, 1998). In particular, ICV-STZ causes impairments in working and reference memory (Lannert \& Hoyer, 1998), passive avoidance learning (Mayer, Nitsch, \& Hoyer, 1990), and spatial discrimination (Blokland \& Jolles, 1993; Blokland \& Jolles, 1994).

\section{Cholinergic Deficits}

In addition to abnormal cerebral glucose utilization and energy metabolism, various neurotransmitter systems have been implicated in the progression of AD. Synthesis of acetylcholine, an important neurotransmitter for learning and memory (Hasselmo, 2006), decreases in the AD brain (Sims et al., 1980). Early stages of AD are accompanied by the degeneration of cholinergic nuclei in the basal forebrain as well as their projections in nearly all cortical areas (Whitehouse, Price, Clark, Coyle, \& DeLong, 1981). The degeneration of cholinergic neurons leading to instabilities in serotoninergic, noradrenergic, and dopaminergic systems is correlated with the progression of cognitive decline in AD (Baskin et al., 1999; Wang et al., 2007). Analysis of postmortem brain samples of AD patients has found a significant decrease in cholinergic neurons (Bowen et al., 1976; Davies \& Maloney, 1976; Perry et al., 1977). It is also worth noting that one of the key components of acetylcholine, acetyl-CoA, is controlled by glucose/energy metabolism (Gibson, Jope, \& Blass, 1975). Because there is a decrement in glucose/energy metabolism in $\mathrm{AD}$, corresponding reductions in acetyl-CoA may explain the vulnerability in the cholinergic system (Wurtman, 1992).

ICV-STZ causes cholinergic system dysfunctions (Blokland \& Jolles, 1994; Hellweg et al., 1992). One week after ICV-STZ administration, activity of choline acetyltransferase, an enzyme needed to synthesize acetylcholine, is reduced in the hippocampus (Blokland \& Jolles, 1994; Hellweg et al., 1992). ICV-STZ also increases activity of the enzyme that breaks down 
acetylcholine, acetylcholinesterase (Agrawal, Tyagi, Shukla, \& Nath, 2009; de la Monte, Tong, Lester-Coll, Plater, \& Wands, 2006), further exacerbating its reduced presence in the brain. Interestingly, the reduced presence of choline acetyltransferase in the hippocampus is correlated with impaired spatial discrimination ability as measured in the MWM (Blokland \& Jolles, 1994).

\section{Oxidative Stress}

New evidence suggests that oxidative stress may occur before the earliest symptoms of AD (Mao, 2013). The brain is disproportionately susceptible to oxidative stress because of its high oxygen consumption and lipid content coupled with relative scarcity of antioxidant enzymes (Coyle \& Puttfarcken, 1993). Cerebral mitochondria, the organelles in cells that are mainly responsible for generating energy-rich ATP, are structurally damaged in the brains of individuals with AD (Hirai et al., 2001). Damage to the mitochondria results in the release of free radicals, which are implicated in causing oxidative stress (Smith et al., 1996). Oxidative stress has been associated with several neurodegenerative disorders, including Parkinson's disease, amyotrophic lateral sclerosis (ALS), and AD (Markesbery, 1997).

In an ICV-STZ model, oxidative stress precedes memory deficits (Sharma \& Gupta, 2001; Shoham, Bejar, Kovalev, Schorer-Apelbaum, \& Weinstock, 2007). Alkylating properties of STZ produce reactive oxygen species that eventually lead to neurodegeneration and DNA damage (Lester-Coll et al., 2006). An increase in free radicals combined with a decrease in glutathione, an important antioxidant responsible for reacting with free radicals, correlates with greater levels of oxidative stress in an ICV-STZ model of AD (Sharma \& Gupta, 2001). Lipid peroxidation, a gauge of free radical production, also increases in this model (Sharma \& Gupta, 2001). 
Together, these studies suggest that an ICV-STZ model is an ecologically valid method to induce the biochemical and behavioral effects seen in AD.

\section{Testing of Spatial Memory Using the Barnes Maze}

In $\mathrm{AD}$, some of the earliest changes in tau pathology affect the hippocampus, a brain region important in learning and memory (Altman \& Das, 1965; Kaplan \& Hinds, 1977). Because AD has profound effects on the hippocampus (Arriagada, Growdon, Hedley-Whyte, \& Hyman, 1992; Hof et al., 1992; Morris \& Fulling, 1988), it is important to use a test that is sensitive to alterations in hippocampal-dependent memory. In order to assess effects of ICVSTZ administration on the hippocampus, hippocampal-dependent memory test was administered. Although there are several different tests widely used to evaluate hippocampal-based learning and memory in animal models, the Barnes maze is best suited for this study given the ability to test the brain region of most interest with fewer disadvantages than other comparable assessments. The rationale for using the Barnes maze, as opposed to other hippocampaldependent memory tests, is discussed below.

There are four commonly used hippocampal-dependent memory tests: the Morris water maze (MWM; Gerlai, 2001), fear conditioning (Burman \& Gewirtz, 2007; Gerlai, 2001), radial arm maze, and Barnes maze (Barnes, 1979). In the MWM, mice must locate a hidden platform in a large tank of water (Morris, 1984). The mice use distal cues to learn the spatial location of the escape platform. The accurate directionality of swimming paths in the MWM, despite the hidden platform, indicates that spatial learning is indeed assessed (Morris, 1984). The contextual fear conditioning task and trace fear conditioning task, other tests of hippocampal-dependent learning and memory (Burman \& Gewirtz, 2007; Gerlai, 2001), use cue recognition (contextual) or temporal discrimination (trace) to predict the presence of a shock. The radial arm maze 
involves placing food at the ends of the arms of a maze and having a food-restricted animal find the food as efficiently as possible given the extra-maze cues (Meck, Church, \& Olton, 1984). Re-visiting arms where the food has already been eaten indicates a dysfunction in spatial memory. Lastly, the Barnes maze is a large circular platform with many holes around the perimeter in a brightly-lit room. One of the holes allows the mice to exit the maze and hide in a dark box, relying on a tendency for mice to choose dark, enclosed spaces over open, brightly lit ones (Harrison, Reiserer, Tomarken, \& McDonald, 2006). Mice can utilize extra-maze cues to locate the escape box as quickly as possible. Induced hippocampal lesions correlating with hindered performance on the MWM (Logue, Paylor, \& Wehner, 1997) and fear conditioning task (Logue et al., 1997) confirm their validity as measures of hippocampal-dependent memory, and the preceding analogous tests have been developed using the same reliance on spatial learning and memory. Although all of the preceding tests assess spatial learning and memory, different motivational factors, motor behaviors, and environmental conditions differentiate them (Gerlai \& Clayton, 1999).

Of these four different tests of hippocampal-dependent learning and memory, the MWM is the most widely used (Vorhees \& Williams, 2006). Through extensive testing in the past few decades, the ability of the MWM to assess hippocampal-dependent spatial navigation and reference memory has been confirmed (Vorhees \& Williams, 2006). It is also relatively impervious to species and strain differences, and reliable despite variances in tank configurations and testing procedures (Vorhees \& Williams, 2006). The MWM also has its own share of disadvantages. Repeatedly removing the mice from the water tank results in slight hypothermia. Because hypothermia causes tau phosphorylation (Planel et al., 2004; Planel et al., 2007), the practicality of using this test with tau mice is limited. Furthermore, the MWM (Dudchenko, 
Goodridge, Seiterle, \& Taube, 1997) employs an aversive stimulus. The stress induced by these tests may result in unintentional tau phosphorylation because kinases that phosphorylate tau are activated by stress (Goedert et al., 1997).

Contextual and trace fear conditioning tasks are other valuable measures of hippocampaldependent memory. Like the MWM, these tests do not require extensive pre-training and can be used as a test of both nonspatial and spatial learning (McEchron, Bouwmeester, Tseng, Weiss, \& Disterhoft, 1998). However, fear conditioning tasks also use an aversive stimulus (Phillips \& LeDoux, 1992), resulting in an increase of stress-related hormones (Daviu, Delgado-Morales, Nadal, \& Armario, 2012).

The radial arm maze is beneficial in that it does not employ an aversive stimulus; rather, food is used as a reinforcer (Hodges, 1996). However, using food as a reinforcer is a possible confounding variable between the ICV-STZ and control mice. Following ICV-STZ infusion, the threshold for lateral hypothalamic self-stimulation is lowered, suggesting that reward circuitry in the brain is sensitized to electrical impulses (Carr, Kim, \& Cabeza de Vaca, 2000). Given that food is another stimulus known to activate the brain's reward pathway (Lobo, 2012), it was possible that the ICV-STZ mice would differentially respond for food compared to the control mice. Also, in order for food to effectively serve as a reinforcer, the mice must have restricted diets or be maintained below their free-feeding weight, which is potentially dangerous for mice with insulin and glucose metabolism deficiencies. There is additional evidence that suggests that hypoglycemia-induced binge feedings may affect body composition (McNay et al., 2012).

The Barnes maze is particularly useful because it does not use a food as a reinforcer. Because implementing a test with a food reinforcer is not feasible for the reasons mentioned above, it is necessary to select a test that relies on a different kind of reinforcer. Although the 
fan used in the Barnes maze is aversive, the stress it induces is negligible compared that of the MWM or fear conditioning task. For example, the MWM results in greater increases in plasma corticosterone, a biological indicator of stress, than the Barnes maze (Harrison, Hosseini, \& McDonald, 2009). A potential downfall of the Barnes maze is its sensitivity to strain differences. For instance, different mouse strains have been shown to react differently to the presence of various stimuli (Youn et al., 2012). It is possible that particular genetic factors of the strains used in this experiment would result in the mice spending more or less time to escape the fans and lights, and thus invalidating the measures used to test memory (Nguyen, Abel, Kandel, \& Bourtchouladze, 2000). For the purpose of this experiment, the advantages of the Barnes maze outweigh its disadvantages. Neither the TauP301L nor TauWT lines have been previously evaluated in the Barnes maze. However, previous studies suggest PS19 mice, which overexpress human tau (1N4R) containing the P301S mutation found in FTDP-17, exhibit deficits in spatial learning and memory as assessed by the Barnes maze (Brunden et al., 2010). Given the particular limitations of the MWM, fear conditioning task, and radial arm maze for this model, the Barnes maze was implemented in this study. The unique combination of advantages and disadvantages present in the Barnes maze made it best-suited for the unique challenges of this particular experiment given that the Barnes maze minimizes corticosterone spikes (Harrison et al., 2009), food deprivation, and hypothermia.

\section{Statement of the Problem}

Alzheimer's disease (AD) is a common neurodegenerative disorder affecting millions of people with no known cause or cure. It is characterized by the presence A $\beta$ plaques and NFTs composed primarily of tau, a microtubule-binding protein (Kolarova et al., 2012). Late-stage $\mathrm{AD}$ ends with profound neuronal loss. To date, most research has focused on the role of $\mathrm{A} \beta$ in 
initiating the disorder; however, clinical trials using $A \beta$-modifying drugs have failed to slow or halt the progression of the disease, despite successfully decreasing A $\beta$ levels (Small \& Duff, 2008). Thus, it is necessary to investigate other potential etiologies, including abnormalities in the tau protein.

Tau, a protein in the brain responsible for microtubule nucleation and stabilization (Eckermann et al., 2007), aggregates into the pathological NFTs seen in AD. Tau pathology alone is capable of causing the neurodegeneration found in sporadic and familial tauopathies (Sorrentino \& Bonavita, 2007), and the aberrant phosphorylation of tau is an essential neuropathological event in AD (Kolarova et al., 2012). The mechanisms by which tau is hyperphosphorylated are not fully understood, but numerous metabolic abnormalities, such as a decrease in insulin levels in the brain (Frölich et al., 1999) and a drop in cerebral glucose utilization (Hoyer \& Nitsch, 1989), are present in AD and result in tau phosphorylation (de la Monte, 2012).

Recent advancements made in AD mouse models allow for the pathological role of tau to be better evaluated. Mice expressing mutant human tau, referred to as TauP301L, have a transgene with a proline-to-leucine mutation at the $301^{\text {st }}$ amino acid found in frontotemporal dementia with parkinsonism-17 (FTDP-17), another tauopathy (Orr, Pitstick, Canine, Ashe, \& Carlson, 2012). Although the mutation is found in FTDP-17, TauP301L mice are generally considered a mouse model of AD because (1) use of a CaMKII promoter restricts pathology to brain regions implicated in $\mathrm{AD}$ (i.e., the forebrain) and (2) the mutation, when restricted to the forebrain, results in formation of NFTs, neuronal death, and progressive memory loss as observed in AD (Ramsden et al., 2005). Finally, TauWT mice are another valuable mouse model because they express the $4 \mathrm{R}$ version of human (rather than rodent) tau without a genetic 
mutation. These mice allow for the manipulation of variables that may precipitate AD and subsequent evaluation of tau pathology. TauWT mice can also serve as controls for the overexpression of human tau in mice to yield support for the assumption that any memory deficits or pathological changes are attributable to alterations in tau (e.g., tau hyperphosphorylation) and not the overexpression of human tau per se.

ICV-STZ was administered to both the TauP301L and TauWT mice, as well as littermate controls, to emulate the early metabolic changes found in the AD brain. By doing so, it was anticipated that a more ecologically valid mouse model of AD would be developed using the TauWT mice that does not rely on genetic mutations.

\section{Method}

\section{Subjects and Treatments}

In total, 56 male mice were used (Figure 1A). These mice had unrestricted access to food and water and were group housed in a temperature- and humidity-controlled colony room with a 12-hour light/dark cycle.

The generation of TauWT and TauP301L mice has been described extensively in the past (Hoover et al., 2010; Ramsden et al., 2005; SantaCruz et al., 2005). Briefly, mice expressing mutant human four-repeat tau lacking the $\mathrm{N}$-terminal sequences $(4 \mathrm{R} 0 \mathrm{~N})$, referred to as TauP301L, were created by crossing responder and activator lines. Responder mice on the FVB/N background, heterozygous for the Tetracycline Response Element (TRE)-TauP301L transgene, are bred with activator mice on the 129S6 background, heterozygous for the tet-off tetracycline transactivator $(\mathrm{tTa})$ reading frame downstream of a $\mathrm{Ca}^{2+}$-calmodulin (CaMKII) promoter element (SantaCruz et al., 2005). The breeding of heterozygous responder and activator mice produces four genotypes with the following nomenclature, TauP301L/CKtTA, 
and encompasses what is referred to as the TauP01L mice (+/+) and Controls (-/+, +/-, -/-). To limit the variability introduced by tTa expression, only activator positive mice (-/+) were used as controls. No behavioral differences exist between the three control groups, and human tau is not expressed (Hoover et al., 2010; Ramsden et al., 2005; Santacruz et al., 2005). TauWT mice were produced in the same manner, with the exception that TauWT mice express 4R0N human tau without the P301L mutation.

In TauP301L and TauWT mice, the expression of human tau is limited to the forebrain with a CaMKII promoter and controlled through the use of a tetracycline transactivator (tTa) protein (Ramsden et al., 2005). TauP301L mice have a proline-to-leucine mutation at the $301^{\text {st }}$ amino acid found in frontotemporal dementia with parkinsonism-17 (FTDP-17), another tauopathy (Orr, Pitstick, Canine, Ashe, \& Carlson, 2012). Although the mutation is found in FTDP-17, the pathology in TauP301L mice is restricted to areas of the brain that are affected by $\mathrm{AD}$ (i.e., the forebrain) by the CaMKII promoter. The mutation, when restricted to the forebrain, results in formation of NFTs, neuronal death, and progressive memory loss as observed in AD (Ramsden et al., 2005). Approximately half of the controls were (-/+) littermates of the TauWT mice and half were (-/+) littermates of the TauP301L mice. To control for differences in transgene copy number, which can affect transgene expression (Kong et al., 2009), no more than two mice of the same transgene $[\mathrm{Tg}$; i.e., $(-/+)$ or $(+/+)]$ from one litter were assigned to the same treatment condition.

The tet-off system allowed for regulatable expression of tau protein with the use doxycycline (Figure 1B). In the tet-off system, the presence of doxycycline prevents the transcription of tau by preferentially binding to the TRE. In the absence of doxycycline, transcription occurs when the tTa protein binds to the TRE. During conception until 2 months of 
age, the mice received water with 40 parts per million (ppm) doxycycline hyclate to suppress tau expression during development (Figure 2C; Liu, Wang, Brenner, Paton, \& Kasparov, 2008).

Dams were placed on doxycycline water 2 weeks prior to breeding, and experimental offspring continued doxycycline until they were approximately 2.5 months of age. On the day of the surgery, doxycycline water was replaced with regular water and transcription of tau was allowed to occur for approximately 3.5 months (SantaCruz et al., 2005). All experimental procedures were approved by the West Virginia University Animal Care and Use Committee.

\section{Surgery and ICV-STZ Administration}

On the same day mice were removed from doxycycline, mice received either a single, bilateral infusion of ICV-STZ (2-deoxy-2-(3-(methyl-3-nitrosoureido)-D-glucopyranose); 3 $\mathrm{mg} / \mathrm{kg} ; 2.5 \mu \mathrm{l} / \mathrm{side}$ ) dissolved in $0.05 \mathrm{M}$ citrate vehicle ( $\mathrm{pH} 4.5$ ) or vehicle (citrate buffer) into the lateral ventricles. Sterile conditions were maintained during surgeries. After induction with 5\% isoflurane for $3 \mathrm{~min}$, the mice were injected subcutaneously with $1 \mathrm{mg} / \mathrm{kg}$ ketoprofen, $1 \mathrm{mg} / \mathrm{kg}$ bupivacaine, and $3 \mathrm{mg} / \mathrm{kg}$ sterile saline. The fur in the surgical site was clipped and shaved, the area was cleaned with alternating $70 \%$ isopropyl and iodine, and a $2 \mathrm{~cm}$ longitudinal incision was made at the skull midline. The infusions were performed while the mice were anesthetized with $2-4 \%$ isoflurane and placed into a stereotaxic device. Coordinates of the infusions, based off of bregma, were $\pm 1.0 \mathrm{~mm}$ lateral, $-0.5 \mathrm{~mm}$ posterior, and $-2.5 \mathrm{~mm}$ ventral (Coomans, De Rydt, \& Van Proeyen, 2011). To facilitate the flow of the infusion into the brain, the syringe was slowly pulled up through the ICV from $-2.5 \mathrm{~mm}$ to $-2.2 \mathrm{~mm}$. Microinfusion of STZ or vehicle was controlled by a GenieTouch Syringe Pump (Kent Scientific, Connecticut, USA). Twenty-eight gauge injectors were attached to $25 \mu 1$ Hamilton syringes to deliver STZ or vehicle 
at a steady rate of $1 \mu \mathrm{l} / \mathrm{min}$ for $2.50 \mathrm{~min}$ per side with an additional $5 \mathrm{~min}$ for diffusion. The holes in the skull were filled in with bone wax and the incision was closed with surgical glue.

Immediately following surgery, the mice were removed from anesthesia, placed into a cage half-covered with a heating pad, and examined closely for appropriate respiration patterns and the return of reflexes. The mice remained alone in this post-operative cage for $30 \mathrm{~min}$. For at least one hour after surgery, the mice were monitored for signs of distress and the ability to ambulate before being returned to the colony in cages with no more than three mice. On postoperative days 1,2 , and 3, $3 \mathrm{mg} / \mathrm{kg}$ sterile saline and $1 \mathrm{mg} / \mathrm{kg}$ ketoprofen were injected intraperitoneally and subcutaneously, respectively, to alleviate discomfort. Mice also received moist chow during this period. After post-operative day 3, the mice were allowed to return to their original cage.

\section{Barnes Maze}

At approximately 5.5 months of age (Figure 1C), the mice began the first of two habituation days for behavioral testing, which immediately preceded the five acquisition days and two probe trials.

Apparatus. The Barnes maze is a large, flat, white platform (diameter $=122 \mathrm{~cm}$ ) with forty holes (diameter $=5 \mathrm{~cm}$ ) equally spaced around the perimeter. The platform was raised approximately $108 \mathrm{~cm}$ above the ground. Between every trial, the maze was cleaned with a $35 \%$ ethanol solution. A Logitech HD Pro Webcam C920 (Romanel-sur-Morges, Switzerland) camera mounted above the platform recorded all trials using Logitech Webcam software. Recorded trials were later viewed by a blinded experimenter, and slowed-down or repeated as necessary, to assess for the variables of interest. 
Habituation. For the two days preceding acquisition trials, the mice were habituated to the maze. In this stage, the spatial cues around the room were not present, the fans were turned off, and the room light was turned on. On Day 1 of habituation, the mice were placed on the platform next to its respective escape hole under a transparent, plastic breaker. The mice were able to explore the escape box and the area immediately surrounding it, but were not able to access the rest of the maze. This allowed the mice to learn how to access the escape box underneath the platform. After $5 \mathrm{~min}$, the mice were returned to its home cage. The mice were each subjected to two trials of this procedure with about 25 min between trials. On Day 2 of habituation, the mice began in the center of the platform under a transparent, plastic beaker. After $10 \mathrm{~s}$, the beaker was raised and the mice were gently guided to the escape box in the target hole. Once the mice entered the box, the hole was covered for $2 \mathrm{~min}$. After the $2 \mathrm{~min}$ had elapsed, the mice were returned to its home cage. The two stages of habituation ensured that the mice learned how to access the escape hole, and that the escape hole could be found from the center of the platform to escape from the aversive stimuli. The mice each completed two trials on habituation Day 2 and there was approximately 25 min between trials.

Acquisition. The acquisition phase took place on Days 3 through 7. Under one hole, a small, dark recessed chamber, referred to as the escape box, was attached to the bottom of the platform. The escape box was accessible by entering the target hole. The room light was turned on straight above the maze, fans were directed at the platform from four sides, and spatial cues were placed around the room. The escape box was placed in the same hole for each trial relative to extra-maze spatial cues placed on the walls of the room. Although the maze was cleaned with ethanol between each trial, it was also rotated around its central axis to control for possible remaining odor cues. After rotation, the escape box was realigned with the extra-maze cues. 
The mice began the trial under a transparent, plastic beaker in the center of the platform. After $10 \mathrm{~s}$, the beaker was raised and the mice were free to find the escape box. The trials ended $30 \mathrm{~s}$ after the mice entered the escape box. If the mice did not enter the escape box during the 3 min trial, the experimenter gently guided the mice into it and covered the hole for $30 \mathrm{~s}$. The mice were each subjected to three trials on each day with approximately $20 \mathrm{~min}$ between trials.

The following variables were assessed during the acquisition trials: hole deviation, total errors, total latency, primary errors, primary latency, and search strategy. For each of these variables, an encounter with a hole was defined as the mice sticking their entire heads into the hole. The hole deviation was measured by determining how many holes were between the target hole and first hole the mice encountered on the platform. Total errors included the number of holes the mice encountered before entering the escape box, and total latency included the total time before the mice entered the escape box. Total errors and latency may be confounded by the tendency of some mice to explore the maze even after initially locating the hole (Harrison et al., 2006). With this in mind, primary errors and primary latency were also used. Primary errors included the number of holes that the mice encountered before dipping its head into the target hole and primary latency was the time lapse between the beginning of the trial and the first encounter with the target hole. Lastly, there were three different search styles: random, serial, and spatial. Random was a nonsystematic searching strategy characterized by multiple crossings through the center of the platform or inability to find the target hole. A serial search strategy involved encounters with three consecutive holes around the edge of the platform. Finally, a spatial search strategy was used when mice rely on extra-maze cues to navigate directly within two holes of the target hole. 
Probe. The first of two probe trials took place $24 \mathrm{~h}$ after the last acquisition trial. The second probe trial was one week following the first. The escape box was removed for the probe trials. The mice were placed into a transparent, plastic beaker at the center of the platform. After $10 \mathrm{~s}$, the beaker was removed and the mice were free to search the maze. In addition to total session time $(90 \mathrm{~s})$, three $30 \mathrm{~s}$ bins were also evaluated Probe trials lasted $90 \mathrm{~s}$ with three bins: 0-30 s, 31-60 s, and 61-90 s. It was expected that the response of head pokes into the target hole would begin to be extinguished in the 31-60 s and 61-90 s bins as the mice search for the box without being able to locate the correct hole. The variables measured during the probe trials included the time spent to reach the target hole where the escape box was previously hidden, the number of encounters with the target hole per bin, and the number of encounters with each error hole per bin.

\section{Glucose Testing}

One day after the last probe trial of Barnes maze testing, fasting blood glucose readings were obtained from the mice to ensure no peripheral effects of ICV-STZ treatment. All food was removed from the cages in the morning, and 5.5 hours later, testing took place. To obtain a blood sample, the mice were first restrained in a $50 \mathrm{ml}$ conical vial with drilled air holes, and the upper thighs of the mice were shaved with electric clippers and cleaned with $70 \%$ alcohol. A 27 gauge needle was used to puncture the saphenous vein, and a TRUEresult Blood Glucose Monitoring System with TRUEtest Blood Glucose Test Strips (Nipro Diagnostics, Osaka, Japan) was used to provide a reading.

\section{Antibodies}

To assess progression of tau pathology, antibodies with differential abilities to detect stage-specific, biochemical changes in tau were used after the mice had been euthanized (Table 
1; Chai et al., 2011). Tau-5 (Invitrogen, Carlsbad, CA) recognizes both human and mouse tau and serves as a general marker for tau, independent of pathology. MC-1 and CP-13 detect conformation- and phosphorylation-specific epitopes, respectively, in the earliest stages of AD pathology. PG-5 identifies changes in tau related to mid-stage tau pathology, including pretangles (the accumulations of nonargyrophilic hyperphosphorylated tau) in the neuronal cell body. Lastly, Alz-50 and PHF-1 identify conformational changes in tau and paired helical filaments indicative of late-stage tau pathology. MC-1, CP-13, PG-5, Alz-50, and PHF-1 were generous gifts from Dr. Peter Davies (Albert Einstein College of Medicine, Bronx, NY). Blots were normalized with actin (Santa Cruz Biotechnology, Dallas, TX) to control for variations in loading. To investigate pathological changes in tau, the steps described below were used.

Dissection and extraction of mouse hippocampus. Two days after the conclusion of Barnes maze testing, all mice were euthanized. Brains were immediately removed and separated into the olfactory bulbs, the cerebellum, the prefrontal cortex (PFC), the hippocampi, and the remaining forebrain hemispheres, immediately frozen on dry ice, and then stored in the freezer at $-80{ }^{\circ} \mathrm{C}$. The hippocampi were placed into $200 \mu \mathrm{l}$ sucrose buffer $(10 \mathrm{mM}$ HEPES, $0.32 \mathrm{M}$ sucrose added the day of use, $40 \mathrm{mM} \beta$-glycerophosphoate, $20 \mathrm{mM}$ sodium pyrophosphate, $1 \mathrm{mM}$ sodium orthovanadate, $30 \mathrm{mM} \mathrm{NaF}, 1 \mathrm{mM}$ EDTA, 1 mM EGTA, $15 \mu \mathrm{M}$ calpeptin, pH 7.4) with protease inhibitors (cOmplete ULTRA tablets, mini, EDTA-free, Roche diagnostics, Laval, QC, Canada) and phosphatase inhibitors (phosSTOP EASYpack, Roche diagnostics, Laval, WC, Canada) added fresh the day of extraction. To homogenize the tissue, the hippocampus was passed through a one milliliter $(\mathrm{ml})$ syringe without a needle five times. The tissue was then passed through a syringe with a 20 -gauge needle 20 times, and then further dissociated by passing it through a 27 -gauge needle five times. The tissue lysate was centrifuged for 10 min at 
$1,000 \mathrm{x} \mathrm{g}$ at $4{ }^{\circ} \mathrm{C}$, and the resulting supernatant was collected and centrifuged again for 6 min at $1,000 \mathrm{x}$ g. Once again, the supernatant was centrifuged at $12,000 \mathrm{xg}$ for $20 \mathrm{~min}$, the resulting pellet was discarded, and the supernatant was stored at $-80{ }^{\circ} \mathrm{C}$. Protein concentrations in each sample were determined by performing a bicinchoninic acid (BCA; Thermo Scientific, Rockford, IL) protein assay using bovine serum albumin (BSA; Sigma, St. Louis, MO) as a standard. To adjust the samples so that they had protein concentrations in the BCA linear range, the samples were diluted 1:5 with fresh sucrose buffer with added protease and phosphatase inhibitors and then frozen at $-80^{\circ} \mathrm{C}$.

Western blotting. After the diluted hippocampal tissue samples were thawed, equal amounts of protein were aliquoted and mixed with loading buffer $(450 \mathrm{mM}$ Tris $\mathrm{HCl}, \mathrm{pH} 8,8 \%$ SDS, 24\% glycerol, $5 \% \beta$-mercaptoethanol, $0.1 \%$ bromophenol blue, $0.1 \%$ phenol red). Samples were then heated to $95{ }^{\circ} \mathrm{C}$ for $5 \mathrm{~min}$, separated on $8 \%$ or $8-16 \%$ Tris- $\mathrm{HCl}$ sodium dodecyl sulfate polyacrylamide gel electrophoresis (SDS-PAGE) gels (Bio-Rad, Hercules, CA), and transferred onto $0.45 \mu \mathrm{m}$ polyvinylidene difluoride membranes (Millipore, Bedford, MA). Membrane blots were blocked for one hour at room temperature in 5\% BSA in $0.1 \%$ Tween 20/Tris-buffered saline (TTBS; $396 \mathrm{mM} \mathrm{NaCl,} 20 \mathrm{mM}$ Trizma base, pH 7.4). After blocking, membranes were incubated with an antibody directed against the site of interest (Table 1) in 5\% BSA in TTBS either for one hour at room temperature or overnight at $4^{\circ} \mathrm{C}$. After washing the membranes with TTBS four times for 5 min each, they were incubated with an HRP-coupled secondary antibody (GE Healthcare, Buckinghampshire, UK) in TTBS for 2 hours at room temperature. All blots contained a consistent loading control and were stripped with Restore Western Blotting Stripping Buffer (Thermo Scientific, Rockford, IL) and re-probed with actin (Santa Cruz Biotechnology, Dallas, TX) to ensure equal loading of samples within and across 
blots. Actin blots were incubated with an AP-coupled secondary antibody (Santa Cruz Biotechnology, Dallas, TX) and immunofluoresced with Lumi-Phos (Thermo Scientific, Rockford, IL).

Immunoreactive bands were visualized by enhanced chemiluminescence with either SuperSignal West Pico Chemiluminescent Substrate (Thermo Scientific, Rockford, IL) for HRPconjugated secondaries or Lumi-Phos (Thermo Scientific, Rockford, IL) for AP-conjugated secondaries. Band density was measured using a FluorChem E Imager (Protein Simple, Santa Clara, CA). All blots were quantified using Alphaview (Protein Simple, Santa Clara, CA). Using various exposure lengths, the loading control band on different blots of the same antibody was matched within $10 \%$ across blots. Both tau and actin bands were quantified as the average pixel values in the region. To account for unequal loading during western blotting, the pixel values of the tau bands were divided by the pixel values of the actin bands of the same samples.

\section{Statistical Analyses}

Assumptions regarding normality, homogeneity of variance, and independence of errors were assessed and met. Variables of interest during the acquisition trials of the Barnes maze test (i.e., hole deviation, primary errors, primary latencies, total errors, and total latencies) were evaluated using two-way repeated-measures analyses of variance (RMANOVAs) with the day as a within-subjects factor and transgene (Tg: Control, TauWT, or TauP301L) and treatment condition (Tx: ICV-vehicle or ICV-STZ) as between-subjects factors. Variables of interest during the probe trials of the Barnes maze (i.e., time spent to reach the target hole, the number of encounters with the target hole per bin, and the number of encounters with each error hole per bin) were examined using two-way analyses of variance (ANOVAs) with Tg and Tx condition as the between-subjects factors. Search strategy was assessed using chi-square tests. 
Immunoblotting was also analyzed with two-way ANOVAs with Tg and Tx conditions as between-subjects factors. Bonferroni post-hoc tests followed all significant analyses. For all tests, statistical significance was defined as $\alpha=.05$. Reported statistics are the mean \pm standard error of the mean (SEM).

\section{Results}

\section{Physiological Parameters}

Figure 2A shows fasting blood glucose levels taken on the day between the conclusion of behavioral testing and euthanasia. There were no differences among treatment (Tx) and transgene $(\mathrm{Tg})$ groups [Tx: $F(1,33)=1.07, p=.31$; Tg: $F(2,33)=1.669, p=.20 ; \mathrm{Tx} * \mathrm{Tg}$ : $F(2,33)=.29, p=.75]$. At the time of euthanasia, neither body weights (Figure 2B) nor brain weights (Figure 2C) differed among the groups [body weight: Tx: $F(1,50)=.06, p=.80$; Tg: $F(2,50)=1.01, p=.37$; Tx ${ }^{*} \mathrm{Tg}: F(2,50)=1.88, p=.16$ and brain weight: Tx: $F(1,46)=.51, p=.48$; Tg: $F(2,46)=1.74, p=.19 ; \mathrm{Tx} * \mathrm{Tg}: F(2,46)=1.18, p=.32]$.

\section{Behavioral Testing}

Acquisition. For hole deviation, the distance of the first hole visited relative to the target hole, there were no statistically significant improvements across days [Figure 3; Table 2]. For primary errors (Figure 4A), fewer error hole visits were made as the days progressed [Day: $F(4,200)=12.16, p<.001]$. Figure 4B demonstrates the Day*Tg interaction $[F(8,200)=2.77$, $p<.01]$; TauWT mice made significantly more primary errors than the Control mice on Day 1, but did not differ on any other days. With the exception of the Day*Tg interaction, the number of primary errors did not differ among Tx or Tg groups (Table 2). Primary latency, the time to initially locate the target hole, decreased with additional training [Figure 5; Day: 
$F(4,200)=80.91, p<.01]$. However, neither Tx nor Tg significantly impacted the time required for the mice to first locate the target hole (Table 2).

Total errors decreased as training progressed [Figure 6; Day: $F(4,200)=8.34, p=<.001$ ]. In addition, there was a Day*Tx*Tg interaction $[F(8,200)=1.98, p=.05]$. The Vehicle-TauP301L mice did not differ from any other groups until Day 5, at which point the Vehicle-TauP301L mice made significantly more errors than both the STZ-Control and Vehicle-TauWT mice. Neither the effect of Tg and Tx group alone, nor the two-way interactions with Day, were statistically different for total errors (Table 2). For total latency, the mice entered the escape box more quickly with each subsequent day of acquisition [Figure 7A; Day: $F(4,200)=8.34, p<.001$ ]. As shown in Figure 7B, a main effect of Tg was observed [Tg: $F(2,50)=3.88, p=.027]$; TauP301L mice, regardless of ICV-STZ treatment or Day, took longer to enter the escape box than the Control mice $(p=.03)$, but not the TauWT mice $(p=.16)$. There were no significant differences for total latency between Tx groups or interactions (Table 2).

Search strategy for Tg, Tx, and Tg-Tx groups was evaluated using chi-squared tests for each of the three strategies on Days 1 to 5 of acquisition (Table 3). On Day 1, there was a significant Tx effect for which the use of a serial strategy was significantly higher in vehicletreated mice than STZ-treated mice [Figure $8 \mathrm{~A} ; \chi(3)=9.05, p=.03$ ] and also a significant $\mathrm{Tx} * \mathrm{Tg}$ effect such that Vehicle-TauWT mice used a serial search strategy more than STZ-Control mice [Figure $8 B ; \chi(15)=25.84, p=.04]$.

Probe. For Probe 1 (Table 4), there were no significant $\mathrm{Tx} * \mathrm{Tg}$ effects for total errors (Figure 9A), the 31-60 s bin (Figure 9C), or the 61-90 s bin (Figure 9D), but there was a Tx*Tg effect for 0-30 s bin [Figure 9B; $F(2,50)=3.34, p=.04]$. Post-hoc analyses indicated that, although Control and TauWT mice in the ICV-STZ condition did not differ significantly from 
their respective transgene groups in the vehicle condition, TauP301L mice in the ICV-STZ condition made more errors than the TauP301L mice in the vehicle condition in the first time bin $(p=.04)$. In addition, there was a main effect of Tx (Figure 10) for total errors $[\mathrm{F}(1,50)=5.49$, $\mathrm{p}=.02], 0-30 \mathrm{~s}[\mathrm{~F}(1,50)=4.39, \mathrm{p}=.04], 31-60 \mathrm{~s}[\mathrm{~F}(1,50)=3.89, \mathrm{p}=.05]$, and 61-90 s $[\mathrm{F}(1,50)=5.49$, $\mathrm{p}=.02]$. There was no Tg effect for any of these bins (Table 4). For escape latency in Probe 1, there were no significant differences (Table 4) among Tg or Tx groups (Figure 11). Escape hole visits (Figure 12) also did not significantly differ among groups (Table 2) during the total bin (Figure 12A), 0-30 s bin (Figure 12B), 31-60 s bin (Figure 12B), or 61-90 s bin (Figure 12D).

For Probe 2 error hole visits, there were no $\mathrm{Tx}^{*} \mathrm{Tg}$ interactions for total errors (Table 4) in the total bin (Figure 13A), the 0-30 s bin (Figure 13B), the 31-60 s bin (Figure 13C), or the 61-90 s bin (Figure $13 \mathrm{D})$. There was, however, a significant effect of Tx for errors in the 0-30 s bin [Figure $14 ; F(1,50)=4.08, p=.05]$, but not any of the other bins (Table 2 ). Escape latency in Probe 2 did not differ among treatment or transgene groups [Figure 15; Table 4). Escape hole visits (Figure 16) also did not differ among treatment or transgene groups (Table 4).

\section{Western Blotting}

Tau-5, an antibody that detects both mouse and human tau, indicated that total tau levels in TauWT $(p<.001)$ and TauP301L $(p=.002)$ mice were higher than Controls [Figure 17; Tg: $F(2,34)=11.20, p<.001]$. As previously reported (Hoover et al., 2010), TauWT express wild-type human tau at concentrations equivalent to P301L human tau in rTgP301L mice. ICV-STZ did not alter tau levels as there were no observed differences between Tx groups $[F(1,34)=.21$, $p=.65]$, and there was also no interaction between $\operatorname{Tx}$ and $\operatorname{Tg}[F(2,34)=2.82, p=.07]$.

Levels of MC-1, specific for a conformational change in tau associated with early-stage AD pathology, were significantly increased in TauP301L mice [Figure 18; Tg: $F(1,35)=3.65$, 
$p=.04]$ compared to Controls $(p=.03)$, but not TauWT mice $(p=0.41)$. There was neither a significant main effect of $\mathrm{Tx}[F(1,35)=0.00, p=.99]$ nor an interaction between $\mathrm{Tx}$ and $\mathrm{Tg}$ $[F(2,35)=.19, p=.83]$. Use of CP-13 (Figure 19), an antibody that detects a phosphorylated serine indicative of early-stage AD pathology, showed significantly different levels among the groups $[F(2,34)=13.82, p<.001]$. TauWT mice exhibited significantly higher CP-13 levels than both Controls $(p<.001)$ and TauP301L $(p=.01)$, but the Control and TauP301L mice did not differ. There was no main effect of $\operatorname{Tx}[F(1,34)=1.13, p=.30]$ or an interaction between $\mathrm{Tx}$ and $\mathrm{Tg}$ $[F(2,34)=.26, p=.78]$.

There was no positive staining in any of the groups when probed using PG-5 or Alz-50 antibodies. Positive staining with actin confirms the lack of PG-5 and Alz-50 signal was not due to inaccurate loading.

Finally, PHF-1, an antibody that detects paired helical filaments, showed a significant main effect of $\mathrm{Tg}$ [Figure 20; $F(2,21)=4.18, p=.03$ ] such that the TauP301L mice exhibited significantly higher levels of paired helical filaments than the Control mice $(p=.03)$, but not the TauWT $(p=1.00)$ mice. No effect of Tx $[F(1,21)=.21, p=.65]$ or interaction between $\mathrm{Tx}$ and $\mathrm{Tg}$ $[F(2,21)=.15, p=.87]$ was found.

\section{Discussion}

Although ICV-STZ has been used extensively to emulate metabolic changes found in the AD brain, the findings of the current study provide inconsistent support for the use of an ICVSTZ model in mice with wild-type human tau. For many variables of interest for the Barnes maze and western blotting, ICV-STZ did not result in an apparent induction or exacerbation of pathology in the TauWT or TauP301L groups, respectively. It is unclear if the lack of ICV-STZ 
effect in the present study is due to an absence of pathology, perhaps due to a methodological divergence from other ICV-STZ studies, or a lack of sensitive measures to detect subtle deficits.

Results of the Barnes maze did not indicate that there was a learning or memory deficit in the Vehicle-TauP301L mice after approximately three months of tau expression. The total time allowed for the expression of tau plays a key role in the presence and severity of pathology. It may be possible that the assessed time-point was too early for the existence of detectable learning and memory deficits. After two months of tau expression, TauP301L mice have been shown to exhibit increases in long-term potentiation in the dentate gyrus and improvements in spatial learning and memory accompanied by lower levels of tau phosphorylation than wildtypes at sites detected by AT8, AT180, and AD2 (Boekhoorn et al., 2006). This finding suggests that it is not solely the presence of P301L tau that causes deficits in TauP301L mice; rather, the time-dependent alterations in P301L tau such as tau cleavage (Rizzu et al., 2000), hyperphosphorylation (Hoover et al., 2010; Ramsden et al., 2005; Terwel et al., 2005), and mislocalization (Hoover et al., 2010; Kuchibhotla et al., 2014), that produce synaptic dysfunction and cognitive decline. The mice in the present study represented a time-point at which early pathology was expected, but it is possible that it was too premature and that deficits were not yet present.

ICV-STZ also did not produce an obvious induction or exacerbation of behavioral deficits. The period of time between surgery and subsequent behavioral testing and brain analyses in the present study was long compared to other published reports. In most cases, the time between STZ-treatment and biochemical and behavioral assays is fewer than six weeks (Blokland \& Jolles, 1993; Chen et al., 2013; de la Monte et al., 2006, Deng et al., 2009; Hoyer \& Lannert, 2008; Lester-Coll et al., 2006, Planel et al., 2007). The current study, in contrast, 
assessed behavioral deficits at three months post-surgery, and biochemical pathology 3.5 months post-surgery. In one study of non-transgenic rats that received ICV-STZ, there were memory deficits as measured by the MWM as far as two months post-surgery (Grünblatt et al., 2007). In a study that encompassed the same time range between ICV-STZ and behavioral and biochemical assays as the present study, it was noted that levels of active GSK3 $\beta$, a kinase that phosphorylates tau, in the hippocampus were significantly higher in ICV-STZ rats one month post-surgery, but declined to control levels at three months post-surgery (Salkovic-Petrisic et al., 2006). The same study, however, found memory deficits at both of the time-points as indicated by the MWM (Salkovic-Petrisic et al., 2006). In one of the longest timeframes, nine-month-old transgenic mice with a mutation in the $\mathrm{A} \beta$ precursor protein showed deficits in the MWM 6 months after ICV-STZ (Plaschke et al., 2010). Because the ICV-STZ studies with longer timeframes used either non-transgenic rats or mice with $\mathrm{A} \beta$ mutations, it is unclear if there may be partial or complete recovery of deficits from the effects of ICV-STZ in mice with human tau. Future studies should investigate a potential resistance in human tau to long-term alterations induced by ICV-STZ.

Although it is possible that there were no learning and memory deficits induced by ICVSTZ in the present study, one additional concern involves the possible inability of the Barnes maze to have detected subtle deficits if present. The definition of search strategy, in particular, may need to be revised to truly encompass a spatial search strategy. The definition of a serial search strategy in the present study indicated that the first hole visited must be within two holes of the target hole, and the mouse cannot visit a hole further than two holes from the target hole. Because the Barnes maze used has 40 holes, this definition may be too restrictive. In a 12-hole Barnes maze with mice, a serial search strategy was indicated by the mouse first visiting the 
target hole or the hole on either side, thus making $25 \%$ of the holes correspond to a serial search strategy (Harrison et al., 2006). In a 20-hole Barnes maze, the same definition of a spatial search strategy encompassing either adjacent hole was used, corresponding to a total of $15 \%$ of the holes on the platform (Sunyer, Patil, Höger, \& Lubec, 2007). In the 40-hole Barnes maze used in the current study, only $12.5 \%$ of holes correspond to a spatial search strategy. This strict definition may have resulted in coding some trials as serial or random even when a spatial search strategy was being used. The persistent use of a serial search strategy is often an indication of a spatial memory deficit (Harrison et al., 2006), and by coding a large number of trials as serial due to strict requirements for a spatial search strategy, differences between truly impaired and unimpaired mice are potentially minimized. Although amending the search strategy definitions may improve the accuracy of future behavioral testing, in the present study, however, recoding the search strategy for each trial was not warranted given the overall lack of significant main effects.

An unexpected finding came from the significantly higher levels of CP-13 immunoreactivity in the TauWT mice compared to the TauP301L mice, regardless of STZ exposure. The low levels of tau phosphorylation at Ser202 detected by CP-13, coupled with the lack of consistent behavioral deficits, may again be explained by the facilitated learning and memory reported in young TauP301L mice prior to the onset of severe pathology (Boekhoorn et al., 2006).

Positive staining was not observed for PG-5 or Alz-50. Neither PG-5 nor Alz-50 have been used in any studies evaluating the effects of STZ treatment. The epitope recognized by PG5, pSer409, is phosphorylated in a pKa-dependent manner (Jicha et al., 1999). Although it is known that ICV-STZ acts through pathways involving GSK3 $\beta$, PI3K-Akt (Ponce-Lopez, Liy- 
Salmeron, Hong, \& Meneses, 2011), and Akt/GSK-3/PP-2A (Qu et al., 2011), it is unknown if a pKa-dependent pathway capable of phosphorylating Ser409 is similarly induced by ICV-STZ. Furthermore, lack of PG-5 immunoreactivity has previously been observed in TauP301L and related mutations (Dutschmann et al., 2010; Vanhelmont et al., 2010) suggesting that the particular mutation present in these models may not induce phosphorylation at Ser409. In TauP301L and Tau-R406W (another FTDP-17 model of AD) mutations expressed in yeast, levels of PG-5 epitopes are drastically reduced and almost absent, respectively, compared to epitopes defined by other antibodies specific for pathological tau changes including AT8, AT180, and AT270 (Vanhelmont et al., 2010). It is also possible that the timeframe of the current study played a prominent role in the lack of PG-5 staining. PG-5 epitopes have been characterized as absent or occasional until after four to 5.5 months of tau expression (Ramsden et al., 2005). If the timeframe of the present study had continued beyond 3.5 months of tau expression, it is possible that PG-5 epitopes could have been detected.

Even though the conformational change recognized by Alz-50 has been previously detected after 2.5 months of tau expression in TauP301L mice (Ramsden et al., 2005) and even after only three weeks in 3xTg-AD mice, which have a TauP301L mutation and mutations in A $\beta$ (Oh et al., 2010), no Alz-50 staining was found in the present study. Because there is no literature on effects of ICV-STZ on Alz-50 immunoreactivity, it is unclear what effect STZ may have on the amino acids involved in the conformation-specific change. In the present study, the dilution of Alz-50 was 1:50, which has been shown to be strong enough to detect a prominent signal (Ramsden et al., 2005; Uéda et al., 1990). However, dilutions as high as 1:10 have also been successfully used (Vincent \& Davies, 1990), and may have been capable of detecting a weaker signal, if present at all. 
Even though there was no positive staining with PG-5 and Alz-50, there was detectable immunoreactivity with PHF-1. It was not anticipated that late-stage markers of AD pathology would be detected in the absence of the mid-stage markers; however, paired helical filaments detected by PHF-1 have previously been found in high levels in STZ-treated rodents (Grünblatt et al., 2007; Planel et al., 2007; Qu et al., 2011). At three months post ICV-STZ in three- to four-month old male Wistar rats, levels of phosphorylated tau visualized through the use of PHF1 were significantly increased over vehicle-treated controls (Grünblatt et al., 2007). In nontransgenic mice injected peripherally with STZ, there was also a mild increase at 10 days postinfusion in the phosphorylation of Ser396 and Ser404, the sites recognized by PHF-1. This significant increase continued to rise substantially through the final 40-day time-point (Planel et al., 2007). The present study assessed pSer396 and pSer404 after approximately 3.5 months of tau expression, and it is possible that the phosphorylation of PHF-1 epitopes similarly increased with time.

It is still plausible that ICV-STZ treatment can be used to induce cerebral glucose metabolism deficiencies in mice with human wild-type tau, but additional studies should use alternative and multiple behavioral assays to detect subtle differences among groups. It may also be necessary to train the mice for additional acquisition trials to improve the performance of the Controls and thus increase the dynamic range. Future studies should also investigate effects of ICV-STZ on human tau at different time periods post-surgery, and also at older ages at which more severe pathology would be expected. 


\section{References}

Adams, S. J., DeTure, M. A., McBride, M., Dickson, D. W., \& Petrucelli, L. (2010). Three repeat isoforms of tau inhibit assembly of four repeat tau filaments. PloS One, 5(5), e10810. doi:10.1371/journal.pone.0010810

Agrawal, R., Tyagi, E., Shukla, R., \& Nath, C. (2009). A study of brain insulin receptors, AChE activity and oxidative stress in rat model of ICV STZ induced dementia. Neuropharmacology, 56(4), 779-787. doi:10.1016/j.neuropharm.2009.01.005

Ahlijanian, M. K., Barrezueta, N. X., Williams, R. D., Jakowski, A., Kowsz, K. P., McCarthy, S., . . McNeish, J. D. (2000). Hyperphosphorylated tau and neurofilament and cytoskeletal disruptions in mice overexpressing human $\mathrm{p} 25$, an activator of cdk5. Proceedings of the National Academy of Sciences of the United States of America, 97(6), 2910-2915. doi:10.1073/pnas.040577797

Albert, M. S., DeKosky, S. T., Dickson, D., Dubois, B., Feldman, H. H., Fox, N. C., ... Phelps, C. H. (2011). The diagnosis of mild cognitive impairment due to Alzheimer's disease: Recommendations from the National Institute on Aging-Alzheimer's Association workgroups on diagnostic guidelines for Alzheimer's disease. Alzheimer's \& Dementia: The Journal of the Alzheimer's Association, 7(3), 270-279. doi:10.1016/j.jalz.2011.03.008

Altman, J., \& Das, G. D. (1965). Autoradiographic and histological evidence of postnatal hippocampal neurogenesis in rats. The Journal of Comparative Neurology, 124(3), 319336.

Alzheimer's Association. (2012). 2012 Alzheimer's disease facts and figures. Alzheimer's \& Dementia: The Journal of the Alzheimer's Association, 8(2), 131-168. doi:10.1016/j.jalz.2012.02.001 
Arriagada, P. V., Growdon, J. H., Hedley-Whyte, E. T., \& Hyman, B. T. (1992). Neurofibrillary tangles but not senile plaques parallel duration and severity of Alzheimer's disease. Neurology, 42(3), 631-639.

Aviles-Olmos, I., Limousin, P., Lees, A., \& Foltynie, T. (2013). Parkinson’s disease, insulin resistance and novel agents of neuroprotection. Brain: A Journal of Neurology, 136(2), 374-384. doi:10.1093/brain/aws009

Barghorn, S., \& Mandelkow, E. (2002). Toward a unified scheme for the aggregation of tau into Alzheimer paired helical filaments. Biochemistry, 41(50), 14885-14896

Barnes, C. A. (1979). Memory deficits associated with senescence: A neurophysiological and behavioral study in the rat. Journal of Comparative and Physiological Psychology, 93(1), 74-104.

Baskin, D. S., Browning, J. L., Pirozzolo, F. J., Korporaal, S., Baskin, J. A., \& Appel, S. H. (1999). Brain choline acetyltransferase and mental function in Alzheimer disease. Archives of Neurology, 56(9), 1121-1123.

Bekris, L. M., Millard, S., Lutz, F., Li, G., Galasko, D. R., Farlow, M. R., . . Peskind, E. R. (2012). Tau phosphorylation pathway genes and cerebrospinal fluid tau levels in Alzheimer's disease. American Journal of Medical Genetics: Part B, 159B(7), 874-883. doi:10.1002/ajmg.b.32094

Bennecib, M., Gong, C. X., Grundke-Iqbal, I., \& Iqbal, K. (2001). Inhibition of PP-2A upregulates CaMKII in rat forebrain and induces hyperphosphorylation of tau at Ser 262/356. FEBS Letters, 490(1-2), 15-22. 
Berg, L., McKeel, D. W., Miller, J. P., Storandt, M., Rubin, E. H., Morris, J. C., . . Saunders, A. M. (1998). Clinicopathologic Studies in Cognitively Healthy Aging and Alzheimer Disease. Archives of Neurology, 55(3), 326-335.

Billingsley, M. L., \& Kincaid, R. L. (1997). Regulated phosphorylation and dephosphorylation of tau protein: Effects on microtubule interaction, intracellular trafficking and neurodegeneration. The Biochemical Journal, 323, 577-591.

Bingham, E. M., Hopkins, D., Smith, D., Pernet, A., Hallett, W., Reed, L., . . Amiel, S. M. (2002). The Role of Insulin in Human Brain Glucose Metabolism. Diabetes, 51(12), 33843390.

Blokland, A., \& Jolles, J. (1993). Spatial learning deficit and reduced hippocampal ChAT activity in rats after an ICV injection of streptozotocin. Pharmacology Biochemistry and Behavior, 44(2), 491-494.

Blokland, A., \& Jolles, J. (1994). Behavioral and biochemical effects of an ICV injection of streptozotocin in old Lewis rats. Pharmacology Biochemistry and Behavior, 47(4), 833837.

Boekhoorn, K., Terwel, D., Biemans, B., Borghgraef, P., Wiegert, O., Ramakers, G. J. a, ... Lucassen, P. J. (2006). Improved long-term potentiation and memory in young tau-P301L transgenic mice before onset of hyperphosphorylation and tauopathy. The Journal of Neuroscience, 26(13), 3514-23. doi:10.1523/JNEUROSCI.5425-05.2006

Bowen, D. M., Smith, C. B., White, P., \& Davison, A. N. (1976). Neurotransmitter-related enzymes and indices of hypoxia in senile dementia and other abiotrophies. Brain, 99(3), $459-496$. 
Brunden, K. R., Zhang, B., Carroll, J., Yao, Y., Potuzak, J. S., Hogan, A.-M. L., . .

Trojanowski, J. Q. (2010). Epothilone D improves microtubule density, axonal integrity, and cognition in a transgenic mouse model of tauopathy. The Journal of Neuroscience, 30(41), 13861-13866. doi:10.1523/JNEUROSCI.3059-10.2010

Buée, L., Bussière, T., Buée-Scherrer, V., Delacourte, A., \& Hof, P. R. (2000). Tau protein isoforms, phosphorylation and role in neurodegenerative disorders. Brain Research Reviews, 33(1), 95-130.

Burman, M. A., \& Gewirtz, J. C. (2007). Hippocampal activity, but not plasticity, is required for early consolidation of fear conditioning with a short trace interval. The European Journal of Neuroscience, 25(8), 2483-2490. doi:10.1111/j.1460-9568.2007.05493.x

Carr, K. D., Kim, G., \& Cabeza de Vaca, S. (2000). Hypoinsulinemia may mediate the lowering of self-stimulation thresholds by food restriction and streptozotocin-induced diabetes. Brain Research, 863(1-2), 160-168.

Chen, Y., Liang, Z., Blanchard, J., Dai, C.-L., Sun, S., Lee, M. H., ... Gong, C.-X. (2013). A non-transgenic mouse model (icv-STZ mouse) of Alzheimer's disease: Similarities to and differences from the transgenic model (3xTg-AD mouse). Molecular Neurobiology, 47(2), 711-25. doi:10.1007/s12035-012-8375-5

Chen, Y., Tian, Z., Liang, Z., Sun, S., Dai, C.-L., Lee, M. H., ... Gong, C.-X. (2012). Brain gene expression of a sporadic (icv-STZ Mouse) and a familial mouse model (3xTg-AD mouse) of Alzheimer's disease. PloS one, 7(12), e51432. doi:10.1371/journal.pone.0051432

Chertkow, H., \& Bub, D. (1990). Semantic memory loss in dementia of Alzheimer's type: What do various measures measure? Brain, 113(2), 397-417. 
Cho, J.-H., \& Johnson, G. V. W. (2003). Glycogen synthase kinase 3beta phosphorylates tau at both primed and unprimed sites: Differential impact on microtubule binding. The Journal of Biological Chemistry, 278(1), 187-193. doi:10.1074/jbc.M206236200

Clavaguera, F., Bolmont, T., Crowther, R. A., Abramowski, D., Frank, S., Probst, A., . . . Tolnay, M. (2009). Transmission and spreading of tauopathy in transgenic mouse brain. Nature Cell Biology, 11(7), 909-913. doi:10.1038/ncb1901.Transmission

Connell, J. W., Gibb, G. M., Betts, J. C., Blackstock, W. P., Gallo, J.-M., Lovestone, S., . . Anderton, B. H. (2001). Effects of FTDP-17 mutations on the in vitro phosphorylation of tau by glycogen synthase kinase 3B identified by mass spectrometry demonstrate certain mutations exert long-range conformational changes. FEBS Letters, 493, 40-44.

Coomans, F., De Rydt, J., \& Van Proeyen, a. (2011). Symplectic gaugings and the field-antifield formalism. Fortschritte der Physik, 59(7-8), 658-664. doi:10.1002/prop.201100006

Correia, S. C., Santos, R. X., Perry, G., Zhu, X., Moreira, P. I., \& Smith, M. A. (2011). Insulinresistant brain state: The culprit in sporadic Alzheimer's disease? Ageing Research Reviews, 10(2), 264-273. doi:10.1016/j.arr.2011.01.001

Coyle, J. T., \& Puttfarcken, P. (1993). Oxidative stress, glutamate, and neurodegenerative disorders. Science, 262(5134), 689-695.

Craft, S., Asthana, S., Newcomer, J. W., Wilkinson, C. W., Matos, I. T., Baker, L. D., ... Veith, R. C. (1999). Enhancement of memory in Alzheimer disease with insulin and somatostatin, but not glucose. Archives of General Psychiatry, 56(12), 1135-1140.

Crespo-Biel, N., Theunis, C., \& Van Leuven, F. (2012). Protein tau: Prime cause of synaptic and neuronal degeneration in Alzheimer's disease. International Journal of Alzheimer's Disease, 2012, 1-13. doi:10.1155/2012/251426 
Davies, P., \& Maloney, A. J. F. (1976). Selective Loss of Central Cholinergic Neurons in Alzheimer's Disease. The Lancet, 308(8000), 1403.

Daviu, N., Delgado-Morales, R., Nadal, R., \& Armario, A. (2012). Not all stressors are equal: Behavioral and endocrine evidence for development of contextual fear conditioning after a single session of footshocks but not of immobilization. Frontiers in Behavioral Neuroscience, 6, 69. doi:10.3389/fnbeh.2012.00069

de la Monte, S.M., \& Wands, J. R. (2008). Alzheimer's disease is type 3 diabetes - Evidence reviewed. Journal of Diabetes Science and Technology, 2(6), 1101-1113.

de la Monte, S. M. (2012). Brain insulin resistance and deficiency as therapeutic targets in Alzheimers isdease. Current Alzheimer Research, 9(1), 35-66. doi:10.2174/156720512799015037

de la Monte, S. M., Tong, M., Lester-Coll, N., Plater, M., \& Wands, J. R. (2006). Therapeutic rescue of neurodegeneration in experimental type 3 diabetes: Relevance to Alzheimer's disease. Journal of Alzheimer's Disease, 10, 89-109.

Deng, Y., Li, B., Liu, Y., Iqbal, K., Grundke-Iqbal, I., \& Gong, C.-X. (2009). Dysregulation of insulin signaling, glucose transporters, O-GlcNAcylation, and phosphorylation of tau and neurofilaments in the brain: Implication for Alzheimer's disease. The American Journal of Pathology, 175(5), 2089-2098. doi:10.2353/ajpath.2009.090157

Dudchenko, P. A., Goodridge, J. P., Seiterle, D. A., \& Taube, J. S. (1997). Effects of repeated disorientation on the acquisition of spatial tasks in rats: Dissociation between the appetitive radial arm maze and aversive water maze moved some distance and direction away from a landmark. Journal of Experimental Psychology: Animal Behavior Processes, 23(2), 194210. 
Duelli, R., Schröck, H., Kuschinsky, W., \& Hoyer, S. (1994). Intracerebroventricular injection of streptozotocin induces discrete local changes in cerebral glucose utilization in rats. International Journal of Developmental Neuroscience, 12(8), 737-743.

Dutschmann, M., Menuet, C., Stettner, G. M., Gestreau, C., Borghgraef, P., Devijver, H., ... Van Leuven, F. (2010). Upper airway dysfunction of Tau-P301L mice correlates with tauopathy in midbrain and ponto-medullary brainstem nuclei. The Journal of Neuroscience, 30(5), 1810-21. doi:10.1523/JNEUROSCI.5261-09.2010

Eckermann, K., Mocanu, M.-M., Khlistunova, I., Biernat, J., Nissen, A., Hofmann, A., . . . Mandelkow, E-M. (2007). The beta-propensity of tau determines aggregation and synaptic loss in inducible mouse models of tauopathy. The Journal of Biological Chemistry, 282(43), 31755-31765. doi:10.1074/jbc.M705282200

Ezquerra, M., Pastor, P., Valldeoriola, F., Luis, J., Blesa, R., Tolosa, E., \& Oliva, R. (1999). Identification of a novel polymorphism in the promoter region of the tau gene highly associated to progressive supranuclear palsy in humans. Neuroscience Letters, 275, 183186.

Frölich, L., Blum-Degen, D., Riederer, P., \& Hoyer, S. (1999). A disturbance in the neuronal insulin receptor signal transduction in sporadic Alzheimer's disease. Annals of the New York Academy of Sciences, 893, 290-293.

Gerlai, R., \& Clayton, N. S. (1999). Analysing hippocampal function in transgenic mice: An ethological perspective. Trends in Neurosciences, 22(2), 47-51.

Gerlai, R., McNamara, A., Choi-Lundberg, D. L., Armanini, M., Ross, J., Powell-Braxton, L., \& Phillips, H. S. (2001). Impaired water maze learning performance without altered 
dopaminergic function in mice heterozygous for the GDNF mutation. The European Journal of Neuroscience, 14(7), 1153-1163.

Gervais, F., Paquette, J., Morissette, C., Krzywkowski, P., Yu, M., Azzi, M., . . Tremblay, P. (2007). Targeting soluble abeta peptide with Tramiprosate for the treatment of brain amyloidosis. Neurobiology of Aging, 28(4), 537-547. doi:10.1016/j.neurobiolaging.2006.02.015

Gibbs, E. L., Gibbs, F. A., Lennox, W. G., \& Nims, L. F. (1942). Regulation of cerebral carbon dioxide. Archives of Neurology and Psychiatry, 47(6), 1236-1245.

Gibson, G. E., Jope, R., \& Blass, J. P. (1975). Decreased synthesis of acetylcholine accompanying impaired oxidation of pyruvic acid in rat brain minces. The Biochemical Journal, 148(1), 17-23.

Gilman, S., Koller, M., Black, R. S., Jenkins, L., Griffith, S. G., Fox, N. C., . . Orgogozo, J. -M. (2005). Clinical effects of abeta immunization (AN1792) in patients with AD in an interrupted trial. Neurology, 64(9), 1553-1562. doi:10.1212/01.WNL.0000159740.16984.3C

Goedert, M., Crowther, R. A., \& Spillantini, M. G. (1998). Tau mutations cause frontotemporal dementias. Neuron, 21, 955-958.

Goedert, M., Hasegawa, M., Jakes, R., Lawler, S., Cuenda, A., \& Cohen, P. (1997). Phosphorylation of microtubule-associated protein tau by stress-activated protein kinases. FEBS Letters, 409(1), 57-62. doi:10.1016/S0014-5793(97)00483-3

Gong, C. -X., Lidsky, T., Wegiel, J., Zuck, L., \& Grundke-Iqbal, I. (2000). Phosphorylation of microtubule-associated protein tau is regulated by protein phosphatase $2 \mathrm{~A}$ in mammalian brain. The Journal of Biological Chemistry, 275(8), 5535-5544. 
Gossen, M., \& Bujard, H. (1992). Tight control of gene expression in mammalian cells by tetracycline-responsive promoters. Proceedings of the National Academy of Sciences of the United States of America, 89(12), 5547-5551.

Götz, J., Chen, F., Barmettler, R., \& Nitsch, R. M. (2001). Tau filament formation in transgenic mice expressing P301L tau. The Journal of Biological Chemistry, 276(1), 529-534. doi:10.1074/jbc.M006531200

Grünblatt, E., Salkovic-Petrisic, M., Osmanovic, J., Riederer, P., \& Hoyer, S. (2007). Brain insulin system dysfunction in streptozotocin intracerebroventricularly treated rats generates hyperphosphorylated tau protein. Journal of Neurochemistry, 101(3), 757-770. doi:10.1111/j.1471-4159.2006.04368.x

Haass, C., Hung, A. Y., Schlossmacher, M. G., Oltersdorf, T., Teplow, D. B., \& Selkoe, D. J. (1993). Normal cellular processing of the beta-amyloid precursor protein results in the secretion of the amyloid beta peptide and related molecules. Annals of the New York Academy of Sciences, 695, 109-116.

Hardy, J. A., \& Higgins, G. A. (1992). Alzheimer's disease: The amyloid cascade hypothesis. Science, 256(5054), 184-185.

Harrison, F. E., Hosseini, A. H., \& McDonald, M. P. (2009). Endogenous anxiety and stress responses in water maze and Barnes maze spatial memory tasks. Behavioural Brain Research, 198(1), 247-251. doi:10.1016/j.bbr.2008.10.015.Endogenous

Harrison, F. E., Reiserer, R. S., Tomarken, A. J., \& McDonald, M. P. (2006). Spatial and nonspatial escape strategies in the Barnes maze. Learning \& Memory, 13, 809-819. doi:10.1101/lm.334306.tors 
Hasselmo, M. E. (2006). The role of acetylcholine in learning and memory. Current Opinion in Neurobiology, 16(6), 710-715. doi:10.1016/j.conb.2006.09.002

Hébert, S. S., Sergeant, N., \& Buée, L. (2012). MicroRNAs and the Regulation of Tau Metabolism. International Journal of Alzheimer's Disease, 2012, 1-6.

Hellweg, R., Nitsch, R., Hock, C., Jaksch, M., \& Hoyer, S. (1992). Nerve growth factor and choline acetyltransferase activity levels in the rat brain following experimental impairment of cerebral glucose and energy metabolism. Journal of Neuroscience Research, 31(3), 479486.

Henderson, V. W., Mack, W., \& Williams, B. W. (1989). Spatial Disorientation in Alzheimer's Disease. Archives of Neurology, 46, 391-394.

Henneberg, N., \& Hoyer, S. (1995). Desensitization of the neuronal insulin receptor: A new approach in the etiopathogenesis of late-onset sporadic dementia of the Alzheimer type (SDAT)? Archives of gerontology and geriatrics, 21(1), 63-74.

Hirai, K., Aliev, G., Nunomura, A., Fujioka, H., Russell, R. L., Atwood, C. S., . . Smith, M. A. (2001). Mitochondrial abnormalities in Alzheimer's disease. The Journal of Neuroscience, 21(9), 3017-3023.

Ho, L., Qin, W., Pompl, P., Xiang, Z., \& Wang, J. (2004). Diet-induced insulin resistance promotes amyloidosis in a transgenic mouse model of Alzheimer's disease. The FASEB Journal, 18(7), 902-904.

Hodges, H. (1996). Maze procedures: The radial-arm and water maze compared. Brain Research. Cognitive Brain Research, 3(3-4), 167-181.

Hodges, J. R., Patterson, K., Oxbury, S., \& Funnell, E. (1992). Semantic dementia: Progressive fluent aphasia with temporal lobe atrophy. Brain, 115(6), 1783-1806. 
Hof, P. R., Bierer, L. M., Perl, D. P., Delacourte, A., Buée, L., Bouras, C., \& Morrison, J. H. (1992). Evidence for early vulnerability of the medial and inferior aspects of the temporal lobe in an 82-year-old patient with preclinical signs of dementia. Regional and laminar distribution of neurofibrillary tangles and senile plaques. Archives of Neurology, 49(9), 946-953.

Hong, M., \& Lee, V. M. (1997). Insulin and insulin-like growth factor-1 regulate tau phosphorylation in cultured human neurons. The Journal of Biological Chemistry, 272(31), $19547-19553$.

Hoover, B. R., Reed, M. N., Su, J., Penrod, R. D., Kotilinek, L. A., Grant, M. K., . . Liao, D. (2010). Tau mislocalization to dendritic spines mediates synaptic dysfunction independently of neurodegeneration. Neuron, 68(6), 1067-1081. doi:10.1016/j.neuron.2010.11.030

Hoyer, S. (2002). The brain insulin signal transduction system and sporadic (type II) Alzheimer disease: An update. Journal of Neural Transmission, 109(3), 341-360. doi:10.1007/s007020200028

Hoyer, S., Henneberg, N., Knapp, S., Lannert, H., \& Martin, E. (1996). Brain glucose metabolism is controlled by amplification and desensitization of the neuronal insulin receptor. Annals of the New York Academy of Sciences, 777, 374-379.

Hoyer, S., \& Lannert, H. (1999). Inhibition of the neuronal insulin receptor causes Alzheimerlike disturbances in oxidative/energy brain metabolism and in behavior in adult rats. Annals of the New York Academy of Sciences, 893, 301-303.

Hoyer, S. (1996). Oxidative metabolism deficiencies in brains of patients with Alzheimer's disease. Acta Neurologica Scandinavica. Supplementum, 165, 18-24. 
Hoyer, S., \& Nitsch, R. (1989). Cerebral excess release of neurotransmitter amino acids subsequent to reduced cerebral glucose metabolism in early-onset dementia of Alzheimer type. Journal of Neural Transmission, 75(3), 227-232.

Hoyer, S. (2004). Glucose metabolism and insulin receptor signal transduction in Alzheimer disease. European Journal of Pharmacology, 490(1-3), 115-125. doi:10.1016/j.ejphar.2004.02.049

Hoyer, S., \& Lannert, H. (2008). Long-term effects of corticosterone on behavior, oxidative and energy metabolism of parietotemporal cerebral cortex and hippocampus of rats: Comparison to intracerebroventricular streptozotocin. Journal of Neural Transmission, 115(9), 12411249. doi:10.1007/s00702-008-0079-7

Iqbal, K., \& Grundke-Iqbal, I. (2008). Tau Pathology as a Target in Alzheimer's Therapeutics. Pharmacological Mechanisms in Alzheimer's Therapeutics (Vol. 2, pp. 223-237).

Ittner, L. M., Ke, Y. D., Delerue, F., Bi, M., Gladbach, A., Van Eersel, J., . . Götz, J. (2010). Dendritic function of tau mediates amyloid-beta toxicity in Alzheimer's disease mouse models. Cell, 142(3), 387-397. doi:10.1016/j.cell.2010.06.036

Jicha, G. A., Weaver, C., Lane, E., Vianna, C., Kress, Y., Rockwood, J., \& Davies, P. (1999). cAMP-Dependent Protein Kinase Phosphorylations on Tau in Alzheimer's Disease. The Journal of Neuroscience, 19(17), 7486-7494.

Kaplan, M. S., \& Hinds, J. W. (1977). Neurogenesis in the adult rat: Electron microscopic analysis of light radioautographs. Science, 197(4308), 1092-1094.

Klafki, H. -W., Staufenbiel, M., Kornhuber, J., \& Wiltfang, J. (2006). Therapeutic approaches to Alzheimer's disease. Brain, 129(11), 2840-2855. doi:10.1093/brain/awl280 
Kolarova, M., García-Sierra, F., Bartos, A., Ricny, J., \& Ripova, D. (2012). Structure and pathology of tau protein in Alzheimer disease. International Journal of Alzheimer's Disease, 2012, 1-13. doi:10.1155/2012/731526

Kopelman, M. D. (1985). Multiple memory deficits in Alzheimer-type dementia: Implications for pharmacotherapy. Psychological Medicine, 15(3), 527-541.

Kuchibhotla, K. V, Wegmann, S., Kopeikina, K. J., Hawkes, J., \& Rudinskiy, N. (2014). Neurofibrillary tangle-bearing neurons are functionally integrated in cortical circuits in vivo. Proceedings of the National Academy of Sciences, 111(1), 510-514. doi:10.1073/pnas.1318807111/-/DCSupplemental

Lalonde, R., Dumont, M., Staufenbiel, M., Sturchler-Pierrat, C., \& Strazielle, C. (2002). Spatial learning, exploration, anxiety, and motor coordination in female APP23 transgenic mice with the Swedish mutation. Brain Research, 956(1), 36-44.

Lannert, H., \& Hoyer, S. (1998). Intracerebroventricular administration of streptozotocin causes long-term diminutions in learning and memory abilities and in cerebral energy metabolism in adult rats. Behavioral Neuroscience, 112(5), 1199-1208.

Lemmens, M. A. M., Sierksma, A. S. R., Rutten, B. P. F., Dennissen, F., Steinbusch, H. W. M., Lucassen, P. J., \& Schmitz, C. (2011). Age-related changes of neuron numbers in the frontal cortex of a transgenic mouse model of Alzheimer's disease. Brain Structure \& Function, 216(3), 227-237. doi:10.1007/s00429-011-0305-1

Lester-Coll, N., Rivera, E., \& Soscia, S. (2006). Intracerebral streptozotocin model of type 3 diabetes: Relevance to sporadic Alzheimer's disease. Journal of Alzheimer's Disease, 9, $13-33$. 
Liu, B., Wang, S., Brenner, M., \& Paton, J. F. R. (2008). Enhancement of cell-specific transgene expression from a Tet-Off regulatory system using a transcriptional amplification strategy in the rat brain. The Journal of Gene Medicine, 10, 583-592. doi:10.1002/jgm

Liu, F., \& Gong, C. -X. (2008). Tau exon 10 alternative splicing and tauopathies. Molecular Neurodegeneration, 3, 8. doi:10.1186/1750-1326-3-8

Liu, F., Grundke-Iqbal, I., Iqbal, K., \& Gong, C. -X. (2005). Contributions of protein phosphatases PP1, PP2A, PP2B and PP5 to the regulation of tau phosphorylation. The European Journal of Neuroscience, 22(8), 1942-1950. doi:10.1111/j.14609568.2005.04391.x

Liu, R., \& Wang, J. -Z. (2009). Protein phosphatase 2A in Alzheimer's disease. Pathophysiology, 16(4), 273-277. doi:10.1016/j.pathophys.2009.02.008

Lobo, M. K. (2012). Lighting up the brain's reward circuitry. Annals of the New York Academy of Sciences, 1260, 24-33. doi:10.1111/j.1749-6632.2011.06368.x

Logue, S. F., Paylor, R., \& Wehner, J. M. (1997). Hippocampal lesions cause learning deficits in inbred mice in the Morris water maze and conditioned-fear task. Behavioral Neuroscience, 111(1), 104-113.

Loubatières-Mariani, M. M., Chapal, J., Alric, R., \& Loubatières, A. (1973). Studies of the cholinergic receptors involved in the secretion of insulin using isolated perfused rat pancreas. Diabetologia, 9(6), 439-446.

Luk, C., Compta, Y., Magdalinou, N., Martí, M. J., Hondhamuni, G., Zetterberg, H., .. . de Silva, R. (2012). Development and assessment of sensitive immuno-PCR assays for the quantification of cerebrospinal fluid three- and four-repeat tau isoforms in tauopathies. Journal of Neurochemistry, 123(3), 396-405. doi:10.1111/j.1471-4159.2012.07911.x 
Mandavia, C., \& Sowers, J. R. (2012). Phosphoprotein phosphatase PP2A regulation of insulin receptor substrate 1 and insulin metabolic signaling. CardioRenal Medicine, 2(4), 308-313. doi: $10.1159 / 000343889$

Mandelkow, E. -M., Stamer, K., Vogel, E., Thies, E., \& Mandelkow, E. (2003). Clogging of axons by tau, inhibition of axonal traffic and starvation of synapses. Neurobiology of Aging, 24(8), 1079-1085. doi:10.1016/j.neurobiolaging.2003.04.007

Mao, P. (2013). Oxidative stress and its clinical applications in dementia. Journal of Neurodegenerative Diseases, 2013, 1-15.

Markesbery, W. R. (1997). Oxidative stress hypothesis in Alzheimer's disease. Free Radical Biology \& Medicine, 23(1), 134-147.

Martin, A., \& Fedio, P. (1983). Word production and comprehension in Alzheimer's disease: The breakdown of semantic knowledge. Brain and Language, 19(1), 124-141.

Mattson, M. P., Gary, D. S., Chan, S. L., \& Duan, W. (2001). Perturbed endoplasmic reticulum function, synaptic apoptosis and the pathogenesis of Alzheimer's disease. Biochemical Society Symposium, 67, 151-162.

Mayer, G., Nitsch, R., \& Hoyer, S. (1990). Effects of changes in peripheral and cerebral glucose metabolism on locomotor activity, learning and memory in adult male rats. Brain Research, 532(1-2), 95-100.

McEchron, M. D., Bouwmeester, H., Tseng, W., Weiss, C., \& Disterhoft, J. F. (1998). Hippocampectomy disrupts auditory trace fear conditioning and contextual fear conditioning in the rat. Hippocampus, 8, 638-646.

McNay, E.C., Teske, J.A., Kotz, C.M., Dunn-Meynell, A., Levin, B.E., McCrimmon, R.J., \& Sherwin, R.S. (2012). Long-term, intermittent, insulin-induced hypoglycemia produces 
marked obesity without hyperphagia or insulin resistance: A model for weight gain with intensive insulin therapy. American Journal of Physiology, 304(2), E131-E138. doi: 10. 1152/ajpendo.00262.2012

Meck, W. H., Church, R. M., \& Olton, D. S. (1984). Hippocampus, time, and memory. Behavioral Neuroscience, 98(1), 3-22.

Menuet, C., Cazals, Y., Gestreau, C., Borghgraef, P., Gielis, L., Dutschmann, M., .. . Hilaire, G. (2011). Age-related impairment of ultrasonic vocalization in Tau.P301L mice: possible implication for progressive language disorders. PloS One, 6(10), e25770. doi:10.1371/journal.pone.0025770

Messier, C., \& Teutenberg, K. (2005). The role of insulin, insulin growth factor, and insulindegrading enzyme in brain aging and Alzheimer's disease. Neural Plasticity, 12(4), 311328.

Miller, E. (1971). On the nature of the memory disorder in presenile dementia. Neuropsychologia, 9(1), 75-81.

Mondragón-Rodríguez, S., Basurto-Islas, G., Santa-Maria, I., Mena, R., Binder, L. I., Avila, J., . . . García-Sierra, F. (2008). Cleavage and conformational changes of tau protein follow phosphorylation during Alzheimer's disease. International Journal of Experimental Pathology, 89(2), 81-90. doi:10.1111/j.1365-2613.2007.00568.x

Morris, J. C., \& Fulling, K. (1988). Early Alzheimer's disease: Diagnostic considerations. Archives of Neurology, 45(3), 345-349. doi:10.1001/archneur.1988.00520270127033

Morris, R. (1984). Developments of a water-maze procedure for studying spatial learning in the rat. Journal of Neuroscience Methods, 11(1), 47-60. 
Nguyen, P. V., Abel, T., Kandel, E. R., \& Bourtchouladze, R. (2000). Strain-dependent differences in LTP and hippocampus-dependent memory in inbred Mice. Learning \& Memory, 7(3), 170-179. doi:10.1101/lm.7.3.170

Oh, K.-J., Perez, S. E., Lagalwar, S., Vana, L., Binder, L., \& Mufson, E. J. (2010). Staging of Alzheimer's pathology in triple transgenic mice: a light and electron microscopic analysis. International Journal of Alzheimer's Disease, 2010. doi:10.4061/2010/780102

Orr, M. E., Pitstick, R., Canine, B., Ashe, K. H., \& Carlson, G. A. (2012). Genotype-specific differences between mouse CNS stem cell lines expressing frontotemporal dementia mutant or wild type human tau. PloS One, 7(6), e39328. doi:10.1371/journal.pone.0039328

Pardridge, W. M. (1983). Brain metabolism: A perspective from the blood-brain barrier. Physiological Reviews, 63(4), 1481-535.

Pennanen, L., Welzl, H., D’Adamo, P., Nitsch, R. M., \& Götz, J. (2004). Accelerated extinction of conditioned taste aversion in P301L tau transgenic mice. Neurobiology of Disease, 15(3), 500-509. doi:10.1016/j.nbd.2003.11.020

Perry, E. K., Perry, R. H., Blessed, G., \& Tomlinson, B. E. (1977). Necropsy evidence of central cholinergic deficits in senile dementia. Lancet, 22(8004), 189.

Phillips, R. G., \& LeDoux, J. E. (1992). Differential contribution of amygdala and hippocampus to cued and contextual fear conditioning. Behavioral Neuroscience, 106(2), 274-285.

Piau, A., Nourhashémi, F., Hein, C., Caillaud, C., \& Vellas, B. (2010). Progress in the development of new drugs in Alzheimer's disease. The Journal of Nutrition, Health \& Aging, 15(1), 45-57. doi:10.1007/s12603-010-0103-0 
Pickering-Brown, S., Baker, M., Yen, S. -H., Liu, W. -K., Hasegawa, M., Cairns, N., ... Hutton, M. (2000). Pick's disease is associated with mutations in the tau gene. Annals of Neurology, 48(6), 859-867.

Planel, E., Miyasaka, T., Launey, T., Chui, D.-H., Tanemura, K., Sato, S., . . Takashima, A. (2004). Alterations in glucose metabolism induce hypothermia leading to tau hyperphosphorylation through differential inhibition of kinase and phosphatase activities: Implications for Alzheimer's disease. The Journal of Neuroscience, 24(10), 2401-2411. doi:10.1523/JNEUROSCI.5561-03.2004

Planel, E., Tatebayashi, Y., Miyasaka, T., Liu, L., Wang, L., Herman, M., . . Takashima, A. (2007). Insulin dysfunction induces in vivo tau hyperphosphorylation through distinct mechanisms. The Journal of Neuroscience, 27(50), 13635-13648.

doi:10.1523/JNEUROSCI.3949-07.2007

Plaschke, K., \& Hoyer, S. (1993). Action of the diabetogenic drug streptozotocin on glycolytic and glycogenolytic metabolism in adult rat brain cortex and hippocampus. International Journal of Developmental Neuroscience, 11(4), 477-483.

Plaschke, K., Kopitz, J., Siegelin, M., Schliebs, R., Salkovic-Petrisic, M., Riederer, P., \& Hoyer, S. (2010). Insulin-resistant brain state after intracerebroventricular streptozotocin injection exacerbates Alzheimer-like changes in Tg2576 AbetaPP-overexpressing mice. Journal of Alzheimer's Disease, 19(2), 691-704. doi:10.3233/JAD-2010-1270

Plattner, F., Angelo, M., \& Giese, K. P. (2006). The roles of cyclin-dependent kinase 5 and glycogen synthase kinase 3 in tau hyperphosphorylation. The Journal of Biological Chemistry, 281(35), 25457-25465. doi:10.1074/jbc.M603469200 
Ponce-Lopez, T., Liy-Salmeron, G., Hong, E., \& Meneses, A. (2011). Lithium, phenserine, memantine and pioglitazone reverse memory deficit and restore phospho-GSK3 $\beta$ decreased in hippocampus in intracerebroventricular streptozotocin induced memory deficit model. Brain Research, 1426, 73-85. doi:10.1016/j.brainres.2011.09.056

Qian, W., Shi, J., Yin, X., Iqbal, K., Grundke-Iqbal, I., Gong, C. -X., \& Liu, F. (2010). PP2A regulates tau phosphorylation directly and also indirectly via activating GSK-3beta. Journal of Alzheimer's Disease, 19(4), 1221-1229.

Qu, Z., Jiao, Z., Sun, X., Zhao, Y., Ren, J., \& Xu, G. (2011). Effects of streptozotocin-induced diabetes on tau phosphorylation in the rat brain. Brain Research, 1383, 300-306. doi:10.1016/j.brainres.2011.01.084

Ramsden, M., Kotilinek, L., Forster, C., Paulson, J., McGowan, E., SantaCruz, K., . . Ashe, K. H. (2005). Age-dependent neurofibrillary tangle formation, neuron loss, and memory impairment in a mouse model of human tauopathy (P301L). The Journal of Neuroscience, 25(46), 10637-10647. doi:10.1523/JNEUROSCI.3279-05.2005

Rizzu, P., Joosse, M., Ravid, R., Hoogeveen, a, Kamphorst, W., van Swieten, J. C., ... Heutink, P. (2000). Mutation-dependent aggregation of tau protein and its selective depletion from the soluble fraction in brain of P301L FTDP-17 patients. Human Molecular Genetics, 9(20), $3075-82$.

Sabuncu, M. R., Desikan, R. S., Sepulcre, J., Yeo, B. T. T., Liu, H., Schmansky, N. J., . . Fischl, B. (2011). The dynamics of cortical and hippocampal atrophy in Alzheimer disease. Archives of Neurology, 68(8), 1040-1048. doi:10.1001/archneurol.2011.167 
Salkovic-Petrisic, M., \& Hoyer, S. (2007). Central insulin resistance as a trigger for sporadic Alzheimer-like pathology: An experimenal approach. Journal of Neural Transmission, 72, $217-233$.

Salkovic-Petrisic, M., Tribl, F., Schmidt, M., Hoyer, S., \& Riederer, P. (2006). Alzheimer-like changes in protein kinase B and glycogen synthase kinase-3 in rat frontal cortex and hippocampus after damage to the insulin signalling pathway. Journal of Neurochemistry, 96(4), 1005-1015. doi:10.1111/j.1471-4159.2005.03637.x

SantaCruz, K., Lewis, J., Spires, T., Paulson, J., Kotilinek, L., Ingelsson, M., . . Ashe, K. H. (2005). Tau suppression in a neurodegenerative mouse model improves memory function. Science, 309(5733), 476-481. doi:10.1126/science.1113694

Schubert, M., Gautam, D., Surjo, D., Ueki, K., Baudler, S., Schubert, D., . . Brüning, J. C. (2004). Role for neuronal insulin resistance in neurodegenerative diseases. Proceedings of the National Academy of Sciences of the United States of America, 101(9), 3100-3105. doi:10.1073/pnas.0308724101

Shanik, M. H., Xu, Y., Skrha, J., Dankner, R., Zick, Y., \& Roth, J. (2008). Insulin resistance and hyperinsulinemia: Is hyperinsulinemia the cart or the horse? Diabetes Care, 31, S262-S268. doi: $10.2337 / \mathrm{dc} 08-\mathrm{s} 264$

Sharma, M., \& Gupta, Y. K. (2001). Intracerebroventricular injection of streptozotocin in rats produces both oxidative stress in the brain and cognitive impairment. Life Sciences, 68(9), $1021-1029$.

Shoham, S., Bejar, C., Kovalev, E., \& Weinstock, M. (2003). Intracerebroventricular injection of streptozotocin causes neurotoxicity to myelin that contributes to spatial memory deficits in rats. Experimental Neurology, 184(2), 1043-1052. doi:10.1016/j.expneurol.2003.08.015 
Shoham, S., Bejar, C., Kovalev, E., Schorer-Apelbaum, D., \& Weinstock, M. (2007). Ladostigil prevents gliosis, oxidative-nitrative stress and memory deficits induced by intracerebroventricular injection of streptozotocin in rats. Neuropharmacology, 52(3), 836843. doi:10.1016/j.neuropharm.2006.10.005

Siemers, E. R., Dean, R. A., Demattos, R., \& May, P. C. (2006). New pathways in drug discovery for Alzheimer's disease. Current Neurology and Neuroscience Reports, 6(5), 372-378. doi:10.1007/s11910-996-0017-8

Sims, N. R., Bowen, D. M., Smith, C. C., Flack, R. H., Davison, A. N., Snowden, J. S., \& Neary, D. (1980). Glucose metabolism and acetylcholine synthesis in relation to neuronal activity in Alzheimer's disease. Lancet, 1(8164), 333-336.

Singh, T. J., Zaidi, T., Grundke-Iqbal, I., \& Iqbal, K. (1996). Non-proline-dependent protein kinases phosphorylate several sites found in tau from Alzheimer disease brain. Molecular and Cellular Biochemistry, 154(2), 143-151.

Sjögren, T., Sjögren, J., \& Lindgren, G. H. (1952). Morbus Alzheimer and Morbus Pick. Acta Psychiatrica Scandinavica, 82, 9-63.

Small, S. A, \& Duff, K. (2008). Linking Abeta and tau in late-onset Alzheimer's disease: A dual pathway hypothesis. Neuron, 60(4), 534-542. doi:10.1016/j.neuron.2008.11.007

Smith, M. A., Perry, G., Richey, P. L., Sayre, L. M., Anderson, V. E., Beal, M. F., \& Kowall, N. (1996). Oxidative damage in Alzheimer's? Nature, 382, 120-121.

Sokoloff, L. (1980). Regional cerebral glucose utilization measured with the 2-[14C] deoxyglucose technique: Its use in mapping functional activity in the nervous system. Acta Neurologica Scandinavica, 62(S78), 128-146. 
Sorrentino, G., \& Bonavita, V. (2007). Neurodegeneration and Alzheimer's disease: The lesson from tauopathies. Neurological Sciences, 28(2), 63-71. doi:10.1007/s10072-007-0789-x

Sunyer, B., Patil, S., Höger, H., \& Lubec, G. (2007). Barnes maze, a useful task to assess spatial reference memory in the mice. Protocol Exchange. doi:10.1038/nprot.2007.390

Terwel, D., Lasrado, R., Snauwaert, J., Vandeweert, E., Van Haesendonck, C., Borghgraef, P., \& Van Leuven, F. (2005). Changed conformation of mutant Tau-P301L underlies the moribund tauopathy, absent in progressive, nonlethal axonopathy of Tau-4R/2N transgenic mice. The Journal of Biological Chemistry, 280(5), 3963-73. doi:10.1074/jbc.M409876200

Tokutake, T., Kasuga, K., Yajima, R., Sekine, Y., Tezuka, T., Nishizawa, M., \& Ikeuchi, T. (2012). Hyperphosphorylation of Tau induced by naturally secreted amyloid- $\beta$ at nanomolar concentrations is modulated by insulin-dependent Akt-GSK3 $\beta$ signaling pathway. The Journal of Biological Chemistry, 287(42), 35222-35233. doi:10.1074/jbc.M112.348300

Uéda, K., Masliah, E., Saitoh, T., Bakalis, S. L., Scoble, H., \& Kosik, K. S. (1990). Alz-50 recognizes a phosphorylated epitope of tau protein. The Journal of Neuroscience, 10(10), 3295-304.

Ugi, S., Imamura, T., Maegawa, H., Egawa, K., Yoshizaki, T., Shi, K., . . Olefsky, J. M. (2004). Protein phosphatase 2A negatively regulates insulin's metabolic signaling pathway by inhibiting Akt (Protein Kinase B) activity in 3T3-L1 adipocytes. Molecular and Cellular Biology, 24(19), 8778-8789. doi:10.1128/MCB.24.19.8778

Unger, J., McNeill, T. H., Moxley, R. T., White, M., Moss, A., \& Livingston, J. N. (1989). Distribution of insulin receptor-like immunoreactivity in the rat forebrain. Neuroscience, 31(1), 143-157. 
Vanhelmont, T., Vandebroek, T., De Vos, A., Terwel, D., Lemaire, K., Anandhakumar, J., ... Winderickx, J. (2010). Serine-409 phosphorylation and oxidative damage define aggregation of human protein tau in yeast. FEMS Yeast Research, 10(8), 992-1005. doi:10.1111/j.1567-1364.2010.00662.x

Vincent, I. J., \& Davies, P. (1990). ATP-induced loss of Alz-50 immunoreactivity with the A68 proteins from Alzheimer brain is mediated by ubiquitin. Proceedings of the National Academy of Sciences, 87(12), 4840-4.

Vorhees, C. V., \& Williams, M. T. (2006). Morris water maze: Procedures for assessing spatial and related forms of learning and memory. Nature Protocols, 1(2), 848-858. doi:10.1038/nprot.2006.116.Morris

Wang, J.-Z., Grundke-Iqbal, I., \& Iqbal, K. (2007). Kinases and phosphatases and tau sites involved in Alzheimer neurofibrillary degeneration. The European Journal of Neuroscience, 25(1), 59-68. doi:10.1111/j.1460-9568.2006.05226.x

Watkins, M. W., \& Pacheco, M. (2001). Interobserver agreement in behavioral research: Importance and calculation. Journal of Behavioral Education, 10(4), 205-212.

Watson, G. S., \& Craft, S. (2004). Modulation of memory by insulin and glucose: Neuropsychological observations in Alzheimer's disease. European Journal of Pharmacology, 490(1-3), 97-113. doi:10.1016/j.ejphar.2004.02.048

Weingartner, H., Grafman, J., Boutelle, W., Kaye, W., \& Martin, P. R. (2013). Forms of Memory Failure. Science, 221(4608), 380-382.

Whitehouse, P. J., Price, D. L., Clark, A. W., Coyle, J. T., \& DeLong, M. R. (1981). Alzheimer disease: Evidence for selective loss of cholinergic neurons in the nucleus basalis. Annals of Neurology, 10(2), 122-126. 
Wickelgren, I. (1998). Tracking insulin to the mind. Science, 280(5363), 517-519.

Wurtman, R. J. (1992). Choline metabolism as a basis for the selective vulnerability of cholinergic neurons. Trends in Neurosciences, 15(4), 117-122.

Youn, J., Ellenbroek, B. A., Van Eck, I., Roubos, S., Verhage, M., \& Stiedl, O. (2012). Finding the right motivation: genotype-dependent differences in effective reinforcements for spatial learning. Behavioural Brain Research, 226(2), 397-403. doi:10.1016/j.bbr.2011.09.034

Zhao, W. -Q., Chen, H., Quon, M. J., \& Alkon, D. L. (2004). Insulin and the insulin receptor in experimental models of learning and memory. European Journal of Pharmacology, 490(13), 71-81. doi:10.1016/j.ejphar.2004.02.045 


\begin{tabular}{|c|c|c|c|c|}
\hline Antibody & Species & Specificity & Use & Dilution \\
\hline Tau-5 & Mouse & $\begin{array}{l}\text { Tau; human/mouse } \\
\text { specific }\end{array}$ & Tau marker & $1: 1,000$ \\
\hline MC-1 & Mouse & $\begin{array}{l}\text { Tau; conformational } \\
\text { epitope, } 7-9 \text { and } 326- \\
330 \text { aa }\end{array}$ & $\begin{array}{l}\text { Conformation specific; early } \\
\text { pathological change in AD }\end{array}$ & $1: 50$ \\
\hline CP-13 & Mouse & Tau; pSer202 & $\begin{array}{l}\text { Phosphorylation specific; early } \\
\text { pathological change in AD }\end{array}$ & $1: 50$ \\
\hline PG-5 & Mouse & Tau; pSer409 & Pre-tangles; mid-stage & $1: 50$ \\
\hline Alz-50 & Mouse & $\begin{array}{l}\text { Tau; conformational } \\
\text { epitope, } 3-15 \text { and 312- } \\
322 \text { aa }\end{array}$ & $\begin{array}{l}\text { Conformation specific; late- } \\
\text { stage }\end{array}$ & $1: 50$ \\
\hline PHF-1 & Mouse & Tau; pSer396/pSer404 & $\begin{array}{l}\text { Paired helical filaments of tau; } \\
\text { late-stage }\end{array}$ & $1: 50$ \\
\hline Actin & Goat & C-terminus & Loading control & $1: 500$ \\
\hline Anti-mouse & Sheep & & HRP-conjugated secondary & $1: 5,000$ \\
\hline Anti-goat & Donkey & & AP-conjugated secondary & $1: 5,000$ \\
\hline
\end{tabular}

Table 1. Antibodies used to assess tau pathology. Several antibodies capable of recognizing distinct characteristics of tau pathology progression were used. 


\begin{tabular}{|c|c|c|c|c|c|}
\hline & Hole Deviation & Primary Errors & Primary Latency & Total Errors & Total Latency \\
\hline Tx & $\begin{array}{l}F(1,50)=1.52 \\
p=.22\end{array}$ & $\begin{array}{l}F(1,50)=0.22 \\
p=.64\end{array}$ & $\begin{array}{l}F(1,50)=1.13 \\
p=.29\end{array}$ & $\begin{array}{l}F(1,50)=1.81, \\
p=.19\end{array}$ & $\begin{array}{l}F(1,50)=0.21 \\
p=.65\end{array}$ \\
\hline $\mathrm{Tg}$ & $\begin{array}{l}F(2,50)=0.74 \\
p=.48\end{array}$ & $\begin{array}{l}F(2,50)=1.22 \\
p=.30\end{array}$ & $\begin{array}{l}F(2,50)=1.24 \\
p=.30\end{array}$ & $\begin{array}{l}F(2,50)=1.80 \\
p=.18\end{array}$ & $\begin{array}{l}F(2,50)=3.88 \\
p=.03 *\end{array}$ \\
\hline $\mathrm{Tx}^{*} \mathrm{Tg}$ & $\begin{array}{l}F(2,50)=0.25 \\
p=.78\end{array}$ & $\begin{array}{l}F(2,50)=0.58 \\
p=.56\end{array}$ & $\begin{array}{l}F(2,50)=1.50 \\
p=.23\end{array}$ & $\begin{array}{l}F(2,50)=1.00 \\
p=.37\end{array}$ & $\begin{array}{l}F(2,50)=0.39 \\
p=.68\end{array}$ \\
\hline Day & $\begin{array}{l}F(4,200)=2.02, \\
p=.09\end{array}$ & $\begin{array}{l}F(4,200)=12.16 \\
p<.001 * * *\end{array}$ & $\begin{array}{l}F(4,200)=80.91, \\
p<.001 * * *\end{array}$ & \begin{tabular}{|l|}
$F(4,200)=8.34$ \\
$p<.001 * * *$
\end{tabular} & $\begin{array}{l}F(4,200)=53.01 \\
p<.001 * * *\end{array}$ \\
\hline Day*Tx & $\begin{array}{l}F(4,200)=1.52 \\
p=.20\end{array}$ & $\begin{array}{l}F(4,200)=1.68 \\
p=.16\end{array}$ & $\begin{array}{l}F(4,200)=2.17 \\
p=.07\end{array}$ & $\begin{array}{l}F(4,200)=1.49 \\
p=.21\end{array}$ & $\begin{array}{l}F(4,200)=1.50 \\
p=.21\end{array}$ \\
\hline Day*Tg & $\begin{array}{l}F(8,200)=0.69 \\
p=.70\end{array}$ & $\begin{array}{l}F(8,200)=2.771, \\
p<.01 * *\end{array}$ & $\begin{array}{l}F(8,200)=0.16 \\
p=.99\end{array}$ & $\begin{array}{l}F(8,200)=0.65 \\
p=.74\end{array}$ & $\begin{array}{l}F(8,200)=0.50 \\
p=.86\end{array}$ \\
\hline Day*Tx*1 & $\begin{array}{l}F(8,200)=0.54 \\
p=.83\end{array}$ & $\begin{array}{l}F(8,200)=1.01 \\
p=.43\end{array}$ & $\begin{array}{l}F(8,200)=0.58 \\
p=.79\end{array}$ & $\begin{array}{l}F(8,200)=1.98 \\
p=.05^{*}\end{array}$ & $\begin{array}{l}F(8,200)=0.77 \\
p=.63\end{array}$ \\
\hline
\end{tabular}

Table 2. Statistical results for acquisition. There were no significant effects of $\mathrm{Tx}, \mathrm{Tx} * \mathrm{Tg}$, or Day*Tx on any variable, and with the exception of total latency $(* p \leq .05)$, there were also no main effects of $\mathrm{Tg}$. For primary errors $(* * * p<.001)$, primary latency $(* * * p<.001)$, total errors $(* * * p<.001)$, and total latency $(* * * p<.001)$, there was a significant effect of Day. For primary errors, there was a significant interaction between Day and $\operatorname{Tg}(* * p<.01)$. Lastly, for total errors, there was a significant Day*Tx*Tg interaction $(* p \leq .05)$. 
Day 1

Day 2

\begin{tabular}{|l|c|c|c|c|c|c|}
\cline { 2 - 7 } \multicolumn{1}{c|}{} & Random & Serial & Spatial & Random & Serial & Spatial \\
\hline \multirow{2}{*}{ Tg } & $X(3)=2.2$, & $X(3)=1.84$, & $X(2)=3.48$, & $X(3)=2.39$, & $X(3)=3.90$, & $X(1)=0.83$, \\
& $p=.54$ & $p=.61$ & $p=.18$ & $p=.50$ & $p=.27$ & $p=0.64$ \\
\hline \multirow{2}{*}{ Tx } & $X(3)=7.0$, & $X(\mathbf{3})=\mathbf{9 . 0 5}$, & $X(2)=1.02$, & $X(3)=1.57$, & $X(3)=1.11$, & $X(1)=0.33$, \\
& $p=.07$ & $\boldsymbol{p = . 0 3 *}$ & $p=.60$ & $p=.67$ & $p=.77$ & $p=.57$ \\
\hline \multirow{2}{*}{ TgTx } & $X(15)=19.30$, & $X \mathbf{( 1 5 ) = \mathbf { 2 5 . 8 4 } ,}$ & $X(10)=8.18$, & $X(15)=14.84$, & $X(15)=13.05$, & $X(5)=4.77$, \\
& $p=.20$ & $\boldsymbol{p = . 0 4 ^ { \# }}$ & $p=.61$ & $p=.46$ & $p=.60$ & $p=.45$ \\
\hline
\end{tabular}

Day 3

Day 4

\begin{tabular}{|l|c|c|c|c|c|c|}
\cline { 2 - 7 } \multicolumn{1}{c|}{} & Random & Serial & Spatial & Random & Serial & Spatial \\
\hline \multirow{2}{*}{ Tg } & $X(3)=2.05$, & $X(3)=2.30$, & $X(2)=0.52$, & $X(2)=3.18$, & $X(3)=3.24$, & $X(2)=1.28$, \\
& $p=.56$ & $p=.51$ & $p=.77$ & $p=.20$ & $p=.36$ & $p=.53$ \\
\hline \multirow{2}{*}{ Tx } & $X(3)=2.02$, & $X(3)=1.24$, & $X(2)=1.13$, & $X(2)=0.92$, & $X(3)=1.46$, & $X(2)=2.02$, \\
& $p=.57$ & $p=.74$ & $p=.57$ & $p=.63$ & $p=.69$ & $p=.37$ \\
\hline \multirow{2}{*}{ TxTg } & $X(15)=16.35$, & $X(15)=13.78$, & $X(10)=9.68$, & $X(10)=6.57$, & $X(15)=9.54$, & $X(10)=9.33$, \\
& $p=.36$ & $p=.54$ & $p=.47$ & $p=.77$ & $p=.85$ & $p=.50$ \\
\hline
\end{tabular}

Day 5

\begin{tabular}{|l|c|c|c|}
\cline { 2 - 4 } \multicolumn{1}{c|}{} & Random & Serial & Spatial \\
\hline \multirow{2}{*}{ Tg } & $X(2)=3.18$, & $X(3)=4.35$, & $X(2)=1.28$, \\
& $p=.20$ & $p=.28$ & $p=.53$ \\
\hline \multirow{2}{*}{ Tx } & $X(2)=1.13$, & $X(3)=4.37$, & $X(2)=4.28$, \\
& $p=.57$ & $p=.22$ & $p=.12$ \\
\hline \multirow{2}{*}{ TxTg } & $X(10)=10.75$, & $X(15)=24.42$, & $X(10)=15.42$, \\
& $p=.38$ & $p=.06$ & $p=.12$ \\
\hline
\end{tabular}

Table 3. Search strategy. On Day 1, there was a significant effect of Tx for the use of a serial search strategy in that a serial approach was utilized more often by mice in the vehicle-treated group than the STZ-treated group $(* p=.03)$. There was also a TxTg effect for serial search strategy on Day 1 such that the Vehicle-TauWT mice the serial search strategy significantly more often than the STZ-Control mice (\#p=.04). 
Tx

Tg

$\mathbf{T x} * \mathbf{T g}$

\begin{tabular}{|c|c|c|c|c|}
\hline \multirow{9}{*}{ Probe 1} & Escape Latency & $F(1,50)=0.20, p=.66$ & $F(2,50)=0.51, p=.61$ & $F(2,50)=1.38, p=.26$ \\
\hline & Escape Holes 0-30s & $F(1,50)=0.79, p=.38$ & $F(2,50)=0.20, p=.82$ & $F(2,50)=1.12, p=.34$ \\
\hline & Escape Holes 31-60s & $F(1,50)=0.38, p=.54$ & $F(2,50)=0.05, p=.96$ & $F(2,50)=0.44, p=.65$ \\
\hline & Escape Holes 61-90s & $F(1,50)=0.00, p=.98$ & $F(2,50)=1.70, p=.19$ & $F(2,50)=1.79, p=.18$ \\
\hline & Escape Holes Total & $F(1,50)=0.06, p=.81$ & $F(2,50)=0.29, p=.75$ & $F(2,50)=1.25, p=.29$ \\
\hline & Error Holes 0-30s & $F(1,50)=4.39, p=.04 *$ & $F(2,50)=0.33, p=.72$ & $F(2,50)=3.34, p=.04 *$ \\
\hline & Error Holes 31-60s & $F(1,50)=3.89, p=.05^{*}$ & $F(2,50)=2.69, p=.08$ & $F(2,50)=0.31, p=.73$ \\
\hline & Error Holes 61-90s & $F(1,50)=7.09, p=.01 *$ & $F(2,50)=2.06, p=.14$ & $F(2,50)=0.23, p=.79$ \\
\hline & Error Holes Total & $F(1,50)=5.49, p=.02 *$ & $F(2,50)=2.90, p=.06$ & $F(2,50)=0.70, p=.50$ \\
\hline
\end{tabular}

\begin{tabular}{|l|l|l|l|l|}
\hline & Escape Latency & $F(1,50)=0.61, p=.44$ & $F(2,50)=0.64, p=.89$ & $F(2,50)=1.22, p=.30$ \\
\cline { 2 - 6 } & Escape Holes 0-30s & $F(1,50)=0.20, p=.66$ & $F(2,50)=1.54, p=.23$ & $F(2,50)=0.29, p=.75$ \\
\cline { 2 - 6 } Probe 2 2 & Escape Holes 31-60s & $F(1,50)=2.05, p=.16$ & $F(2,50)=0.09, p=.91$ & $F(2,50)=0.73, p=.49$ \\
\cline { 2 - 6 } & Escape Holes 61-90s & $F(1,50)=0.24, p=.63$ & $F(2,50)=1.06, p=.36$ & $F(2,50)=0.48, p=.62$ \\
\hline & Escape Holes Total & $F(1,50)=0.61, p=.44$ & $F=(2,50)=0.15, p=.86$ & $\mathrm{~F}(2,50)=0.39, p=.68$ \\
\cline { 2 - 6 } & Error Holes 0-30s & $\mathbf{F ( 1 , 5 0 ) = 4 . 0 8 , p = . 0 5 *}$ & $F(2,50)=1.28, p=.51$ & $\mathrm{~F}(2,50)=0.56, p=.57$ \\
\cline { 2 - 6 } & Error Holes 31-60s & $F(1,50)=0.68, p=.42$ & $F(2,50)=0.12, p=.89$ & $\mathrm{~F}(2,50)=0.09, p=.92$ \\
\cline { 2 - 6 } & Error Holes 61-90s & $F(1,50)=1.81, p=.19$ & $F(2,50)=0.02, p=.98$ & $\mathrm{~F}(2,50)=0.58, p=.57$ \\
\cline { 2 - 5 } & Error Holes Total & $F(1,50)=2.31, p=.13$ & $F(2,50)=0.12, p=.88$ & $\mathrm{~F}(2,50)=0.17, p=.85$ \\
\hline
\end{tabular}

Table 4. Statistical results for Probe 1 and Probe 2. Although there were no significant Tg

effects, for all bins of Probe 1 and the $0-30 \mathrm{~s}$ bin of Probe 2, there were significant effects of Tx $\left({ }^{*} p \leq .05\right)$. There was also a significant interaction between $\mathrm{Tx}$ and $\mathrm{Tg}$ in the $0-30 \mathrm{~s}$ bin of Probe $1(* p \leq .05)$. 
A.

\begin{tabular}{|r|c|c|c|}
\hline & Controls & TauWT & TauP301L \\
\hline Vehicle & 9 & 9 & 9 \\
\hline STZ & 9 & 9 & 11 \\
\hline
\end{tabular}

B. Responder

teto

\section{Tau}

Activator

\section{CAMKIIa promoter \\ $t T a$}

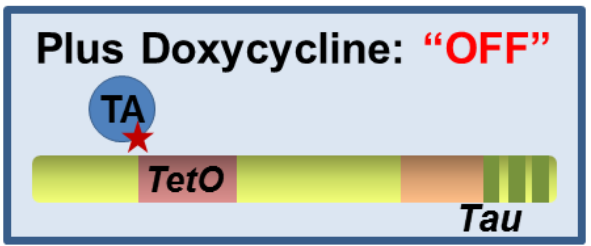

C.

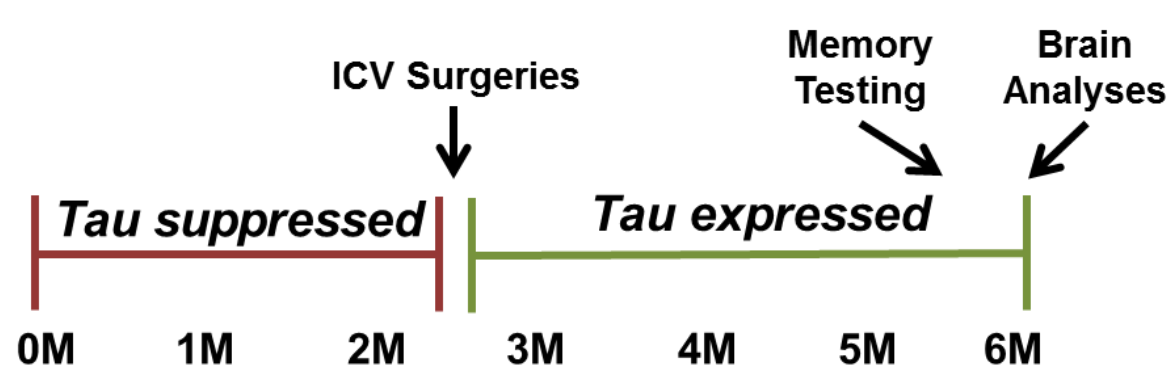

Figure 1. Mouse models and timeline. (A) There was a total of 56 male mice in the experiment, with nine to eleven mice in each group. (B) Both TauWT and TauP301L responder lines encode for human $4 \mathrm{R}$ tau lacking the amino terminal sequences $(4 \mathrm{R} 0 \mathrm{~N})$. The activator line used a forebrain specific promoter $(\mathrm{CaMKII} \alpha)$ to restrict tau expression to $\mathrm{AD}$ relevant brain regions. The addition of doxycycline $(40 \mathrm{ppm})$ to the drinking water prevents the transcription of tau by preferentially binding to the tetracycline transactivator protein. When doxycycline is removed, transcription occurs. (C) Tau expression was suppressed during development using doxycycline and turned on from two to five months of age. ICV-STZ or ICV-vehicle surgery was performed at two months of age, and at the same time, tau expression began. 
A)

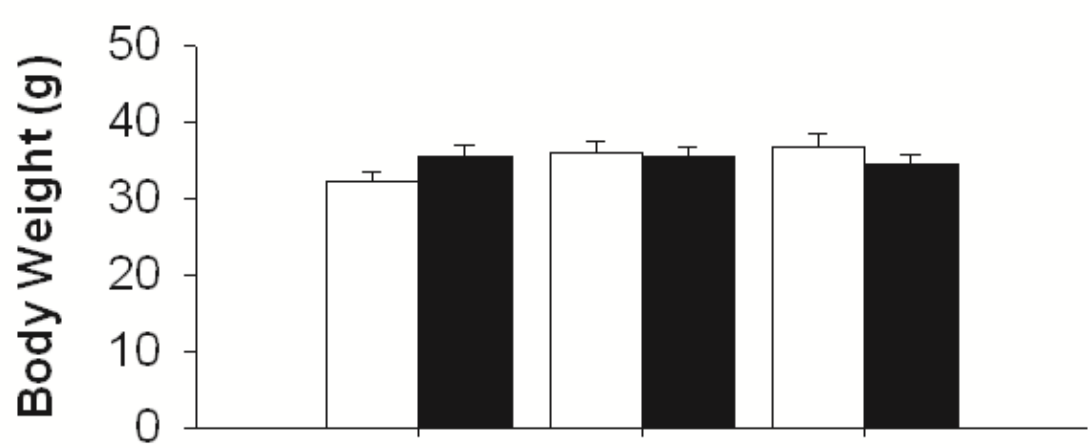

B)

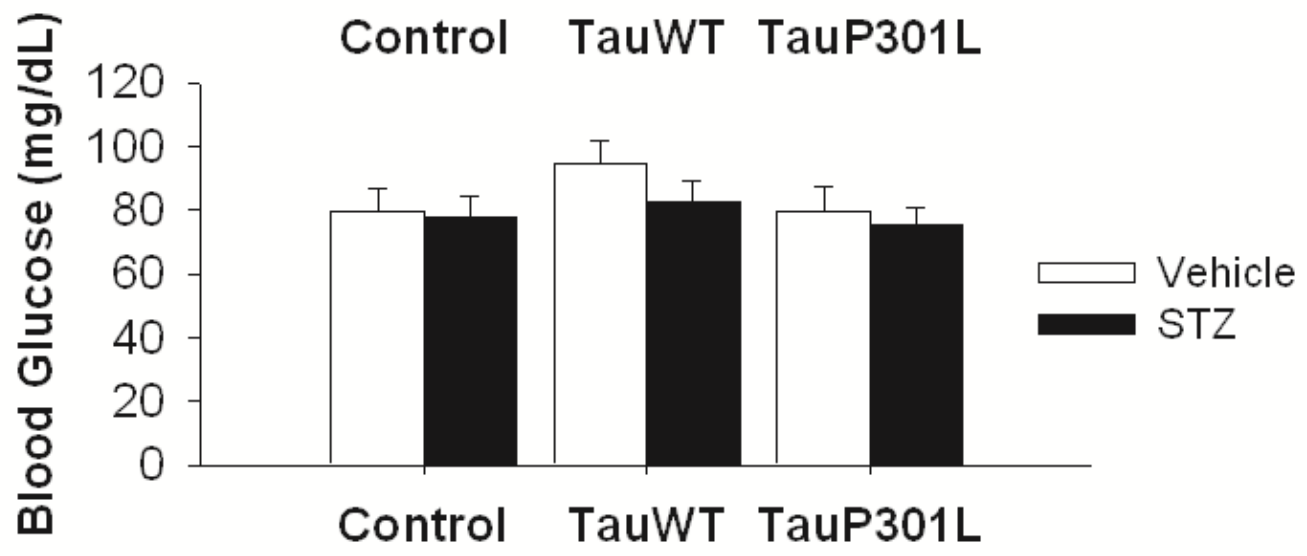

C)

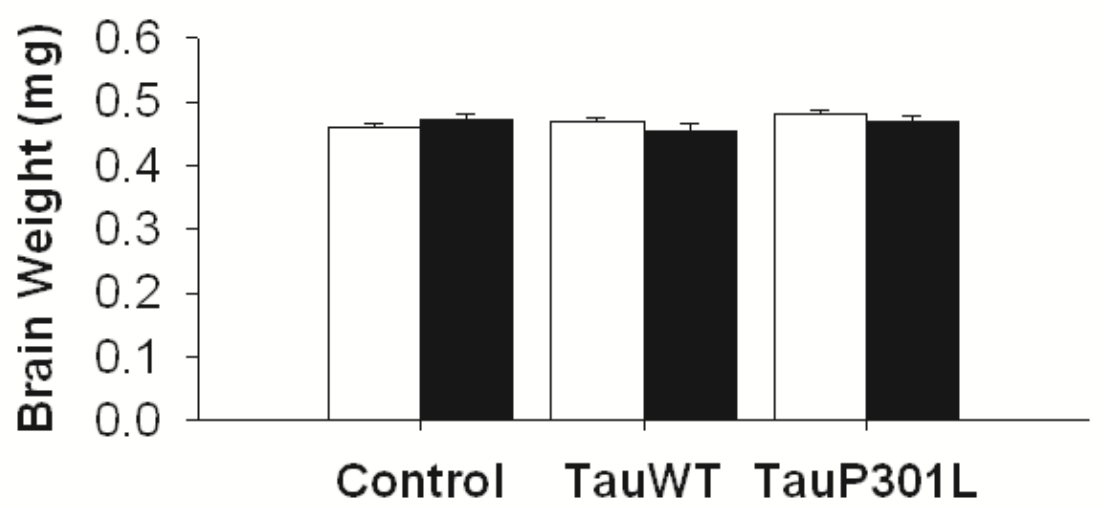

Figure 2. Physiological parameters. (A) Body weight, (B) blood glucose levels, and (C) brain weights did not differ among treatment or transgene groups. 
Hole Deviation

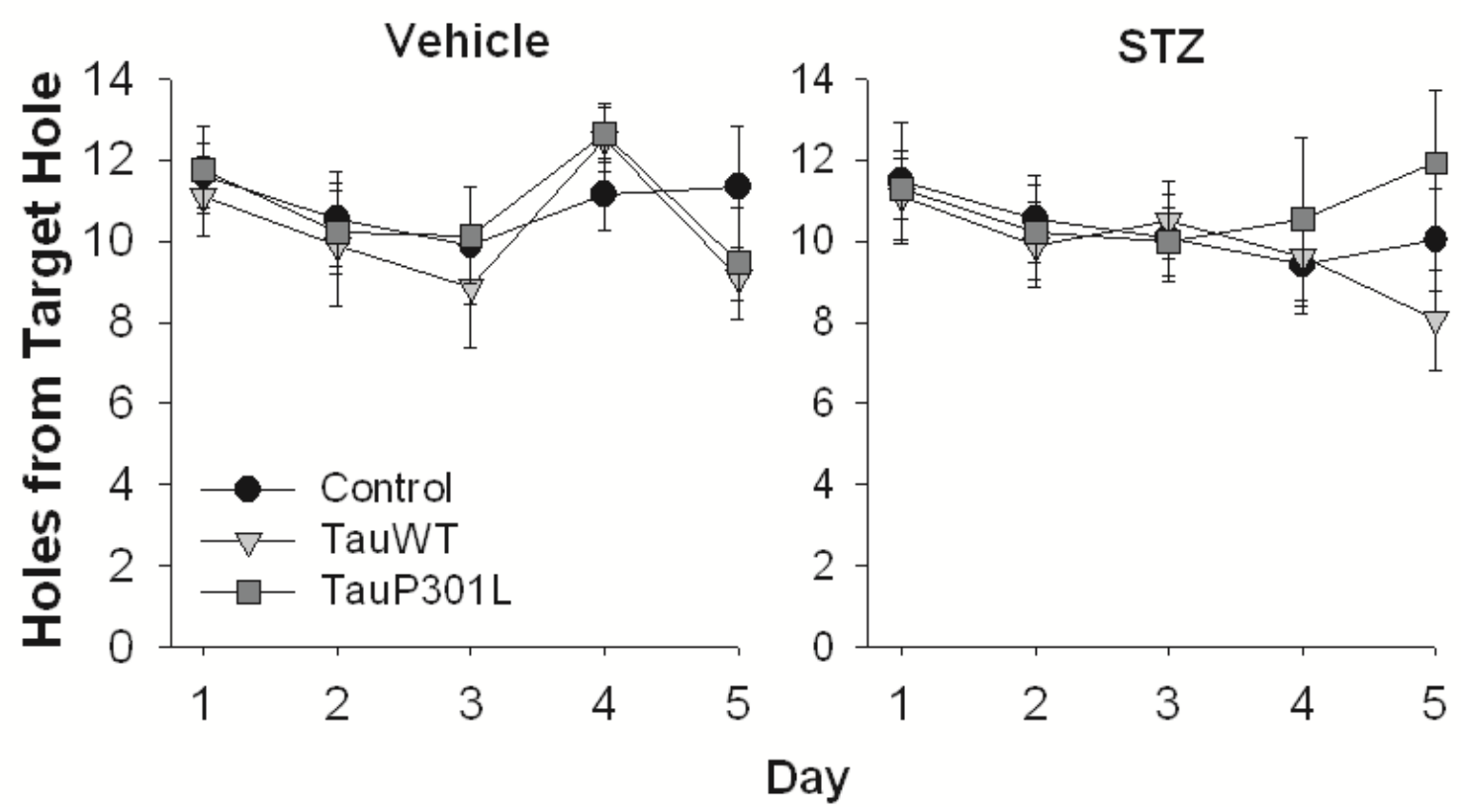

Figure 3. Hole deviation. Unlike the other acquisition variables, there was no significant trend of improvement for hole deviation across days. 
A)

Primary Errors

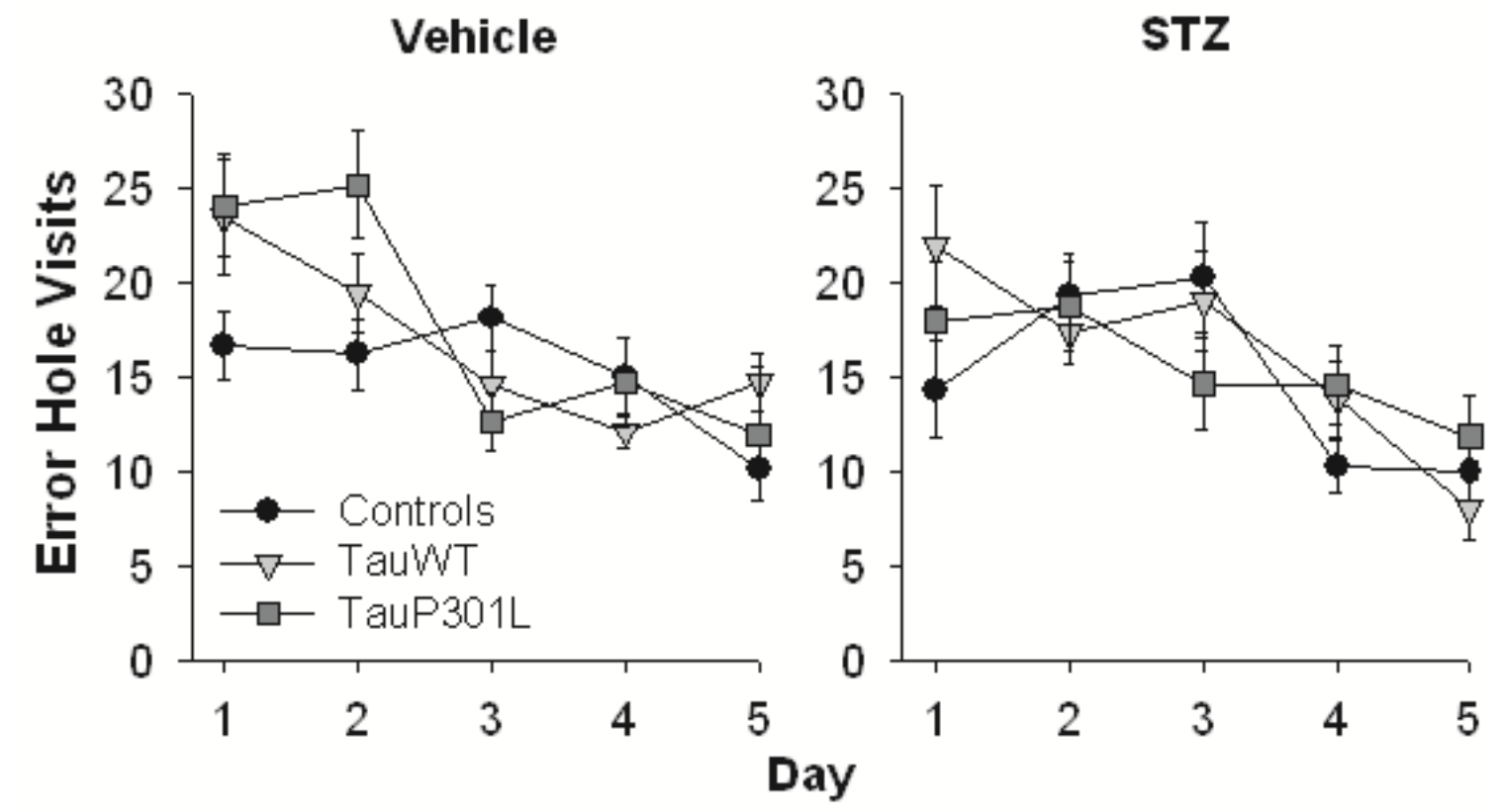

B)

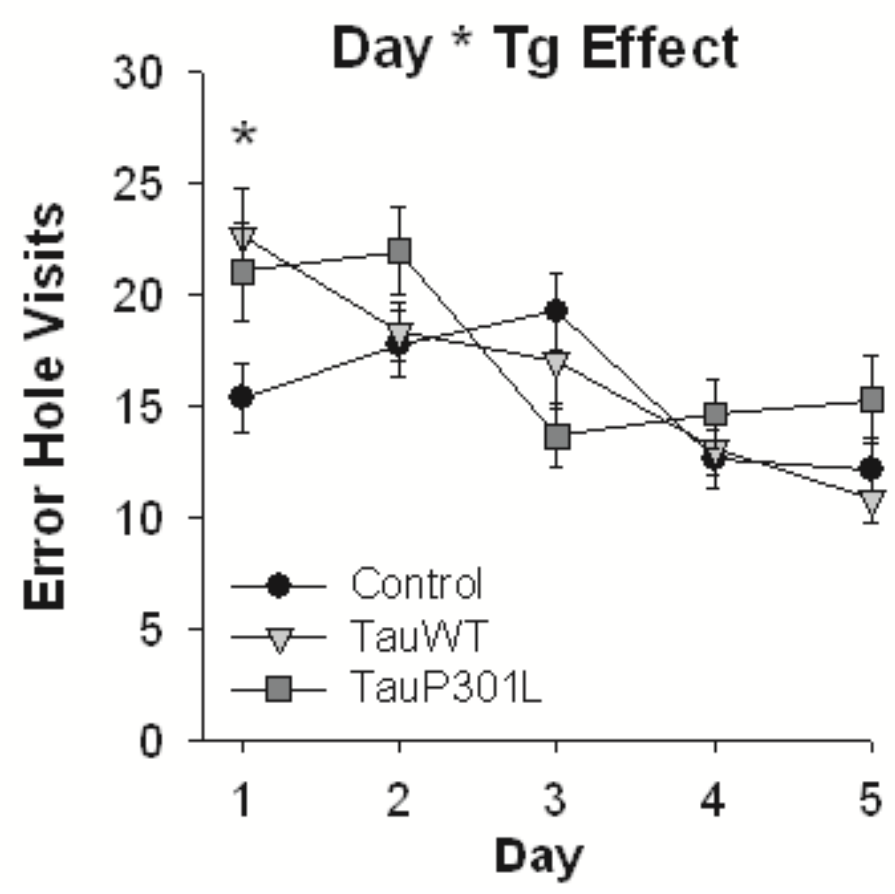

Figure 4. Primary errors. (A) Fewer visits to error holes were made as the acquisition days progressed. (B) On Day 1 of acquisition, there was a Day*Tg interaction in which the TauWT mice made significantly more errors than the Control mice (TauWT vs. Control: ${ }^{*} p=.04$ ), but did not differ on any other days $(p>.05)$. 


\section{Primary Latency}

Vehicle

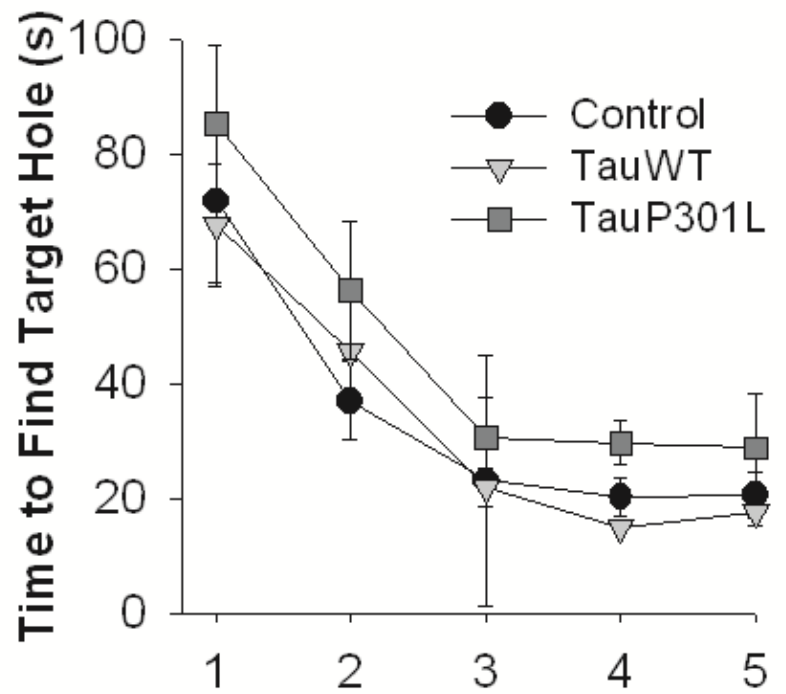

STZ

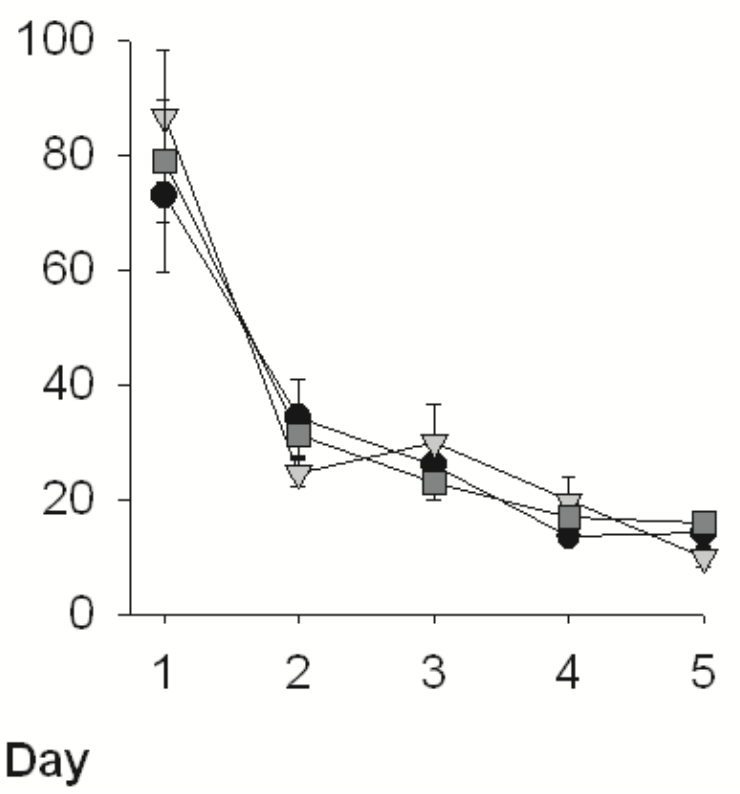

Figure 5. Primary latency. The time required for the mice to initially locate the target hole decreased with subsequent acquisition days. 


\section{Total Errors}

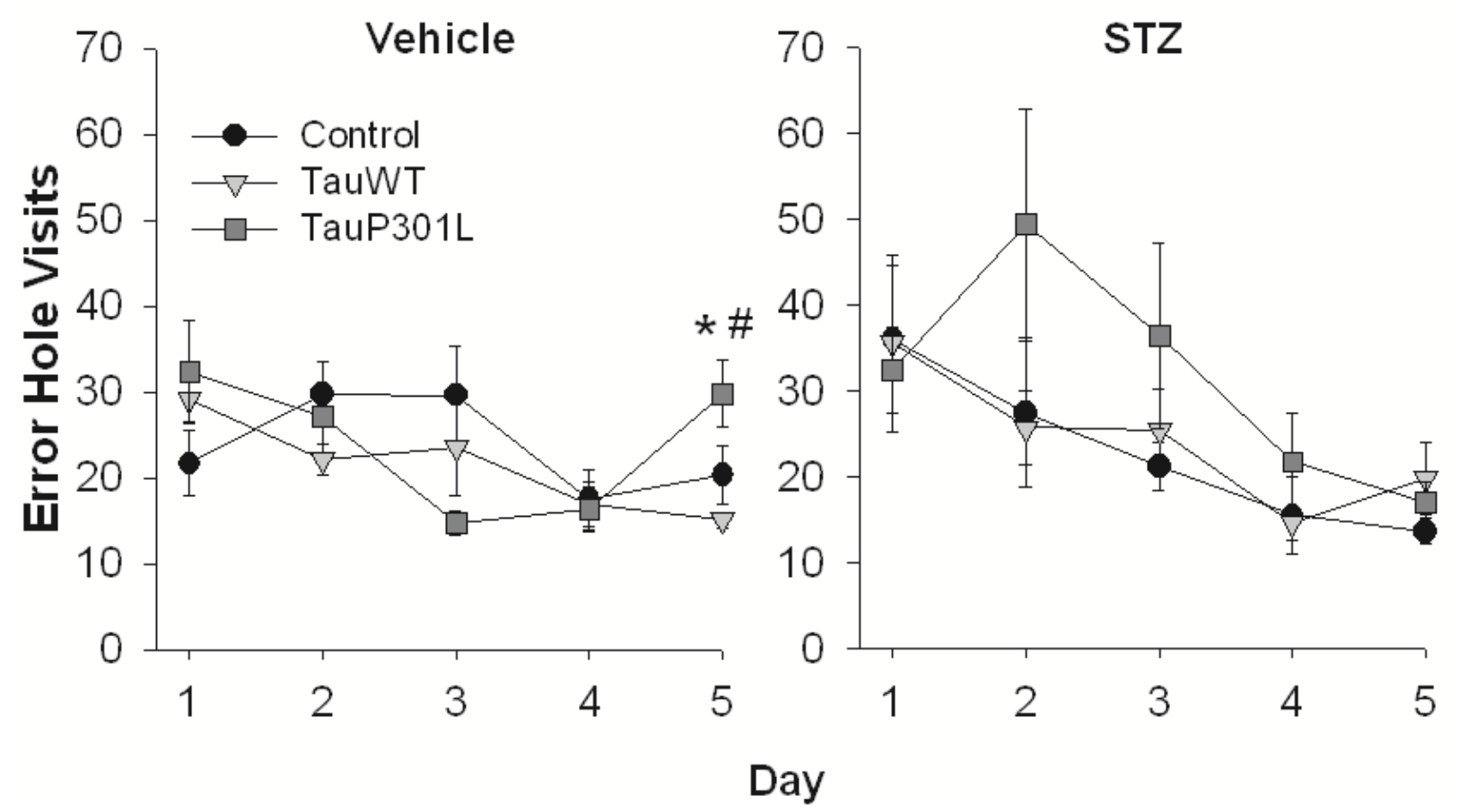

Figure 6. Total errors. The Vehicle-TauP301L mice made more errors than either the STZControl (Vehicle-TauP301L vs. STZ-Control: * $p=.01$ ) or Vehicle-TauWT (Vehicle-TauP301L vs. STZ-Control: $\# p=.02$ ) on Day 5. 


\section{Total Latency}

A)
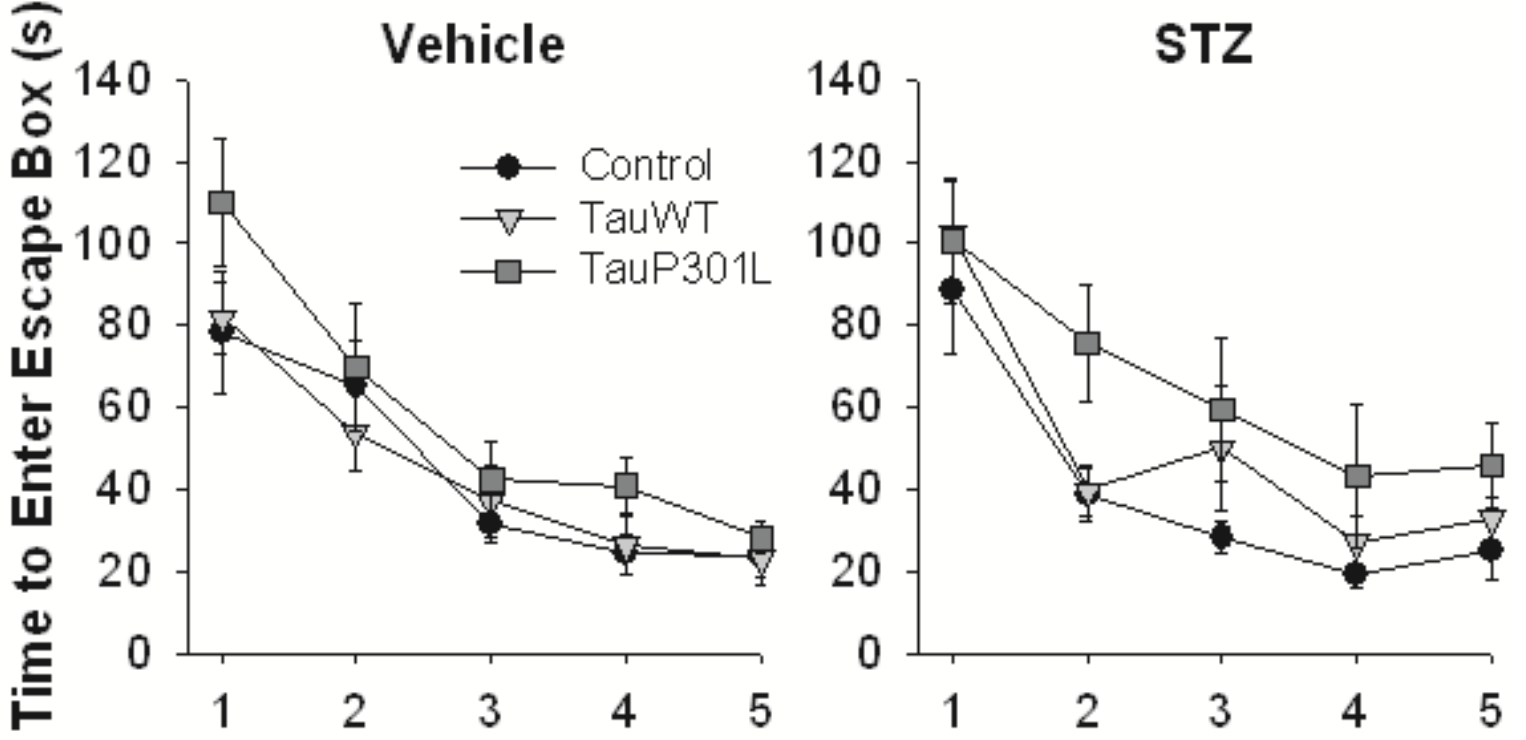

Day

B)

\section{Tg Effect}

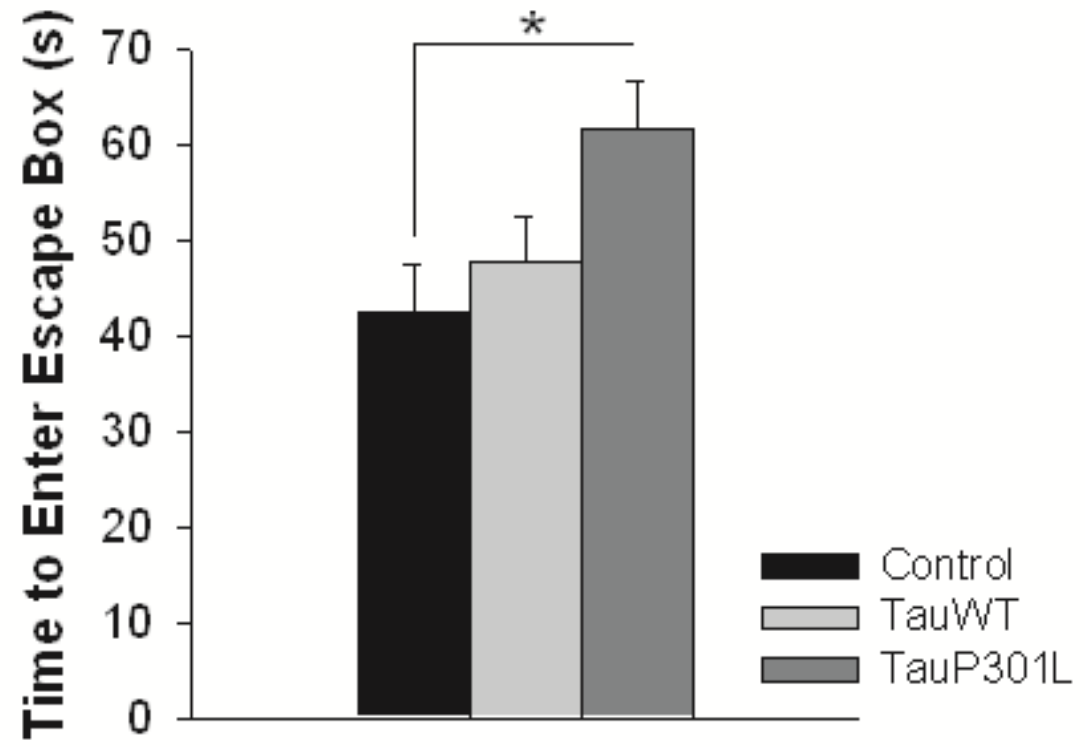

Figure 7. Total latency. (A) All of the groups made improvements in finding the escape box across days. (B) For total latency, there was a Tg effect such that the TauP301L mice consistently required more time to get into the escape box than the Control mice $\left({ }^{*} p=.03\right)$ but not the TauWT mice $(p=.16)$. 


\section{Search Strategy}

A)
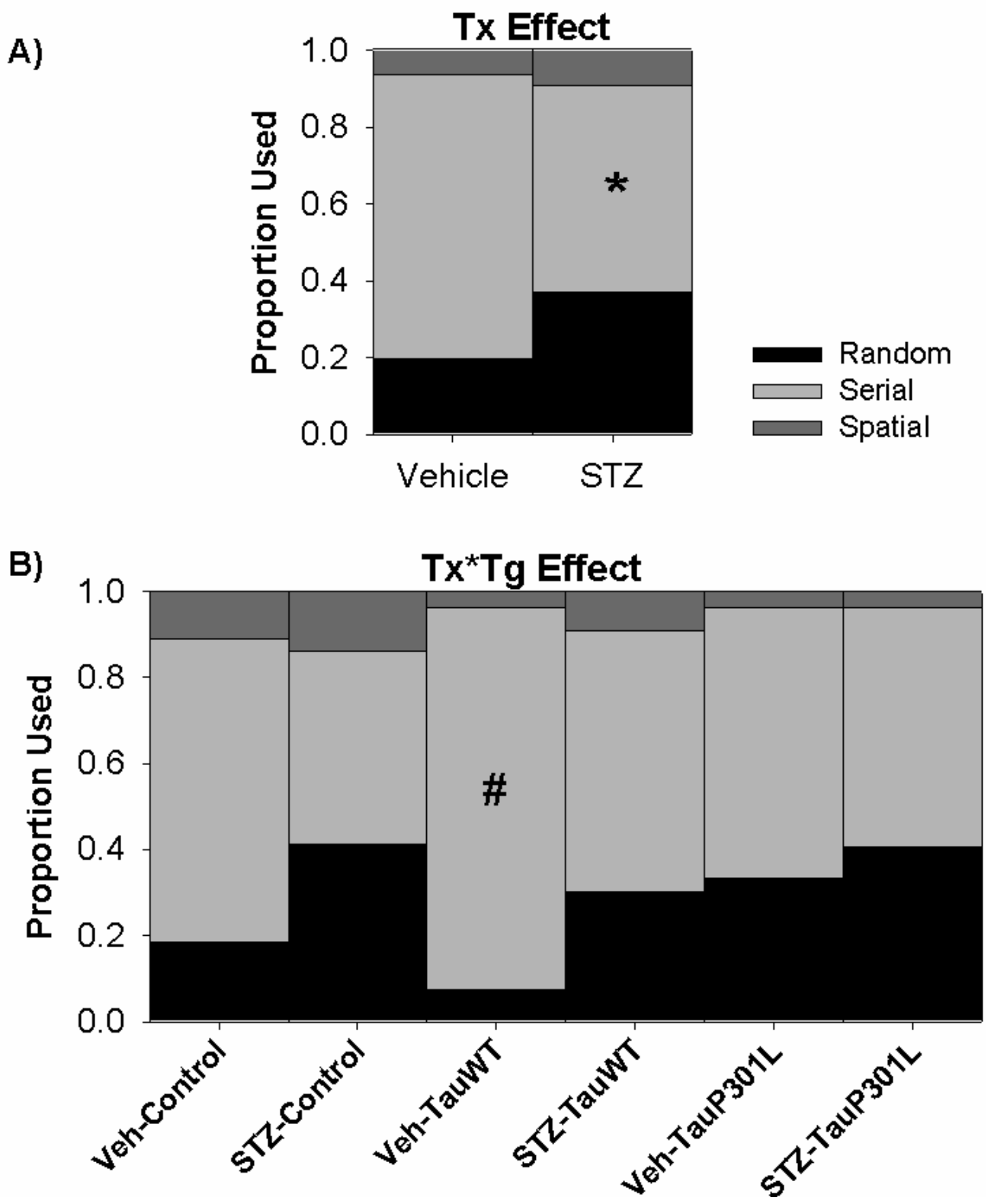

Figure 8. Search strategy on day 1 of acquisition. (A) The vehicle-treated mice were

significantly more likely to use a random search strategy and less likely to use a serial strategy than the vehicle-treated mice (Vehicle vs. STZ: ${ }^{*} p=.03$ ). (B) There was also a Tx*Tg interaction for the use of a serial search strategy (Vehicle-TauWT vs. STZ-Control: \#p=.04), in which the Vehicle-TauWT mice were more likely to use a serial search strategy than the STZ-Control mice. 


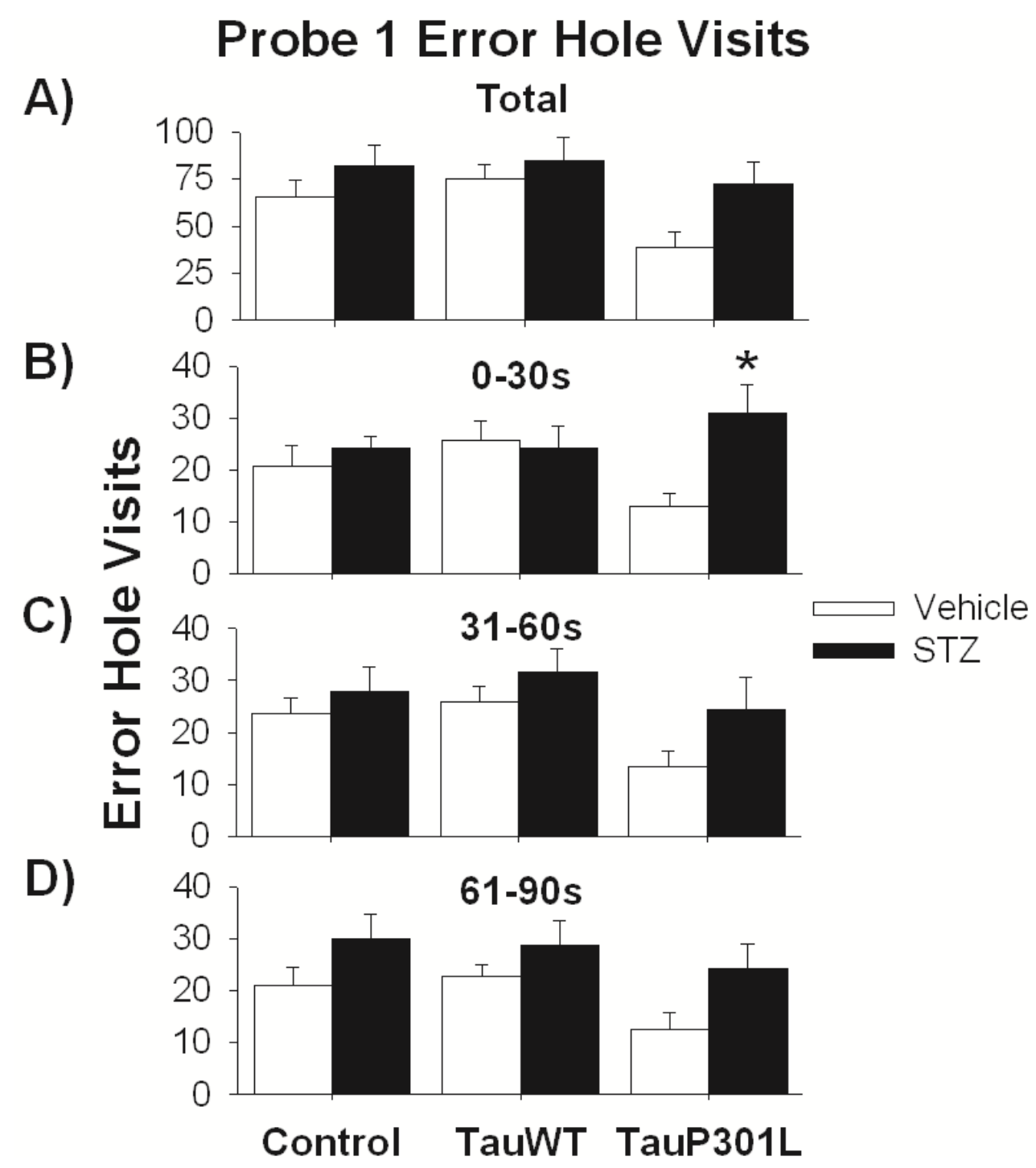

Figure 9. Probe 1 error hole visits. (A) Although there was no $\mathrm{Tx} * \mathrm{Tg}$ interaction in the total bin, (B) there was a Tx*Tg interaction for the 0-30 s bin such that the STZ-TauP301L mice made the most errors of all groups, but the Vehicle-TauP301L mice made fewest errors (Tx*Tg: *p<.05). There was no $\mathrm{Tx} * \mathrm{Tg}$ interaction for either (C) the 31-60 s or 61-90 s bin. 


\section{Probe 1 Error Hole Visits}

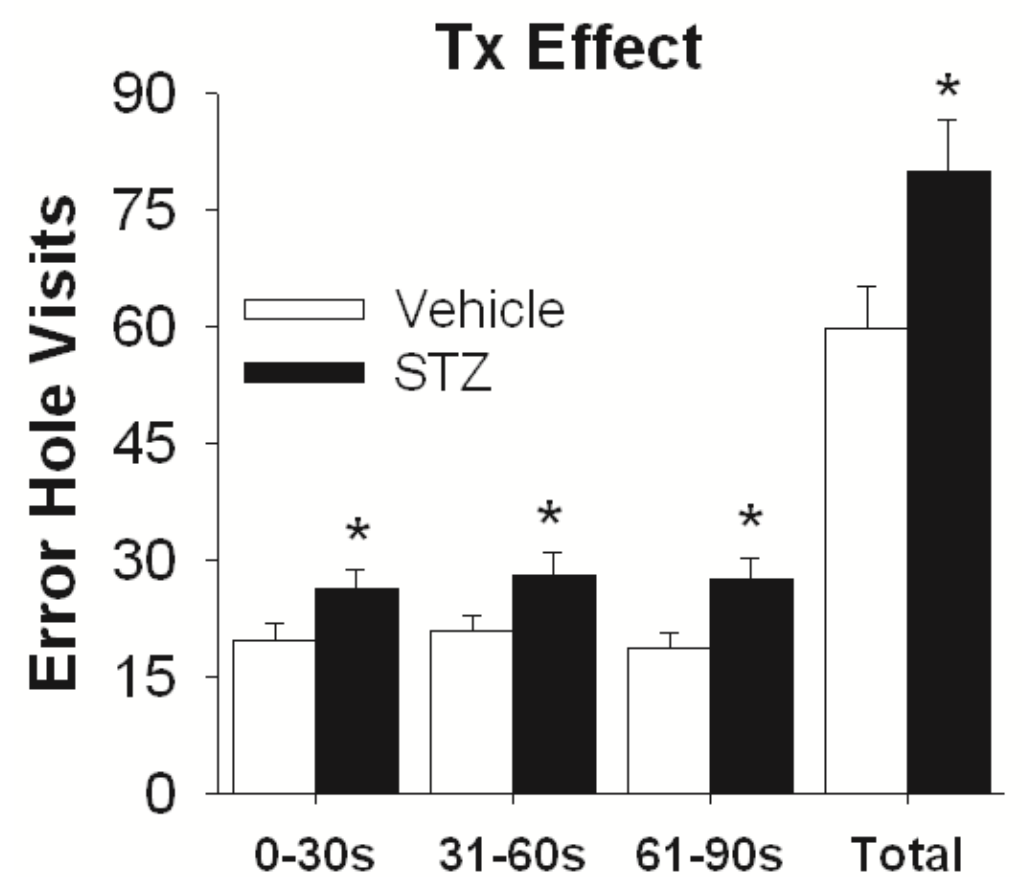

Figure 10. Tx effect for Probe 1 error hole visits. There was a significant Tx effect in each of the bins such that STZ-treated mice made more errors than vehicle-treated mice $\left({ }^{*} p \leq .05\right)$ : total ( $p=.02), 0-30 \mathrm{~s}(p=.05), 31-60 \mathrm{~s}(p=.05)$, and 61-90 s $(p=.01)$. 


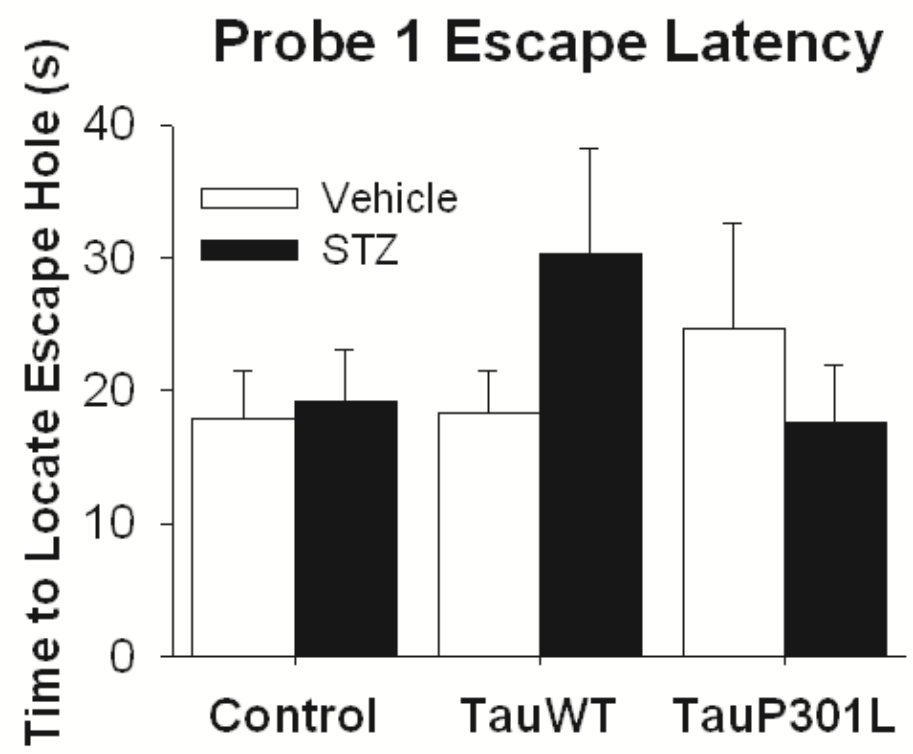

Figure 11. Probe 1 escape latency. There were no significant differences between treatment or transgene groups in the time taken for mice to initially locate the escape hole where the escape box was formerly located in Probe 1. 


\section{Probe 1 Escape Hole Visits}

A)

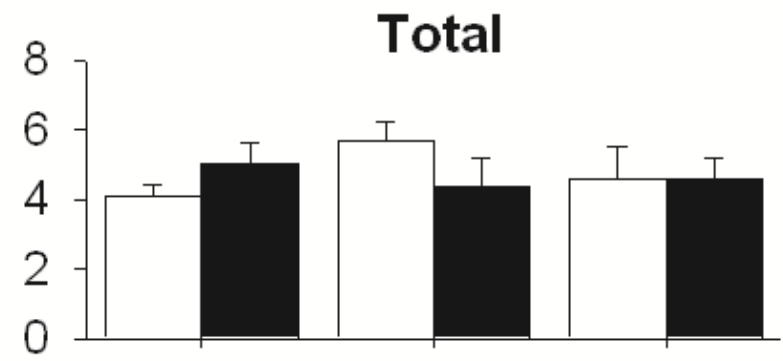

B)

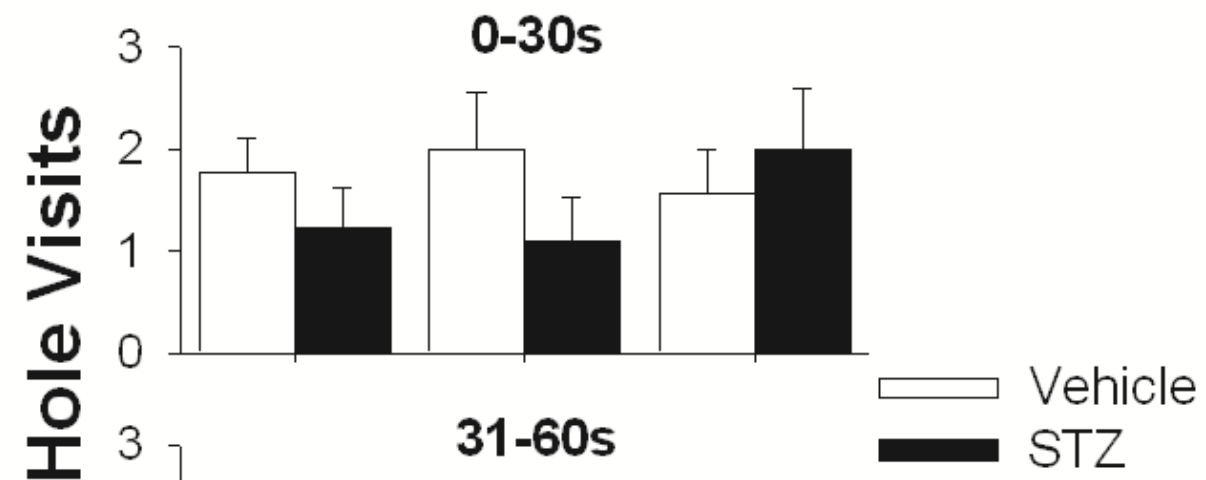

D)

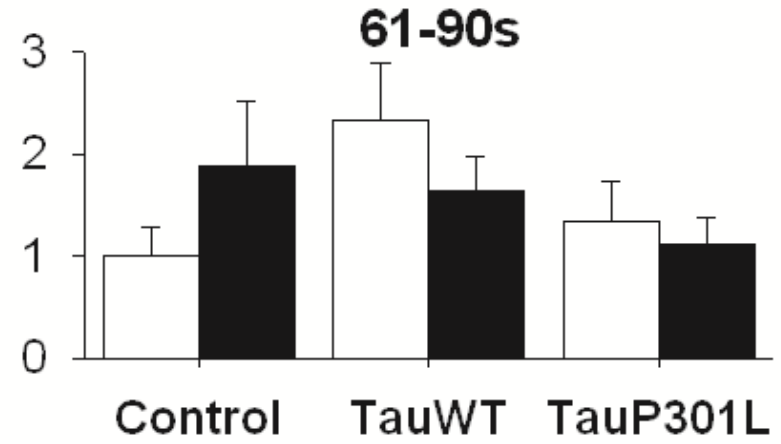

Figure 12. Probe 1 escape hole visits. There were no differences among $\mathrm{Tx}$ and $\mathrm{Tg}$ in the number of visits to the escape holes during any of the bins of Probe 1. 


\section{Probe 2 Error Hole Visits}

A)

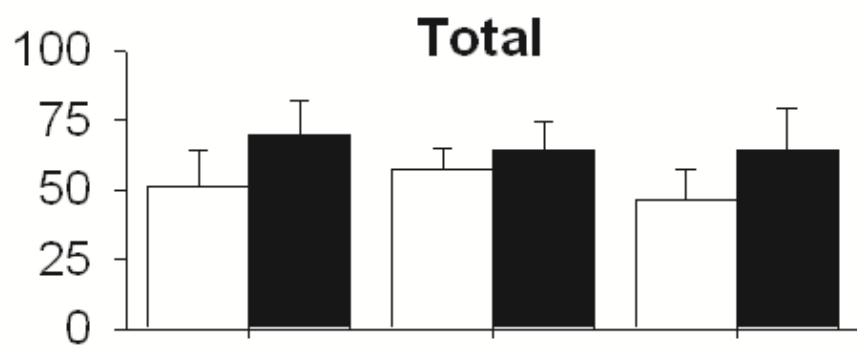

B)

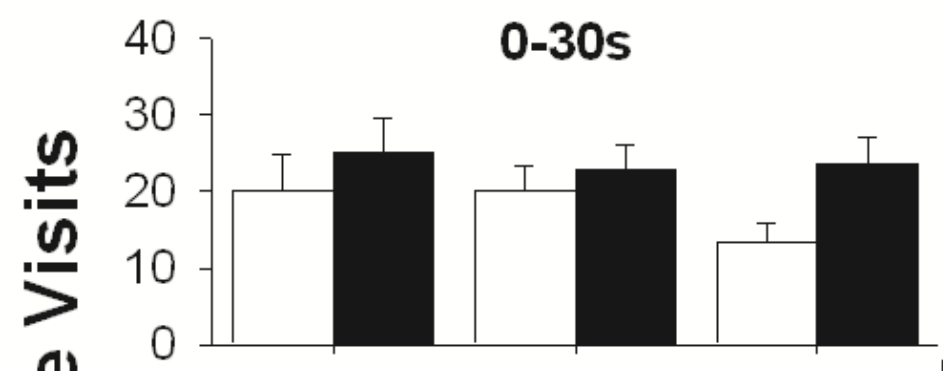

C)

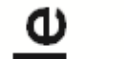

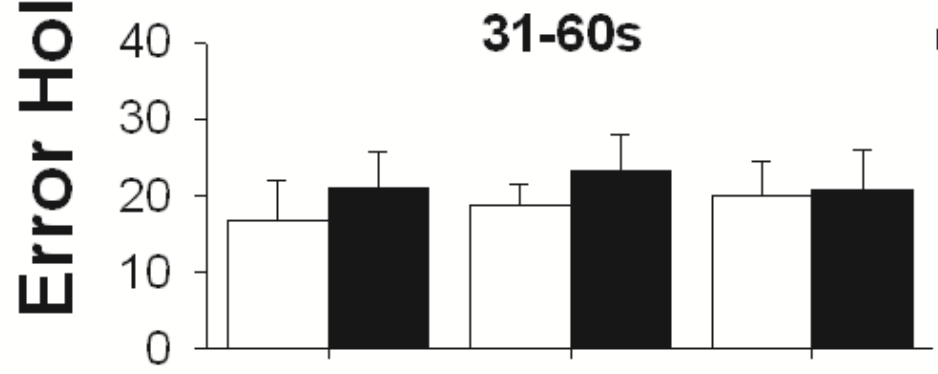

D)

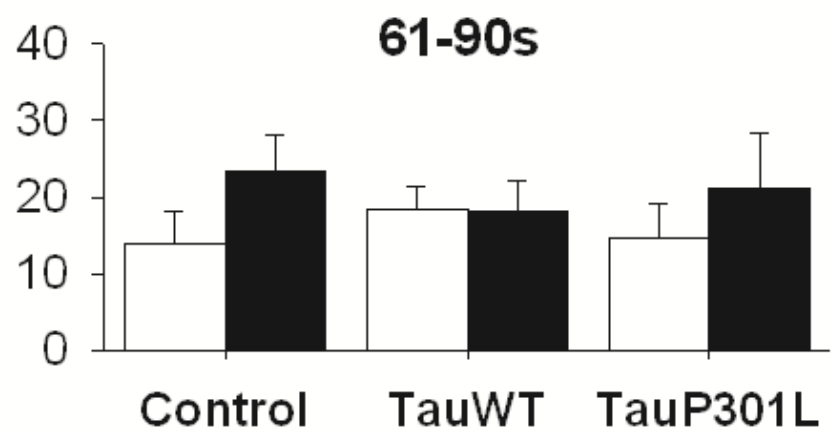

Figure 13. Probe 2 error hole visits. (A) There was not a significant interaction between Tx and

Tg for error hole visits in the (A) total, (B) 0-30 s, (C) 31-60 s, or (D) 61-90 s bins. 


\section{Probe 2 Error Hole Visits}

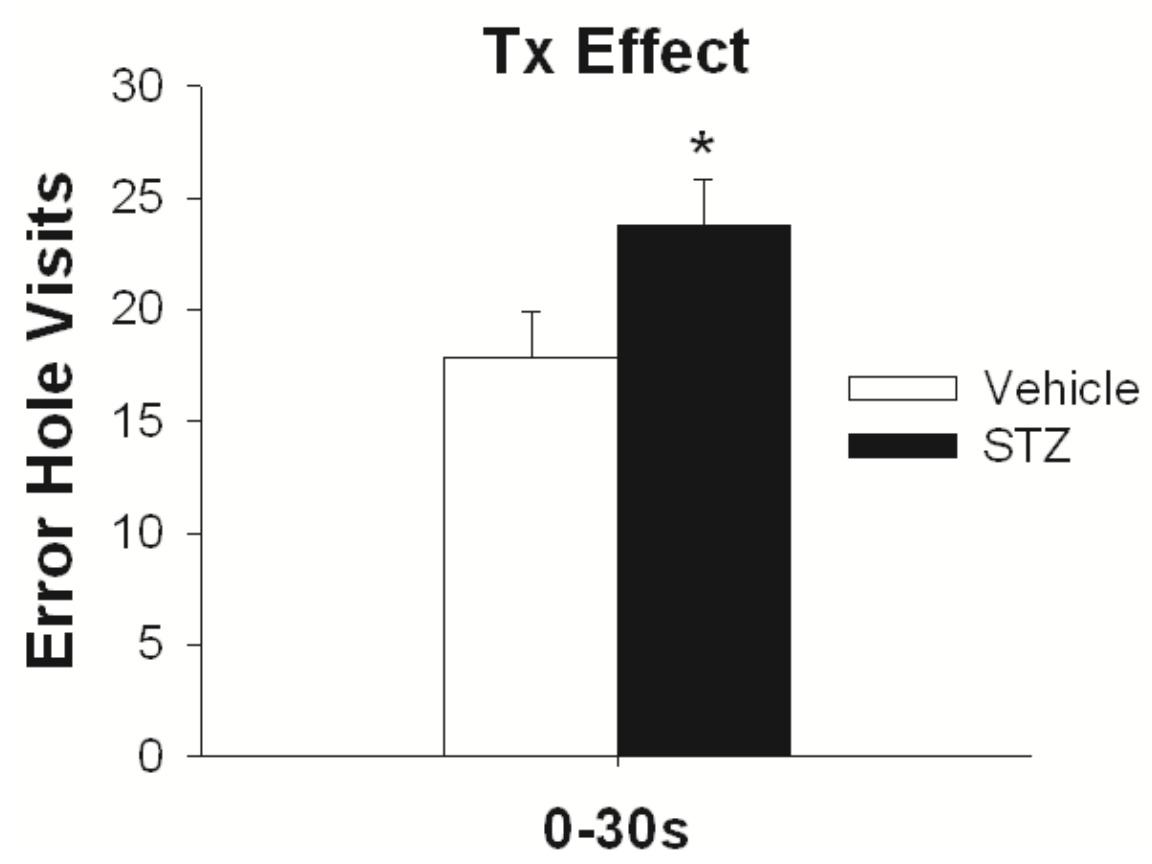

Figure 14. Tx effect for Probe 2 error hole visits. For the 0-30 s bin, the STZ-treated mice visited significantly more error holes $(* p=.05)$. In the remaining time bins, there were no differences between Tx groups. 


\section{Probe 2 Escape Latency}

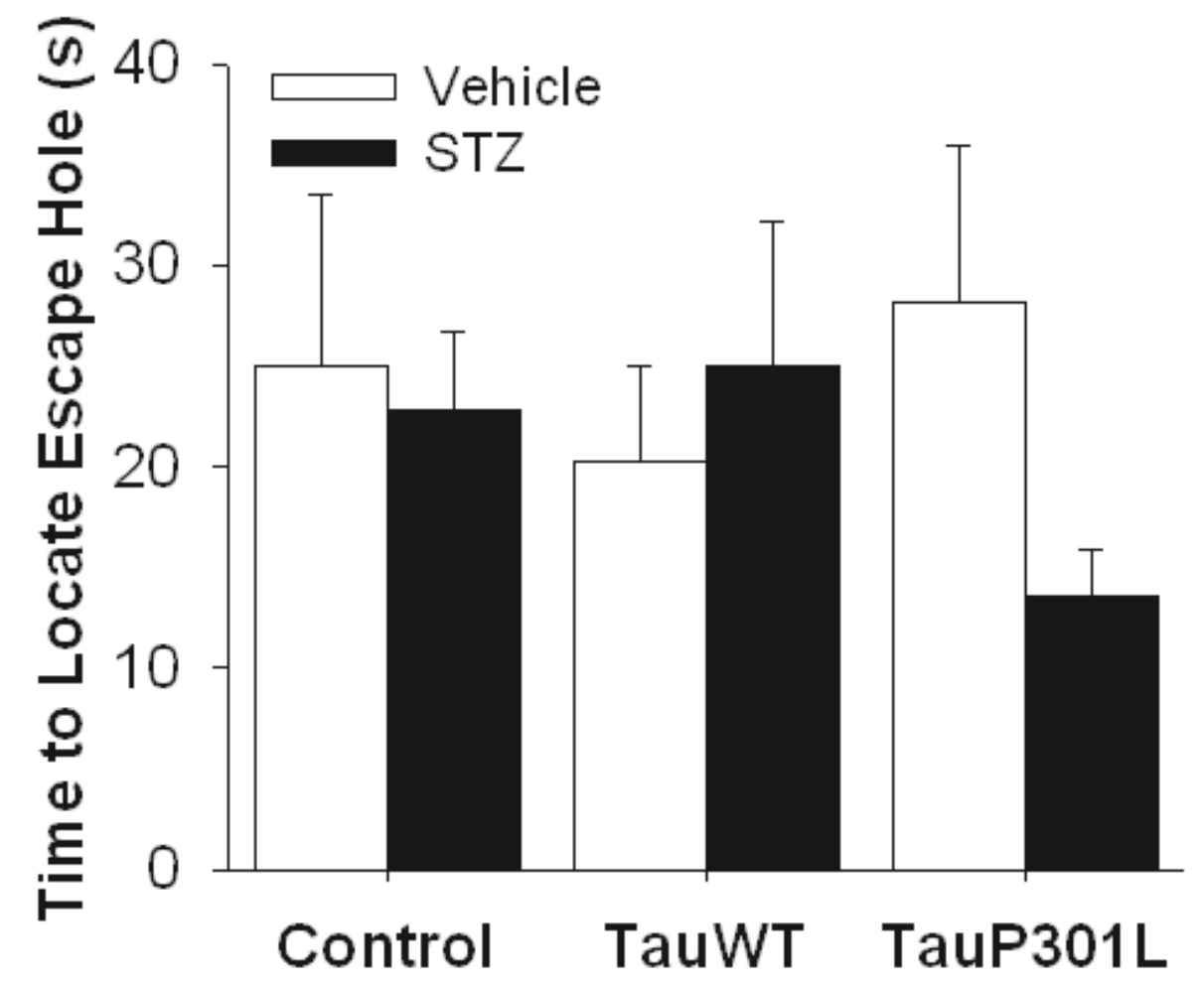

Figure 15. Probe 2 escape latency. There were no significant differences among treatment or transgene groups in the time taken for mice to initially locate the escape hole where the escape box was formerly located in Probe 2. 


\section{Probe 2 Escape Hole Visits}

A)

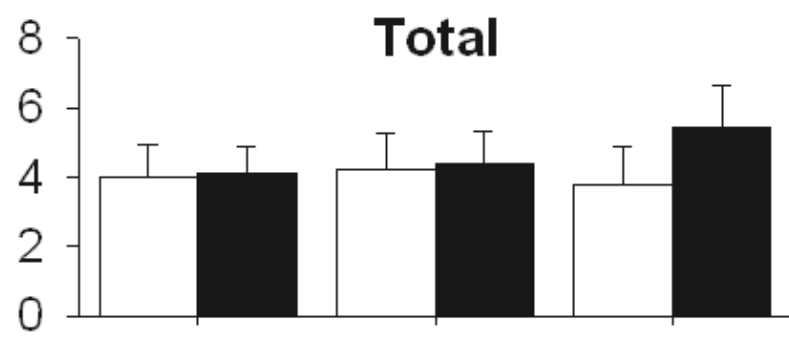

B)

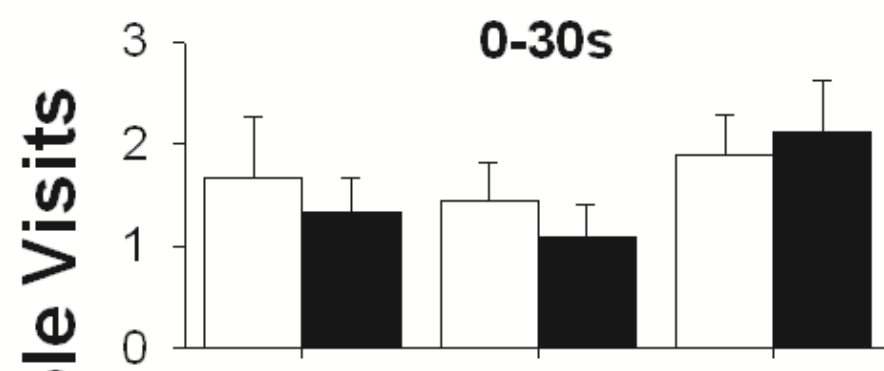

C)

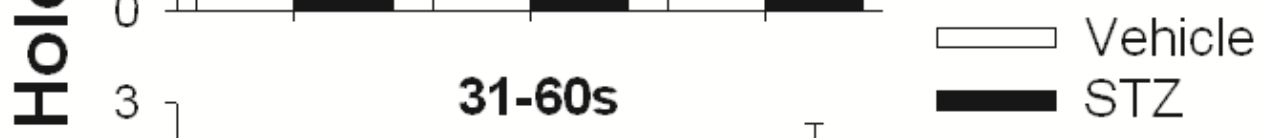

D)

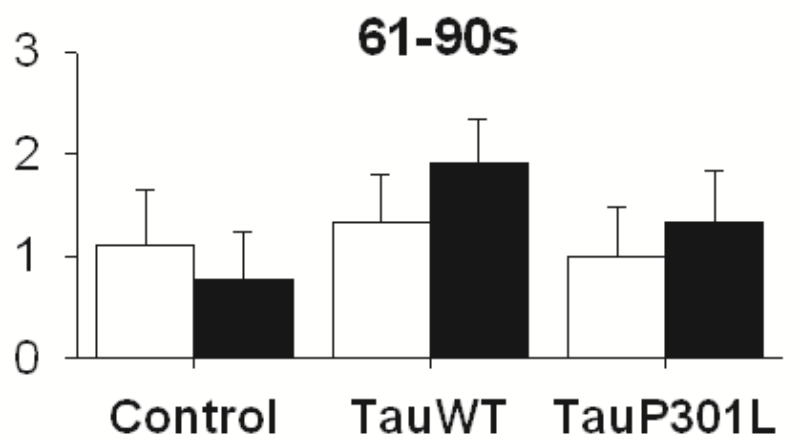

Figure 16. Probe 2 escape hole visits. There were no significant differences among $\mathrm{Tx}$ or $\mathrm{Tg}$ groups in the (A) total number of visits to the escape holes or during the (B) $0-30 \mathrm{~s}$, (C) $31-60 \mathrm{~s}$, or (D) 61-90 s bins. 

A)

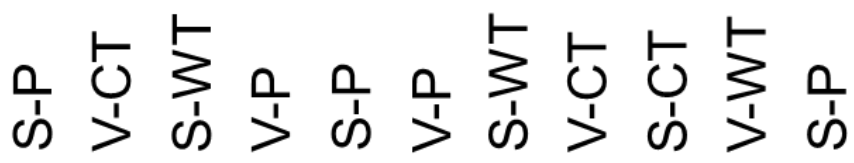
Tau-5
$55 \mathrm{kDa}$

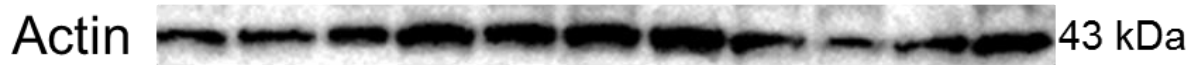

V-CT: Vehicle-Control, S-CT: STZ-Control, V-WT: Vehicle-TauWT, S-WT: STZ-TauWT, V-P: Vehicle-TauP301L, S-P: STZ-TauP301L

B)

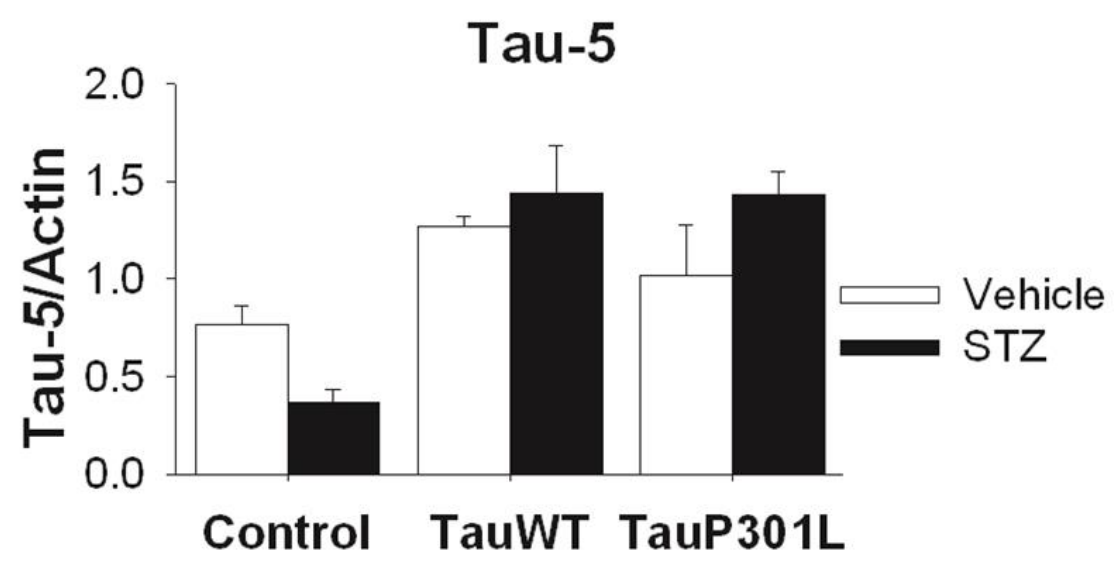

C)

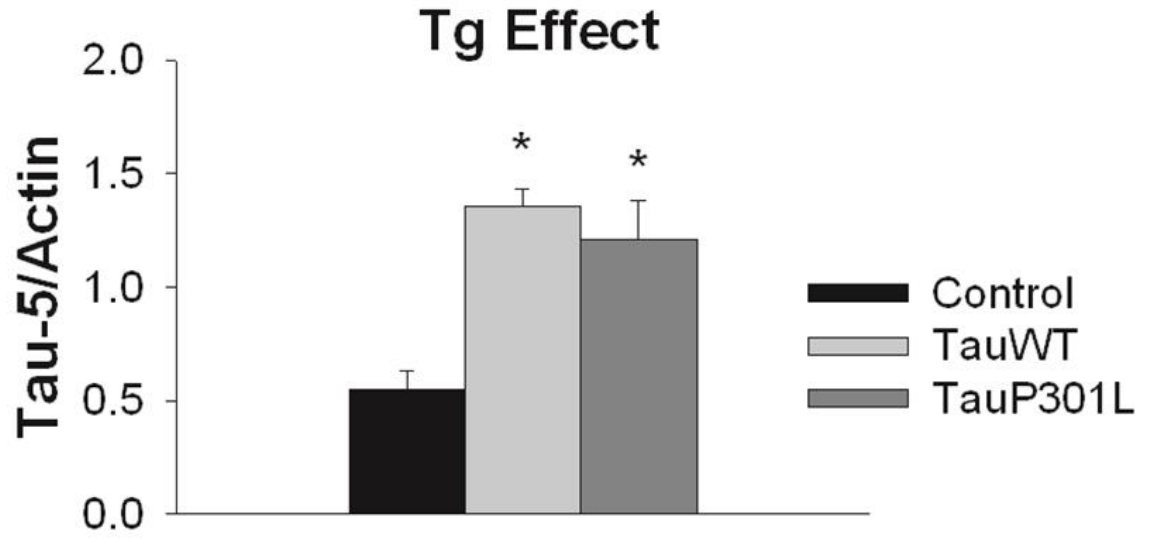

Figure 17. Western blotting with Tau-5. (A) The TauWT and TauP301L both had dark bands of total tau detected by Tau-5 and normalized with actin. (B) Levels of total tau are lower in the Control mice; in fact, (C) a main effect of Tg indicates that the TauWT and TauP301L mice had significantly higher total tau levels $(* p<.05)$ than the Control mice, but did not differ from each other. 
A)

A) $\begin{aligned} & \vdots \\ & \text { ம் }\end{aligned}$

$\mathrm{MC}-1$

$55 \mathrm{kDa}$

Actin

43 kDa

V-CT: Vehicle-Control, S-CT: STZ-Control, V-WT: Vehicle-TauWT,

S-WT: STZ-TauWT, V-P: Vehicle-TauP301L, S-P: STZ-TauP301L

B)

C)
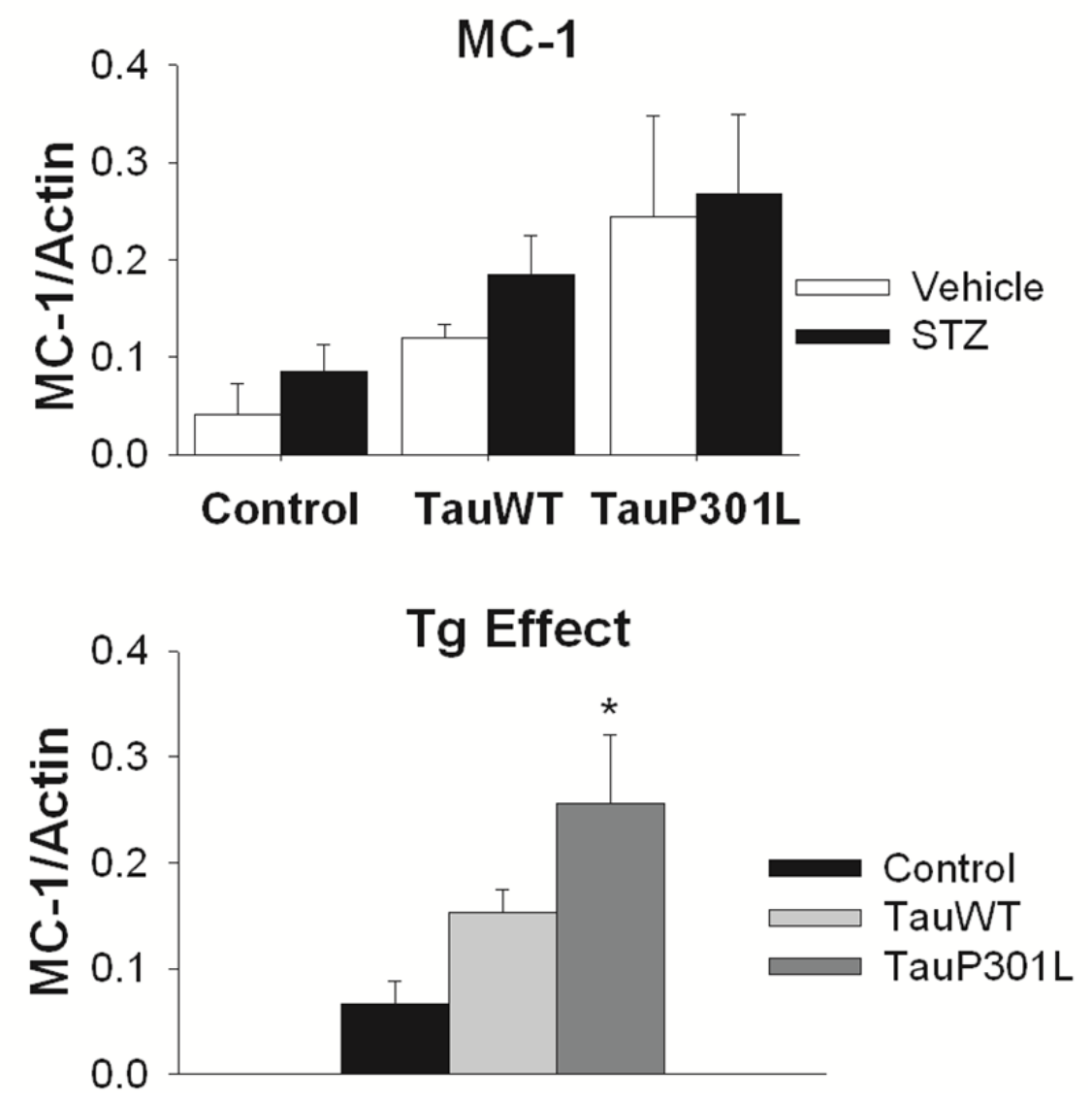

Figure 18. Western blotting with MC-1. (A) Bands of an early-stage conformational change detected by MC- 1 were less profound than the bands of Tau- 5 ( $n=40)$. (B) TauP301L mice had the highest level of MC-1—detected pathology normalized by actin, and (C) a main effect of $\mathrm{Tg}$ demonstrates that the TauP301L mice had significantly higher levels than the Control mice $\left({ }^{*} p<.05\right)$ but not the TauWT mice. 
A)

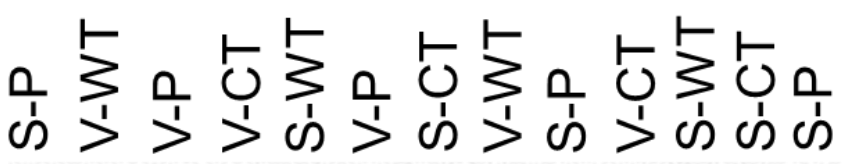

$\mathrm{CP}-13$

$55 \mathrm{kDa}$

Actin

$43 \mathrm{kDa}$

V-CT: Vehicle-Control, S-CT: STZ-Control, V-WT: Vehicle-TauWT,

S-WT: STZ-TauWT, V-P: Vehicle-TauP301L, S-P: STZ-TauP301L

B)

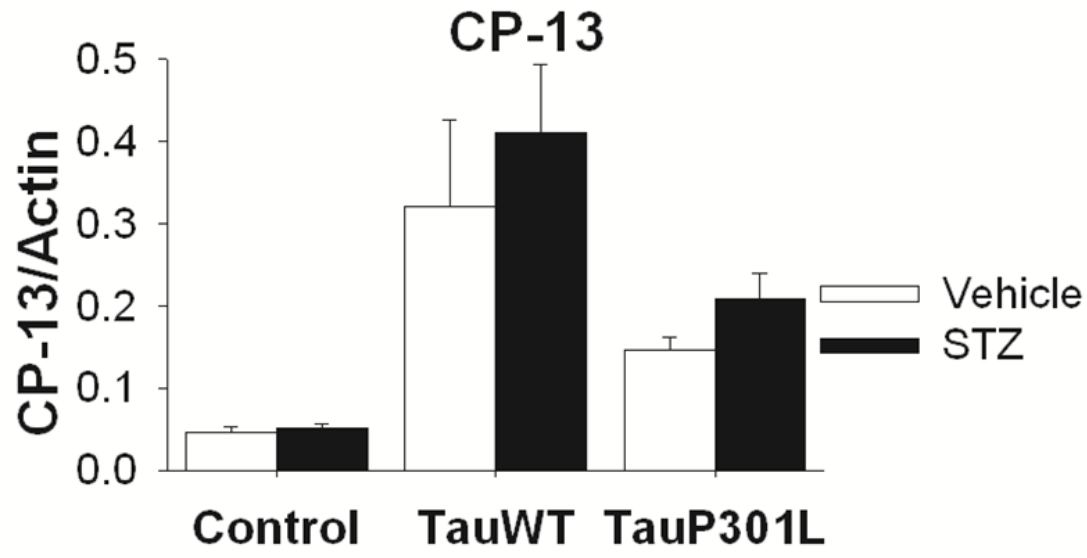

C)

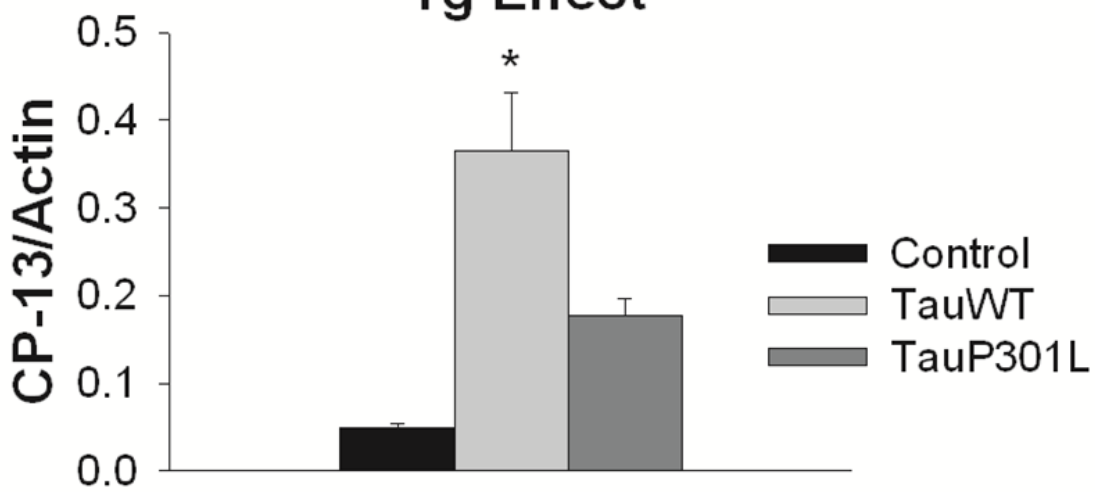

Figure 19. Western blotting with CP-13. (A) Faint bands of phosphorylated serine at the $202^{\text {nd }}$ (pSer202) position, an early-stage change in AD, were detected by CP-13 $(n=40)$. (B) The TauWT mice had higher levels of CP-13 — detected changes normalized with actin. (C) A main effect of Tg shows that the TauWT mice had significantly more $\mathrm{pSer}^{202}$ than the Control and TauP301L mice $(* p<.01)$. 
A)

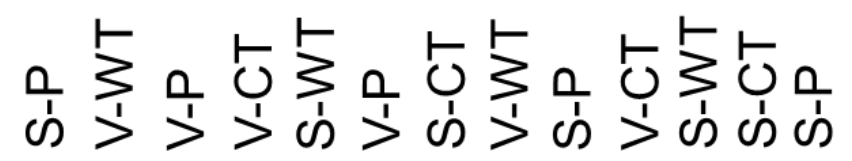

PHF-1

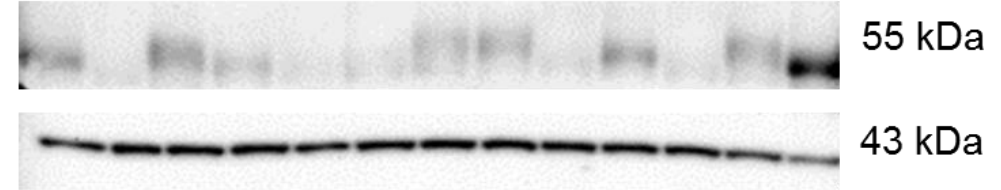

V-CT: Vehicle-Control, S-CT: STZ-Control, V-WT: Vehicle-TauWT, S-WT: STZ-TauWT, V-P: Vehicle-TauP301L, S-P: STZ-TauP301L

B)

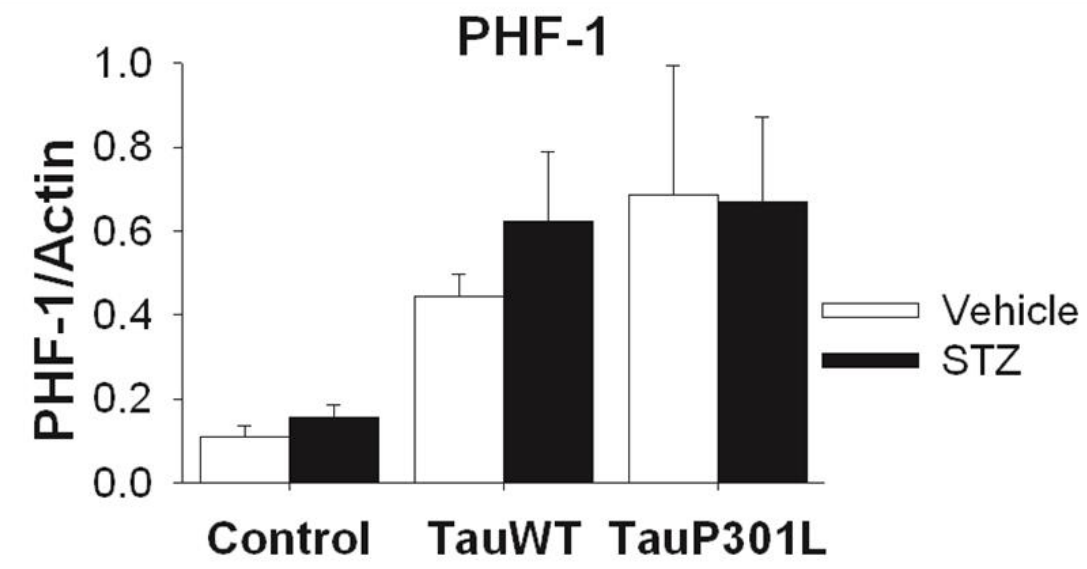

C) Tg Effect

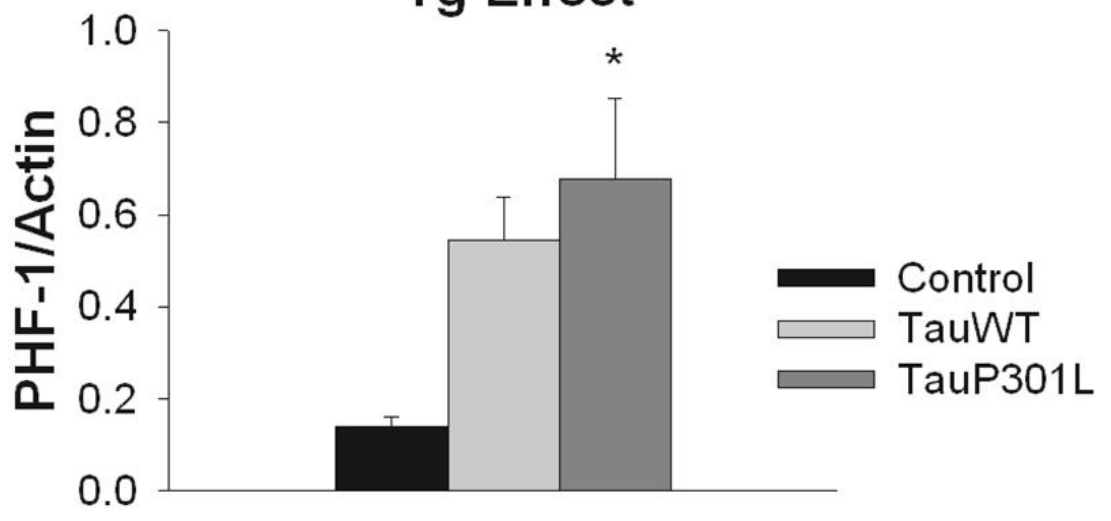

Figure 20. Western blotting with PHF-1. (A) PHF-1 identified paired helical filaments ( $n=27)$.

(B) Levels of paired helical filaments normalized with actin were low in Control mice and higher in the TauWT and TauP301L mice. (C) The main effect of Tg was significant, indicating that the TauP301L mice had higher levels of paired helical filaments than the Control mice $\left({ }^{*} p<.05\right)$, but not the TauWT mice. 